\author{
UNIVERSIDADE DE SÃO PAULO \\ ESCOLA POLITÉCNICA \\ PROGRAMA DE MESTRADO EM ENGENHARIA DE SISTEMAS \\ LOGÍSTICOS
}

TIAGO NOVAES MATHIAS

ANÁLISE DE SISTEMAS INTEGRADOS DE TRANSPORTE RODO-FLUVIAL-MARÍTIMO SOB A INFLUÊNCIA DE REGIMES SAZONAIS

SÃO PAULO 


\section{ANÁLISE DE SISTEMAS INTEGRADOS DE TRANSPORTE RODO-FLUVIAL-MARÍTIMO SOB A INFLUÊNCIA DE REGIMES SAZONAIS}

Dissertação apresentada à Escola Politécnica da Universidade de São Paulo como parte dos requisitos exigidos para obtenção do título de Mestre em Ciências.

Área de Concentração:

Engenharia de Sistemas Logísticos

Orientador: Prof. Dr. Rui Carlos Botter 
Este exemplar foi revisado e corrigido em relaçẫo à versẫo original, sob responsabilidade única do autor e coma anuência de seu orientador.

Sẫo Paulo, de

Assinatura do autor:

Assinatura do orientador:

\section{Catalogação-na-publicação}

Mathias, Tiago Novaes

Análise de sistemas integrados de transporte rodo-fluvial-marítimo sob a influência de regimes sazonais / T. N. Mathias - versăo corr. -- Säo Paulo, 2016 .

$106 p$

Dissertaçăo (Mestrado) - Escola Politécnica da Universidade de Säo Paulo. Departamento de Engenharia de Produção.

1.Simulação Computacional 2. Sazonalidade 3.Transporte de Grâos I.Universidade de Säo Paulo. Escola Politécnica. Departamento de Engenharia de Produçăo II.t. 


\section{DEDICATÓRIA}

À Enedine Novaes, à Maria Novaes e ao Deodoro Novaes (in memorian), exemplos de vida e honestidade. 


\section{AGRADECIMENTOS}

Ao meu orientador, Professor Doutor Rui Carlos Botter, pela oportunidade, convivência, pelos ensinamentos proporcionados, pela amizade e, principalmente, pela confiança que depositou em mim. Ele que, com seu jeito peculiar, nunca se furtou a uma palavra de incentivo.

Aos professores da Escola Politécnica da USP, que auxiliaram na minha formação intelectual.

Ao Professor Dr. Arnaldo R. Vallim Filho, que com grande sabedoria, em suas aulas, inspirou-me a seguir esse caminho.

Aos amigos Daniel Mota, Afonso Celso Medina e Newton Narciso Pereira, pela colaboração intelectual, pela coorientação e por auxiliarem no meu crescimento profissional.

Aos meus companheiros de trabalho e amigos, Joyce Zampirolli, João Netto, Rodolfo Celestino Silva e Suelen Ferrari, pelas trocas de ideias, experiências, risadas, discussões e conversas ao longo desse curso.

Aos amigos Bruno Bonfim, Natália Bonfim, Douglas Rossignolli, Steeve Pigeon, Genevieve Martel, Renan De Simone, Érica Camacho, Edson Neves e Marcela Lourinho, pela confiança e, principalmente, amizade.

À Daniela Caldeira que, apesar das discussões, sempre teve disposição para me ajudar.

A todos do Centro de Inovação em Logística e Infraestrutura Portuária da USP, pelo suporte em todas as horas.

À minha família, que sempre esteve ao meu lado durante todos os momentos. 


\section{RESUMO}

Este trabalho está voltado à avaliação dos problemas do transporte intermodal sob efeito de restrições sazonais que, usualmente, não são consideradas na fase de planejamento e dimensionamento da frota. $E$, considerando a sobreposição de dois fatores sazonais restritivos ao longo da cadeia de transportes - a variação na produção de grãos ao longo do ano e a sazonalidade das cotas de nível d'água nas hidrovias -, um modelo de simulação de eventos discretos mostra as impedâncias sofridas no sistema pela junção de fatores restritivos bem fortes. É possível avaliar o impacto dessas restrições não só no nível de utilização dos silos intermediários e silagem do porto, mas também no número de veículos necessários para fazer o transporte de commodities na região Centro-Oeste do Brasil. Em um sistema de transporte composto pelos modais rodoviário, hidroviário e marítimo, no qual o modelo de simulação abrange desde a produção nas fazendas, passando pelo transporte de caminhão até os armazéns intermediários, posteriormente com o transporte fluvial com destino ao porto para exportação. O presente estudo traz uma série de comparações entre cenários para avaliação dos gargalos existentes neste sistema de transporte intermodal, especialmente avaliando cenários com e sem as restrições sazonais, assim como análises de sensibilidade de performance de equipamentos de carregamento e descarregamento, nos quais a frota e os estoques necessários são substancialmente diferentes se a sazonalidade não for considerada.

Palavras-chave: Logística de grãos, sazonalidade, modelo de simulação, transporte multimodal, transporte intermodal. 


\begin{abstract}
This work focuses on the evaluation of the intermodal transport problems under the influence of seasonal constraints that are not usually considered on the phase of planning and sizing the fleet. Considering the superposition of two different seasonal factors along the transportation chain - first one the variation on grain production and the second one the level of water in the waterways throughout the year -, a discrete event simulation model was built to show the real effects of those constraints in the grain supply chain. So, it is possible to evaluate the impact of those constraints not only on the usage level of storages in this system, but also the number of vehicles required to transport this commodities from the Midwest of Brazil to the port. In a complex multimodal transportation system, the simulation model in this work includes roadways, waterways and seaways to transport all the cargo from farms to the final costumer. This study is composed by a number of scenarios to evaluate the bottlenecks in this intermodal transportation system, specially analyzing scenarios with and without seasonal constraints, as well as analysis of sensitivity of performance of equipment of loading and unloading, in which the fleet and the required stocks are substantially different if seasonality is not considered. In other words, it is possible to evaluate the risks involved when managers are making decisions if they do not take in consideration any of those seasonal constraints.
\end{abstract}

Keywords: Logistic systems, grain logistics, simulation model, seasonality, multimodal transportation, intermodal transportation. 


\section{LISTA DE FIGURAS}

Figura 1: Problemas e soluções do transporte de grãos no Brasil...................... 20

Figura 2: Portos utilizados para a movimentação de soja em 2011 .................... 23

Figura 3: Hidrovias e Pontos de medida ................................................................... 26

Figura 4: Cota de nível d'água em Porto Velho ...................................................... 27

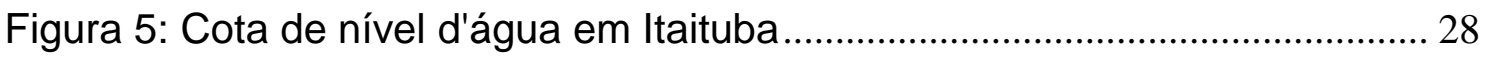

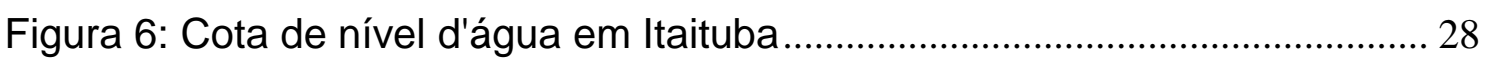

Figura 7: Histórico de Produção de Soja ................................................................. 31

Figura 8: Capacidade de Armazenagem X Produção ........................................... 31

Figura 9: Padrão de consumo em função da renda............................................. 32

Figura 10: Participação do agronegócio no PIB ..................................................... 33

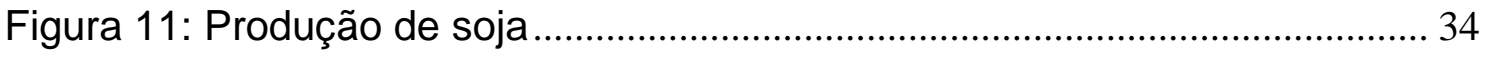

Figura 12: Participação das regiões na produção de soja em 2011 ................... 34

Figura 13: Distribuição da produção de soja por município .................................. 35

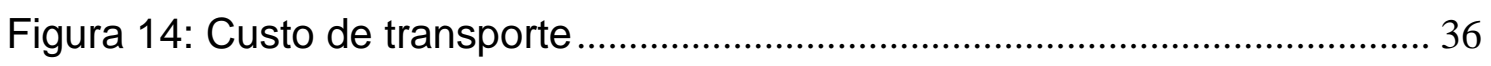

Figura 15: Critérios de avaliação das rodovias ..................................................... 37

Figura 16: Municípios do Brasil X Centroide ........................................................... 37

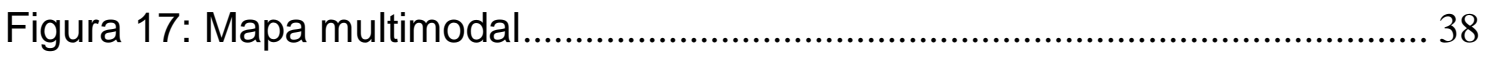

Figura 18: Comparação das ferrovias entre Brasil e EUA ................................... 39

Figura 19: Comparação das hidrovias entre Brasil e EUA ................................... 39

Figura 20: Evolução dos sistemas de simulação .................................................. 41

Figura 21: Etapas de um modelo de simulação ..................................................... 43

Figura 22: Comportamento da média acumulada dos valores após 150

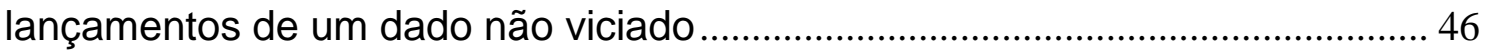

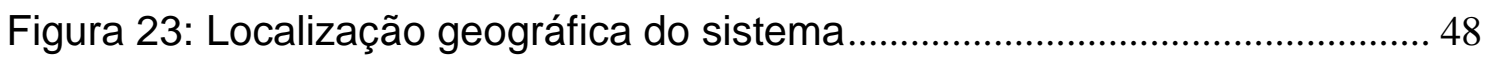

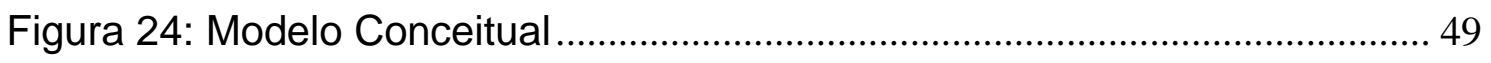

Figura 25: Subsistema Rodoviário ................................................................... 51

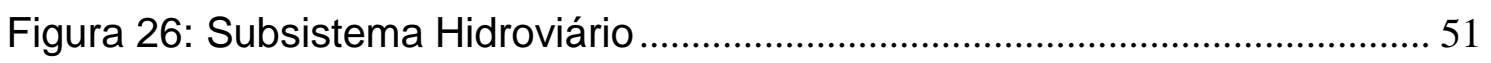

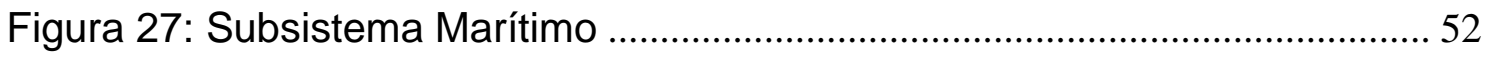

Figura 28: Distribuição da Oferta de grãos ao longo do ano ............................... 53

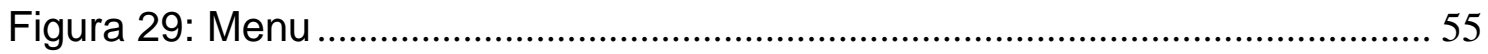

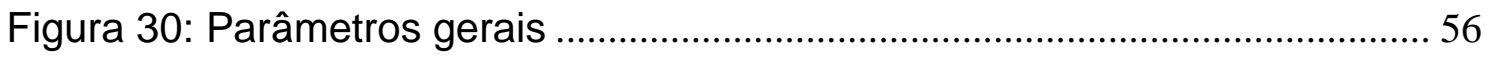




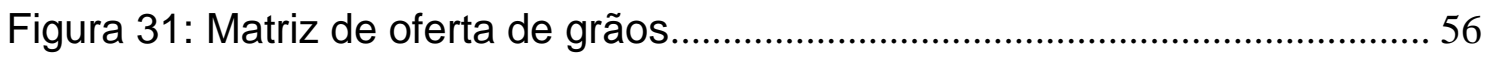

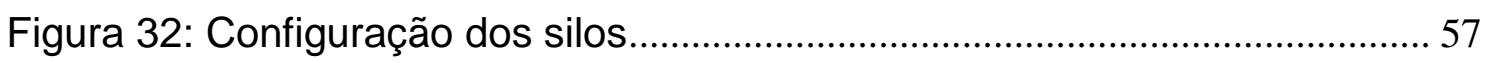

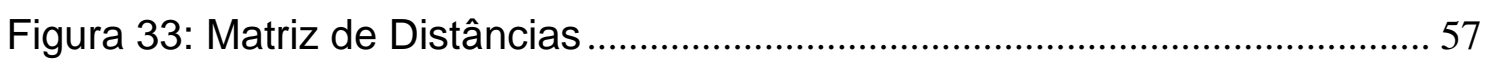

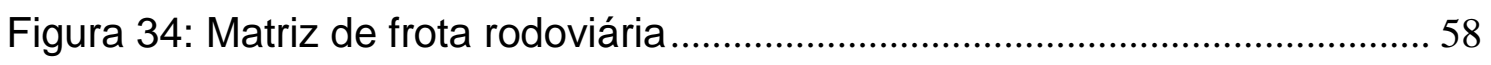

Figura 35: Matriz de distâncias das hidrovias ........................................................ 58

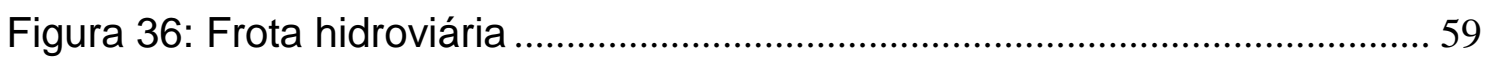

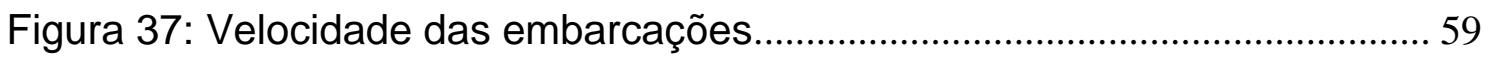

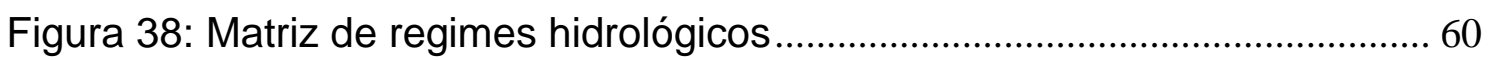

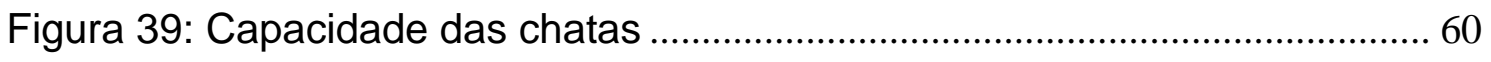

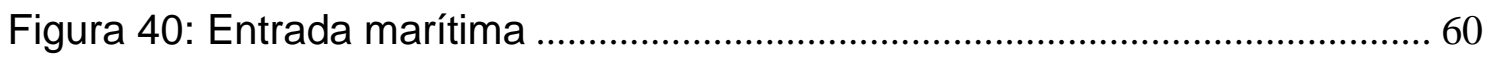

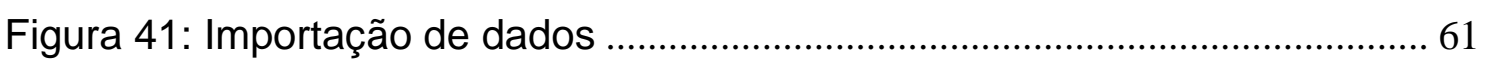

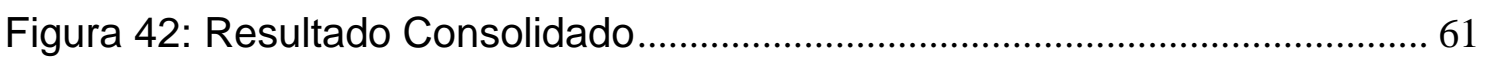

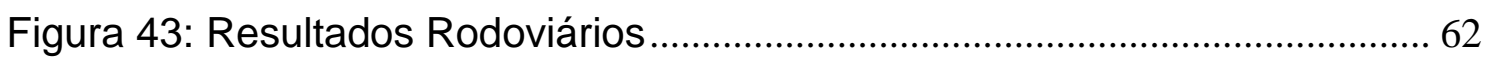

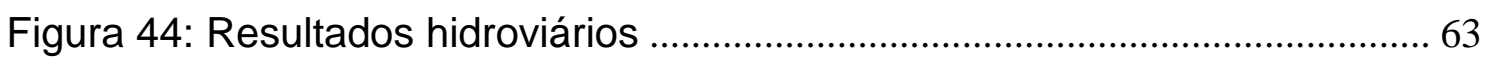

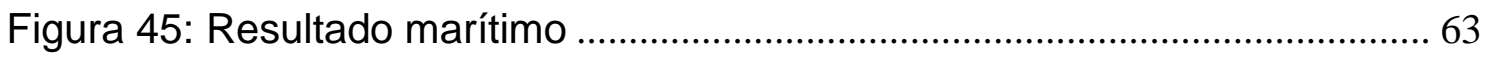

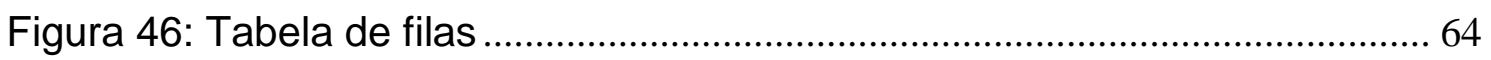

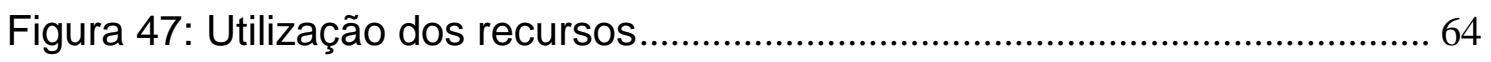

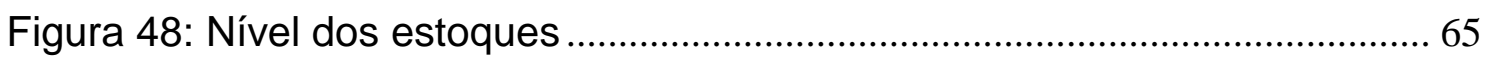

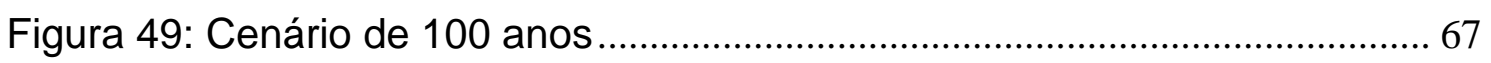

Figura 50: Estoques - cenário A com Handymax ................................................. 72

Figura 51: Estoques - cenário A com Panamax ……………………………….... 72

Figura 52: Estoques - cenário $A$ com mix de navios............................................. 73

Figura 53: Estoques - cenário B com Handymax ……………………................. 76

Figura 54: Estoques - cenário B com Panamax ................................................... 76

Figura 55: Estoques - cenário B com mix de navios........................................... 77

Figura 56: Estoques - cenário C com Handymax.................................................. 80

Figura 57: Estoques - cenário C com Panamax ..................................................... 80

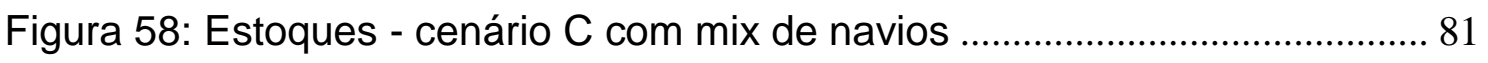

Figura 59: Estoques - cenário D com Handymax................................................. 84

Figura 60: Estoques - cenário D com Panamax ..................................................... 84

Figura 61: Estoques - cenário D com mix de navios ............................................. 85

Figura 62: Comparação dos cenários de sensibilidade......................................... 88

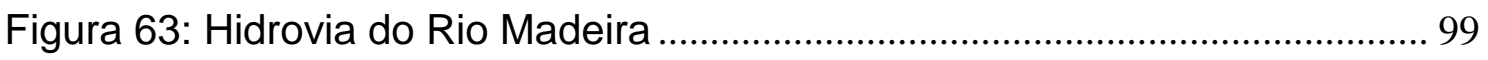

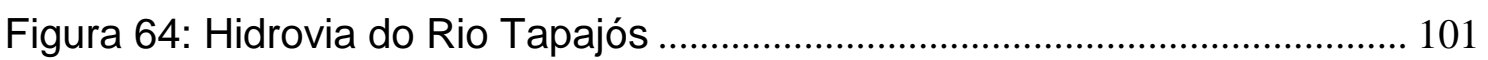


Figura 65: Hidrovia do Rio Tocantins 


\section{LISTA DE TABELAS}

Tabela 1: Movimentação de Soja dos principais portos em 2011 ......................... 21

Tabela 2: Premissas referente às hidrovias ............................................................ 53

Tabela 3: Capacidade Média dos Navios ............................................................... 54

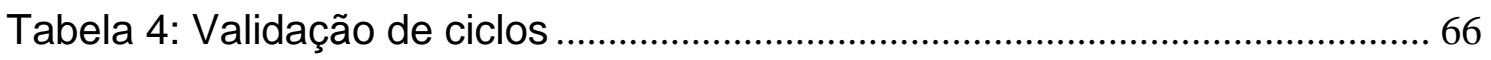

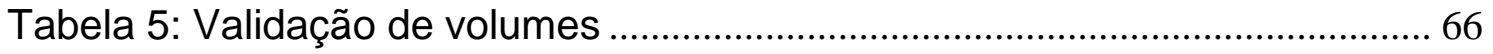

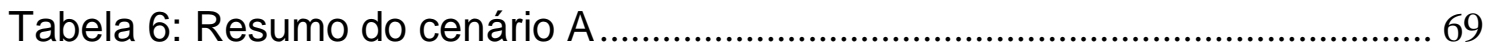

Tabela 7: Tempos de ciclo cenário A para Handymax ............................................. 70

Tabela 8: Tempos de ciclo cenário A para Panamax ............................................ 70

Tabela 9: Tempos de ciclo cenário A para o mix Panamax e Handymax ........... 71

Tabela 10: Frota de caminhões - Cenário A ......................................................... 71

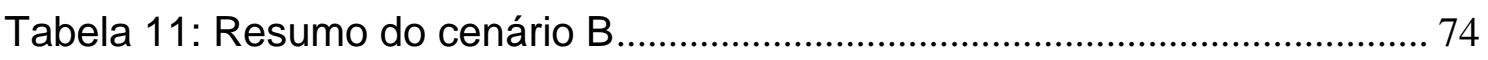

Tabela 12: Tempos de ciclo cenário B para Handymax......................................... 74

Tabela 13: Tempos de ciclo cenário B para Panamax .......................................... 75

Tabela 14: Tempos de ciclo cenário B para o mix de navios .................................. 75

Tabela 15: Frota de caminhões - Cenário B …………………………............... 75

Tabela 16: Resumo do cenário $C$.................................................................... 78

Tabela 17: Tempos de ciclo cenário $C$ para Handymax ........................................ 78

Tabela 18: Tempos de ciclo cenário B para Panamax........................................... 78

Tabela 19: Tempos de ciclo cenário $C$ para o mix de navios................................ 79

Tabela 20: Frota de caminhões - Cenário C ………………………………........ 79

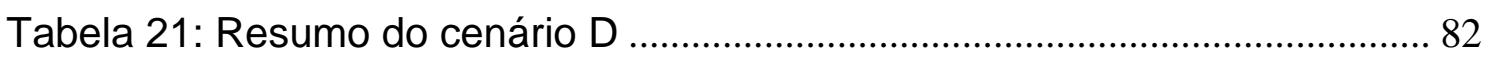

Tabela 22: Tempos de ciclo cenário D para Handymax ....................................... 82

Tabela 23: Tempos de ciclo cenário D para Panamax.......................................... 82

Tabela 24: Tempos de ciclo cenário D para o mix de navios................................. 83

Tabela 25: Frota de caminhões - Cenário D ......................................................... 83

Tabela 26: Comparação entre os cenários A, B, C e D ………………………...... 87

Tabela 27: Comparação entre os cenários de análise de sensibilidade ............. 90 


\section{Sumário}

1. INTRODUÇÃO

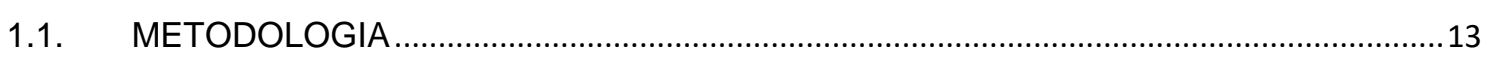

1.2. OBJETIVO

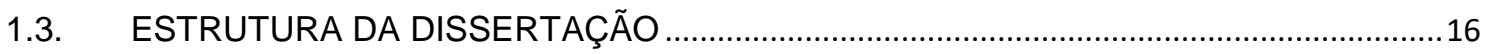

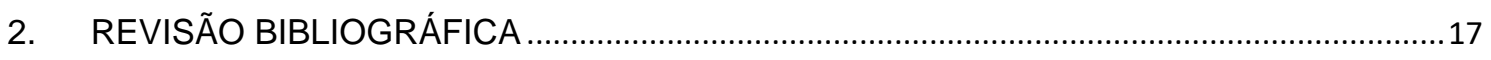

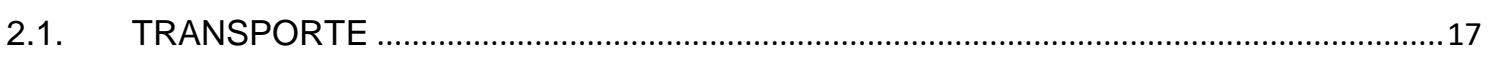

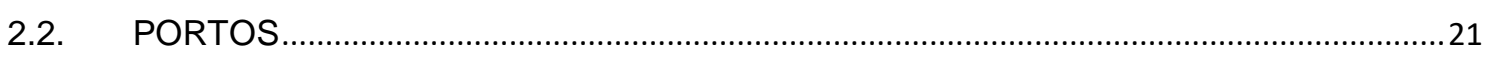

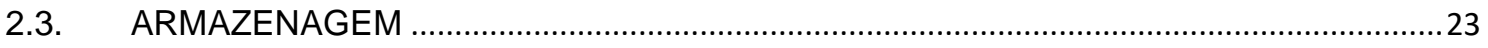

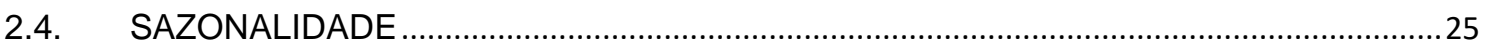

3. O SETOR BRASILEIRO DE COMMODITIES DE GRÃOS ...................................................29

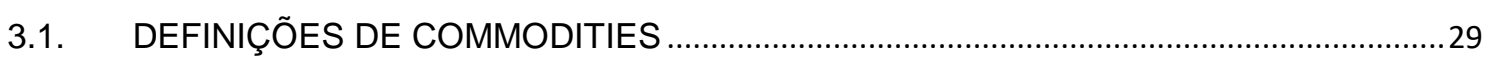

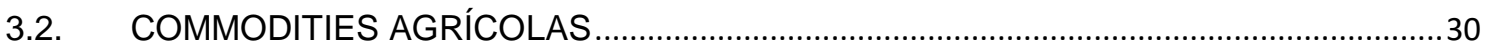

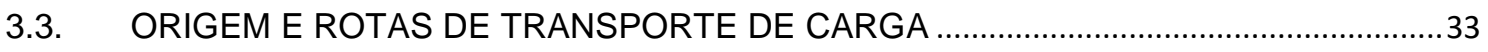

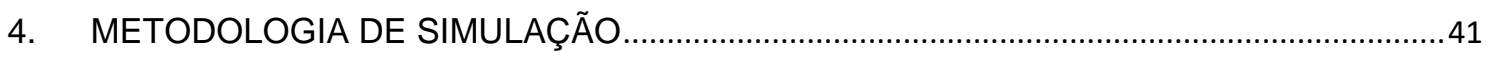

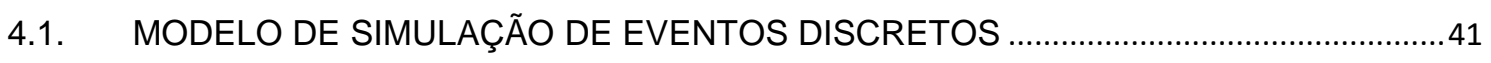

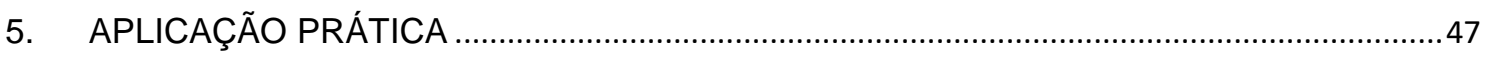

5.1. CONTEXTUALIZAÇÃO DO SISTEMA DE TRANSPORTE DE GRÃOS...........................47

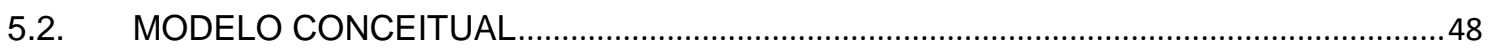

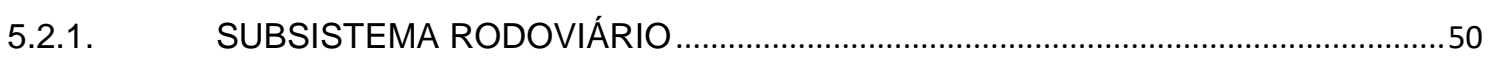

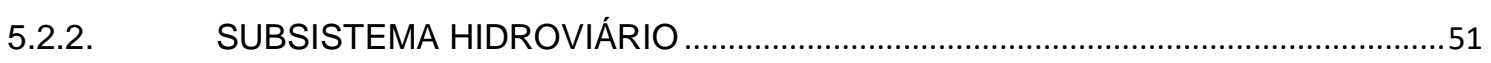

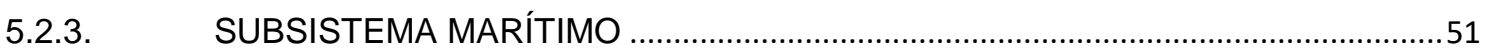

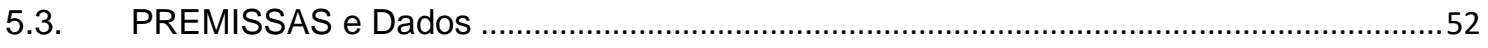

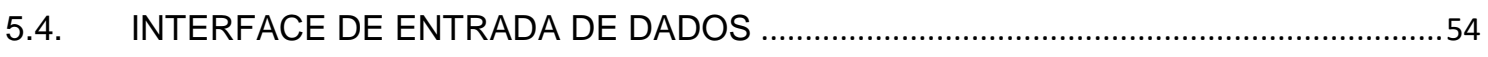

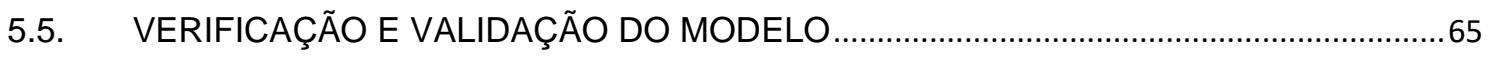

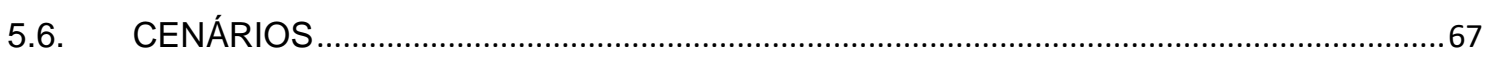

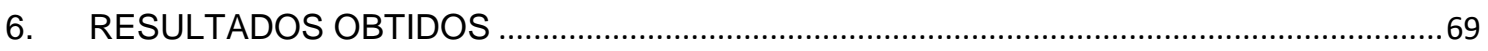

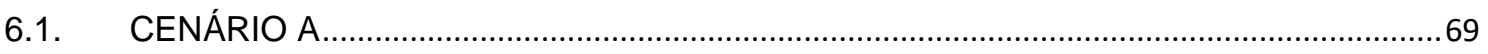

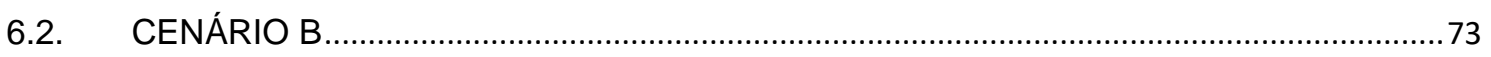

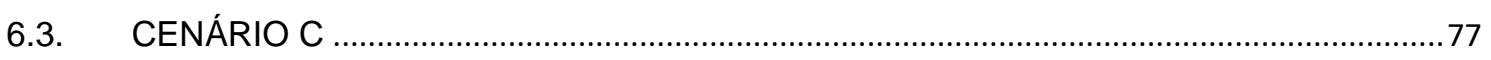

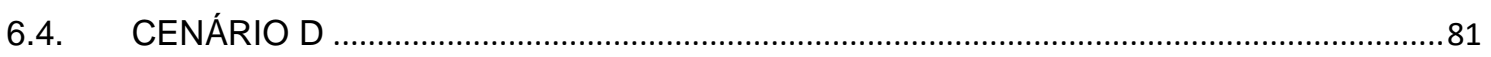

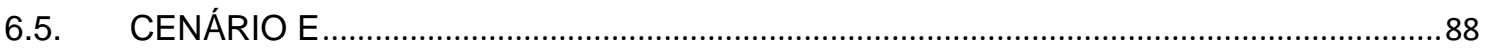

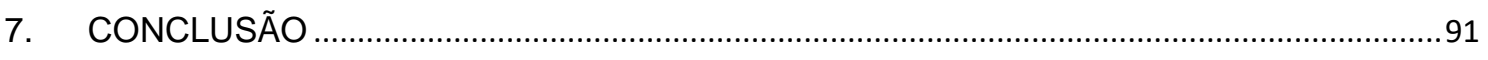

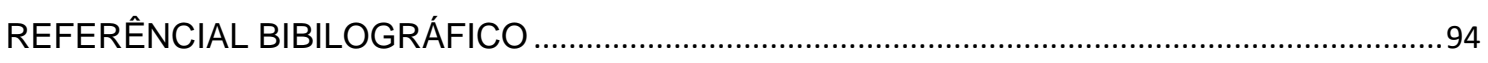

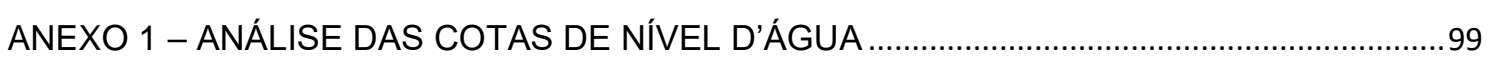




\section{INTRODUÇÃO}

O agronegócio de uma nação é uma área importante para o crescimento econômico do país. Nas últimas décadas, a cultura de soja teve um crescimento expressivo das áreas de plantio, associado a um aumento na produtividade, que está diretamente ligado aos avanços tecnológicos e ao manejo eficiente dos produtores e transportadores de grãos.

No caso brasileiro, o plantio de soja se dá, principalmente, nas regiões CentroOeste e Sul do país, e se tornou um dos produtos mais destacados no mercado de commodities do Brasil. Porém, ainda enfrenta alguns problemas de infraestrutura para transportar grãos das regiões produtoras até os pontos de escoamento para o mercado internacional.

Segundo Hoffe O'Kray (2014), o Brasil é o segundo maior exportador de soja do mundo, com cerca de 85 milhões de toneladas produzidas em 2013 e 2014, perdendo apenas para os Estados Unidos, com aproximadamente 90 milhões de toneladas no mesmo período.

No entanto, o sistema de transporte brasileiro apresenta alto custo operacional, chegando a ser duas vezes mais caro, se comparado ao dos EUA. O escoamento da soja do Centro-Oeste para os portos teve significativas perdas de competitividade devido às precárias condições de conservação das rodovias. O custo logístico do país aumentou expressivamente, superando em 83\%, em média, o dos Estados Unidos e em 94\% o da Argentina - principais concorrentes brasileiros no setor de soja, conforme apontam Jank et al. (2004 e 2005).

Para solucionar alguns dos problemas de planejamento logístico, como o apontado anteriormente, Hodd et al. (2010) acredita que o uso racional dos recursos envolvidos e uma boa gestão das empresas são necessários. Com o avanço da capacidade computacional dos últimos anos, problemas cada vez mais complexos foram estudados por métodos quantitativos oriundos da pesquisa operacional. Sendo assim, os problemas de logística e gestão da cadeia de suprimentos têm despertado grande interesse estratégico das empresas. Isso devido aos significativos ganhos gerados pela utilização da modelagem matemática e das análises estatísticas. 
Os custos logísticos podem ser divididos em: custos de transporte, custos de estoques e custos de processamento de pedidos. E, assim, dentre essas três categorias de custos, o de transporte de carga é, em geral, o que tem a maior parcela, chegando a até dois terços das despesas logísticas empresariais (Ballou, 2006).

Sendo assim, visando melhorar a utilização dos recursos empresariais, neste trabalho, tem-se o transporte integrado de grãos pela rodovia, hidrovia e marítimo, onde a distância a ser percorrida - desde as fazendas produtoras até o porto de exportação - é muito grande e muito custosa para ser feita por apenas um modal. E, se somadas as características sazonais nesse sistema, tanto por parte da produção quanto por parte da hidrovia, nota-se uma complexidade grande nesse sistema. Então, é necessária uma ferramenta para auxiliar os tomadores de decisão quanto ao dimensionamento das frotas e para verificar 0 comportamento dos níveis de estocagem ao longo do ano, considerando essas duas restrições sazonais.

É importante salientar que, devido à saturação da capacidade portuária do Sudeste brasileiro, a opção de utilizar o Nordeste e Norte do Brasil é uma oportunidade para o desenvolvimento dessas regiões. Neste contexto, é importante para o mercado de commodities brasileiro e para as empresas envolvidas com este segmento que os custos associados ao transporte sejam reduzidos.

\subsection{METODOLOGIA}

A simulação de eventos discretos é uma das vertentes da simulação computacional e caracteriza-se pela existência de eventos, que são acontecimentos que se dão em instantes de tempo da simulação e alteram o estado do sistema (KELTON et al., 1998).

Devido à grande complexidade do sistema, optou-se pelo uso de simulação de eventos discretos como metodologia, já que esta possibilita um maior detalhamento de todas as etapas que envolvem o carregamento de grãos nas fazendas produtoras, o transporte até os pontos de armazenagem intermediária, 
transbordo, transporte até o porto de destino e o embarque nos navios para exportação. Além disso, em um modelo de simulação, pode-se facilmente modelar restrições e características peculiares do processo, o que, no caso de um modelo analítico, teria um alto grau de dificuldade.

É utilizada a técnica de simulação de eventos discretos para a modelagem nessa pesquisa, pois foi observada sua eficácia no auxílio à tomada de decisão no estudo de sistemas logísticos complexos, onde há transferência de carga entre diferentes modais de transporte, e no qual devem ser considerados os estoques nos diversos pontos, assim como os estoques em trânsito.

Para Chwif e Medina (2015), a simulação não é capaz de prever soluções e tampouco pode ser confundida com otimização. Simulação é uma ferramenta de análise, onde cada cenário simulado pode ser combinado com outras técnicas, como a própria simulação ou mesmo a análise multicritérios para a tomada de decisão empresarial. Os autores ressaltam também que a simulação não é capaz de substituir o pensamento humano.

Muitos autores buscaram avaliar o transporte e a estocagem de grãos utilizando simulação. No entanto, não foi feita uma avaliação do comportamento dos estoques intermediários e estoque no porto de exportação com a influência de sazonalidade, e em nenhum desses estudos foi avaliada a cadeia logística intermodal. Ou seja, os sistemas de transporte e armazenagem foram estudados separadamente. Para atingir o objetivo deste trabalho, avaliou-se os impactos que as sazonalidades de oferta de produto e de restrição de navegação têm sobre os estoques de toda a cadeia de abastecimento de grãos.

Em um modelo de simulação, pode-se facilmente descrever e definir os circuitos de transporte presentes ao longo da cadeia. Com isso, tem-se uma análise adequada e com rico detalhamento das interações dos diversos equipamentos e recursos contidos nesse processo.

O modelo de simulação desenvolvido foi construído através do software ARENA® e, para o auxílio na construção dos cenários, foi desenvolvido também, em Microsoft Exce周, uma interface de dados na qual são inseridos os dados de entrada de maneira estruturada necessários ao modelo. Além disso, é nessa interface que são gravadas as saídas obtidas em cada cenário da simulação, 
facilitando, assim, a comparação dos resultados obtidos em cada cenário simulado pelo modelo.

O modelo apresentado neste estudo foi desenvolvido para uma aplicação real em uma empresa do setor privado com atuação no Brasil. A empresa forneceu todas as informações e os dados necessários para o desenvolvimento dos cenários a serem simulados, assim como todas as características intrínsecas às atividades relacionadas ao carregamento, transporte e descarregamento, bem como a capacidade de armazenagem dos silos. Além das características das vias utilizadas e das especificações de todos os recursos empregados no processo (caminhões, taxas de carregamento e descarregamento, etc.).

\subsection{OBJETIVO}

O objetivo principal deste trabalho é avaliar o comportamento dos estoques do sistema de abastecimento de grãos, desde as fazendas localizadas no CentroOeste até o porto de exportação à costa leste brasileira, levando em consideração dois fatores sazonais durante 0 ano: a sazonalidade na cultura de grãos produzidos e o nível de cotas d'água das hidrovias, que influencia diretamente na capacidade de carga que pode ser transportada pelas hidrovias. Sendo assim, foi realizada a simulação do sistema atual de transporte, levandose em consideração todos os recursos e operações envolvidos, sendo este, posteriormente, comparado a um sistema semelhante, mas sem algumas restrições, para mensurar a real impedância que cada uma das restrições tem sobre o sistema estudado.

Foi escolhida a ferramenta de simulação matemática de eventos discretos para dimensionar de maneira eficiente a frota de veículos terrestres, fluviais e marítimos necessários para o transporte da demanda de grãos associados aos estoques intermediários, levando-se em consideração todas as características de cada meio de transporte e a sazonalidade da oferta de carga nas fazendas produtoras. 


\subsection{ESTRUTURA DA DISSERTAÇÃO}

Esta dissertação está dividida em capítulos, descritos a seguir:

- O Capítulo 2 apresenta uma breve revisão bibliográfica dos sistemas de transporte, portos, armazenagem e sazonalidade.

- O Capítulo 3 apresenta uma revisão sobre o setor de commodities brasileiro, mais aprofundada em relação às commodities agrícolas de soja, na qual está inserido o tema central abordado neste estudo, assim como as principais regiões e pontos de escoamento dos grãos;

- O Capítulo 4 apresenta a metodologia utilizada e algumas características da simulação de eventos discretos, além de expor justificativas que deem suporte à utilização desta ferramenta na solução do problema abordado nesta dissertação.

- O Capítulo 5 apresenta a contextualização dos assuntos estudados a um caso real, além disso, expõe detalhadamente o modelo desenvolvido para atingir o objetivo deste trabalho, bem como modelagem conceitual, premissas, interface de entrada e saída de dados, validação e cenários.

- O Capítulo 6 mostra os principais resultados obtidos para os cenários propostos no capítulo anterior.

- Para finalizar, o Capítulo 7 apresenta as conclusões tomadas a partir dos resultados obtidos e comentários finais acerca do trabalho realizado. 


\section{REVISÃO BIBLIOGRÁFICA}

Neste capítulo será apresentada uma breve revisão da literatura, buscando mostrar as áreas pesquisadas em relação ao escoamento das commodities de soja no Brasil.

\subsection{TRANSPORTE}

Os crescentes recordes de produção e a necessidade de escoar a soja para os portos têm sobrecarregado os sistemas de transporte no território brasileiro, com destaque para as regiões Sul e Sudeste. Essa tendência de aumento de produção aponta para uma movimentação cada vez maior e, sendo assim, o transporte será cada vez mais demandado. No entanto, nota-se que a infraestrutura de transporte ainda é precária em muitas regiões do Brasil, mesmo ela sendo essencial para essa tendência de crescimento produtivo (Tosta, 2005).

O transporte intermodal de pessoas e carga é definido pela transferência desde o ponto de origem até o ponto de destino, com uma sequência de, pelo menos, dois modais diferentes (Barnhart e Laporte, 2007). Sendo assim, pode-se considerar neste trabalho que os conceitos de transporte intermodal de cargas foram utilizados, já que há transferências de carga desde seu ponto de origem até o ponto de destino por diferentes modais de transporte.

Para Martins et al. (2005), uma melhora do setor de transporte contribui com a redução da estocagem de produtos e, assim, com os custos associados. Segundo a Confederação Nacional dos Transportes (2002), há cerca de $R \$ 120$ bilhões em excesso de estoques que as empresas brasileiras mantêm ao longo de seus processos como forma de se protegerem das ineficiências do transporte. Um dos gargalos encontrados pelo setor do agronegócio é a indisponibilidade de modais alternativos ao rodoviário, no qual, no caso de granéis sólidos, a concentração do modal é muito inadequada, sendo que cerca de $80 \%$ das cargas são transportadas por rodovias, deixando ferrovias com números de $8 \%$ a $10 \%$ e hidrovias com o restante (Caixeta-Filho, 2001). 
Para Hijjar (2004), o modal rodoviário é indicado para o transporte de cargas em distâncias curtas, ou seja, trajetos de até 300 quilômetros, assim como - para maiores distâncias -, os modais ferroviário ou hidroviário são mais indicados por terem menor custo por tonelada $x$ quilômetro. No entanto, isso não acontece no Brasil devido à atual malha de transporte.

O modal ferroviário tem vocação natural para transporte de produtos com baixo valor agregado, para fluxos concentrados (em termos de origens e destinos) e para grandes distâncias. Países de dimensões continentais devem, também, considerar esse modal para o transporte de: minério de ferro, produtos siderúrgicos, produtos agrícolas, carvão mineral e clínquer, cimento e cal, adubos e fertilizantes, contêineres etc. (Pires, 2005).

No entanto, a falta de planejamento, por não ser integrado facilmente aos outros modais e por ter sido construído para atender às exigências do mercado de exportação de bens primários, ligando áreas produtoras aos portos, isoladamente, não houve evolução desse modal de transporte no Brasil (Tosta, 2005).

Silveira e Vargas (2007) utilizaram técnicas de simulação de fluxo em rede para avaliar as estratégias de utilização rodoviária na região Centro-Oeste para o transporte de grãos, estudando, principalmente, a infraestrutura de transporte e identificando as rotas mais viáveis para determinado conjunto de pontos produtores com o intuito de aumentar a competitividade brasileira frente ao mercado de soja internacional.

Embora o custo do modal ferroviário para grandes volumes seja relativamente baixo, ele não foi considerado neste trabalho, pois não há estradas de ferro ligando os centros produtores de soja ao porto de exportação.

Coppead (2002) aponta que o modal hidroviário é composto pela navegação de interior e pela cabotagem, destacando ainda que, com cerca de $45.000 \mathrm{~km}$ de rios navegáveis, esta pode ser uma alternativa para o transporte de grandes volumes produzidos pelo país. No entanto, esta não é a realidade brasileira.

A navegação fluvial está em um patamar inferior se comparado com outros modais de transporte, é o sistema de menos participação no transporte de mercadorias. Isso ocorre devido a alguns fatores como, por exemplo, o fato de 
muitos rios serem de planaltos, tendo cachoeiras que dificultam a navegação. Ou como ocorre nos rios de planícies que, apesar de serem facilmente navegáveis, encontram-se distantes dos centros produtores.

Para Fleury (2005), o transporte é um componente principal de um sistema logístico, representando, em média, $60 \%$ dos custos logísticos. Mesmo sabendo que os valores variam, substancialmente, de setor para setor, pode-se dizer que, quanto menor o valor agregado do produto, maior a participação do transporte no faturamento da empresa. Isso significa que qualquer variação no preço do transporte será rapidamente percebida pelas empresas.

Com isso, Tosta (2005) fez um levantamento dos problemas e dos insumos que levariam à solução dos problemas para os três principais modais de transporte de grandes volumes, Figura 1. 


\begin{tabular}{|c|c|c|c|}
\hline Modal & Problema & Solução & Insumos necessários \\
\hline \multirow[t]{4}{*}{ Rodoviário } & \multirow[t]{2}{*}{$\begin{array}{l}\text { Alta fragmentação e } \\
\text { excesso de oferta }\end{array}$} & $\begin{array}{l}\text { Regulamentação por meio } \\
\text { do PLC } 4358 / 01 \text { que } \\
\text { disciplina o transporte } \\
\text { de cargas }\end{array}$ & $\begin{array}{l}\text { Aprovação pelo Congresso } \\
\text { Nacional }\end{array}$ \\
\hline & & RNTRC & $\begin{array}{l}\text { Já em fase de } \\
\text { cadastramento pela Antt }\end{array}$ \\
\hline & $\begin{array}{l}\text { Alto consumo de } \\
\text { combustiveis }\end{array}$ & Renovação da frota & Garantir linhas de financiamento \\
\hline & $\begin{array}{l}\text { Estado precário } \\
\text { das rodovias }\end{array}$ & Recuperação & $\begin{array}{l}\text { Garantir a destinação } \\
\text { dos recursos da Cide; } \\
\text { Alterar o acordo com o FMI; } \\
\text { Aprovação das PPPs } \\
\text { pelo Congresso; } \\
\text { Alternativas de parcerias a } \\
\text { exemplo do efetuado pelo MT. }\end{array}$ \\
\hline \multirow[t]{4}{*}{ Ferroviário } & $\begin{array}{l}\text { Insuficiência de } \\
\text { linhas }\end{array}$ & Construção & $\begin{array}{l}\text { Aprovação das PPPs } \\
\text { pelo Congresso; } \\
\text { Garantir a destinação } \\
\text { dos recursos da Cide; } \\
\text { Alterar o acordo com o FMI. }\end{array}$ \\
\hline & Diferentes bitolas & $\begin{array}{l}\text { Integração operacional } \\
\text { das malhas }\end{array}$ & $\begin{array}{l}\text { Aprovação das PPPs } \\
\text { pelo Congresso; } \\
\text { Garantir a destinação } \\
\text { dos recursos da Cide; } \\
\text { Alterar o acordo com o FMI. }\end{array}$ \\
\hline & \multirow[t]{2}{*}{ Baixa produtividade } & $\begin{array}{l}\text { Regulamentação do } \\
\text { tráfego mútuo }\end{array}$ & Resolução já publicada \\
\hline & & $\begin{array}{l}\text { Regulamentação do } \\
\text { direito de passagem }\end{array}$ & \\
\hline \multirow[t]{4}{*}{ Aquaviário } & Impedimentos ambientais & Projetos bem fundamentados & Interação com o Poder Judiciário \\
\hline & $\begin{array}{l}\text { Infra-estrutura precária } \\
\text { nos portos }\end{array}$ & $\begin{array}{l}\text { Investimentos em } \\
\text { infra-estrutura }\end{array}$ & \multirow{3}{*}{$\begin{array}{l}\text { Garantir a destinação } \\
\text { recursos da Cide; } \\
\text { Aprovação das PPPs pelo } \\
\text { Congresso; } \\
\text { Alterar o acordo com o FMI }\end{array}$} \\
\hline & $\begin{array}{l}\text { Dependente da } \\
\text { intermodalidade }\end{array}$ & $\begin{array}{l}\text { Investimentos em } \\
\text { infra-estrutura }\end{array}$ & \\
\hline & Rios encachoeirados & Construção de Eclusas & \\
\hline
\end{tabular}

Figura 1: Problemas e soluções do transporte de grãos no Brasil.

Fonte: Tosta, 2005

Stringher (2004) afirma que é importante que as empresas possuam uma frota de veículos eficientemente dimensionada para garantir baixos custos marginais e um nível de serviço adequado às práticas de mercado. Dessa forma, para atender à demanda de soja produzida pelas fazendas, é importante que as operações de carga, transporte e descarga sejam efetuadas com eficiência.

No entanto, com a interdependência desses procedimentos e compartilhamento dos recursos envolvidos, podem ocorrer tempos improdutivos, como formação de filas nos locais de carregamento e descarregamento devido a processos administrativos intrínsecos às operações e também pelo desbalanceamento de 
produtividade dos recursos disponibilizados ao longo dos processos (Mundim, 2009).

Soares et al. (1997) diz que a safra de soja, que ocorre entre os meses de março e abril, é que desestabiliza o mercado de frete brasileiro, pois traz os maiores impactos sobre o mercado de transporte rodoviário de cargas. Isso se dá porque os produtores realizam suas colheitas rapidamente sem ter onde armazenar 0 produto, fato que se acentua cada vez mais devido aos avanços tecnológicos de maquinário agrícola. Ademais, a lentidão no percurso entre as fazendas produtoras e o destino final, e a maior necessidade de manutenção dos caminhões nestes trechos, geralmente não pavimentados, são fatores que também prejudicam o transporte de cargas.

\subsection{PORTOS}

A pesquisa realizada no sistema do SECEX (2012) resulta em uma massa de dados da qual é possível obter a matriz de portos que participam do comércio exterior dos produtos que compuseram o complexo da soja em 2011.

A Tabela 1 mostra os complexos portuários definidos através das movimentações históricas do comércio exterior.

Tabela 1: Movimentação de Soja dos principais portos em 2011

\begin{tabular}{c|cccc|c}
\hline Porto (SECEX, 2012) & Soja $(\mathbf{t})$ & Farelo $(\mathbf{t})$ & Óleo $(\mathbf{t})$ & Total $(\mathbf{t})$ & $\%$ \\
\hline SANTOS - SP & 9.225 .715 & 2.678 .791 & 122.376 & 12.026 .882 & $\mathbf{2 4 , 6 \%}$ \\
\hline PARANAGUÁ - PR & 6.924 .317 & 4.540 .115 & 643.235 & 12.107 .667 & $\mathbf{2 4 , 8 \%}$ \\
\hline RIO GRANDE - RS & 5.755 .691 & 3.078 .595 & 481.450 & 9.315 .736 & $\mathbf{1 9 , 1 \%}$ \\
\hline $\begin{array}{c}\text { S. FRANC. DO SUL - } \\
\text { SC }\end{array}$ & 2.609 .398 & 1.393 .951 & 164.941 & 4.168 .290 & $\mathbf{8 , 5 \%}$ \\
\hline SÂO LUIS - MA & 2.514 .376 & - & - & 2.514 .376 & $\mathbf{5 , 1 \%}$ \\
\hline VITÓRIA - ES & 2.452 .879 & 1.378 .628 & - & 3.831 .507 & $\mathbf{7 , 8 \%}$ \\
\hline SALVADOR - BA & 1.525 .901 & 863.701 & - & 2.389 .602 & $\mathbf{4 , 9 \%}$ \\
\hline MANAUS - AM & 1.086 .216 & 419.162 & 119.378 & 1.624 .756 & $\mathbf{3 , 3 \%}$ \\
\hline SANTARÉM - PA & 789.584 & - & - & 789.584 & $\mathbf{1 , 6 \%}$ \\
\hline ILHÉUS - BA & 89.029 & - & - & 89.029 & $\mathbf{0 , 2 \%}$ \\
\hline GUAÍRA - PR & - & - & - & 0 & $\mathbf{0 , 0 \%}$ \\
\hline
\end{tabular}




\begin{tabular}{c|cccc|c}
\hline $\begin{array}{c}\text { SANTANA DO } \\
\text { LIVRAMENTO - RS }\end{array}$ & - & 1.890 & - & 1.890 & $\mathbf{0 , 0} \%$ \\
\hline URUGUAIANA - RS & - & 201 & - & 201 & $\mathbf{0 , 0} \%$ \\
\hline ASSIS BRASIL - AC & - & 132 & - & 132 & $\mathbf{0 , 0} \%$ \\
\hline CORUMBÁ - MS & - & 2 & - & 2 & $\mathbf{0 , 0} \%$ \\
\hline CORUMBÁ - MS & - & - & - & 0 & $\mathbf{0 , 0} \%$ \\
\hline $\begin{array}{c}\text { GUAJARÁ-MIRIM - } \\
\text { RO }\end{array}$ & - & - & - & 0 & $\mathbf{0 , 0} \%$ \\
\hline ITAJAÍ - SC & - & - & 408 & 408 & $\mathbf{0 , 0} \%$ \\
\hline CHUÍ - RS & - & - & 1347 & 1.347 & $\mathbf{0 , 0} \%$ \\
\hline Total & $\mathbf{3 2 . 9 7 3 . 1 0 6}$ & $\mathbf{1 4 . 3 5 5 . 1 6 8}$ & $\mathbf{1 . 5 3 3 . 1 3 5}$ & $\mathbf{4 8 . 8 6 1 . 4 0 9}$ & \\
\hline
\end{tabular}

Fonte: SECEX (2012)

No Brasil, SECEX (2012) define porto como um local onde ocorre o efetivo embarque, ou seja, o último local do território nacional por onde a mercadoria passa com destino ao exterior.

A Figura 2 mostra os principais portos utilizados para o escoamento de soja no Brasil, na qual foram excluídos os pontos com menos de $0,1 \%$ de todo 0 comércio de soja em 2011, ou seja, restaram 10 portos que representam cerca de $99 \%$ de todo o comércio realizado. 


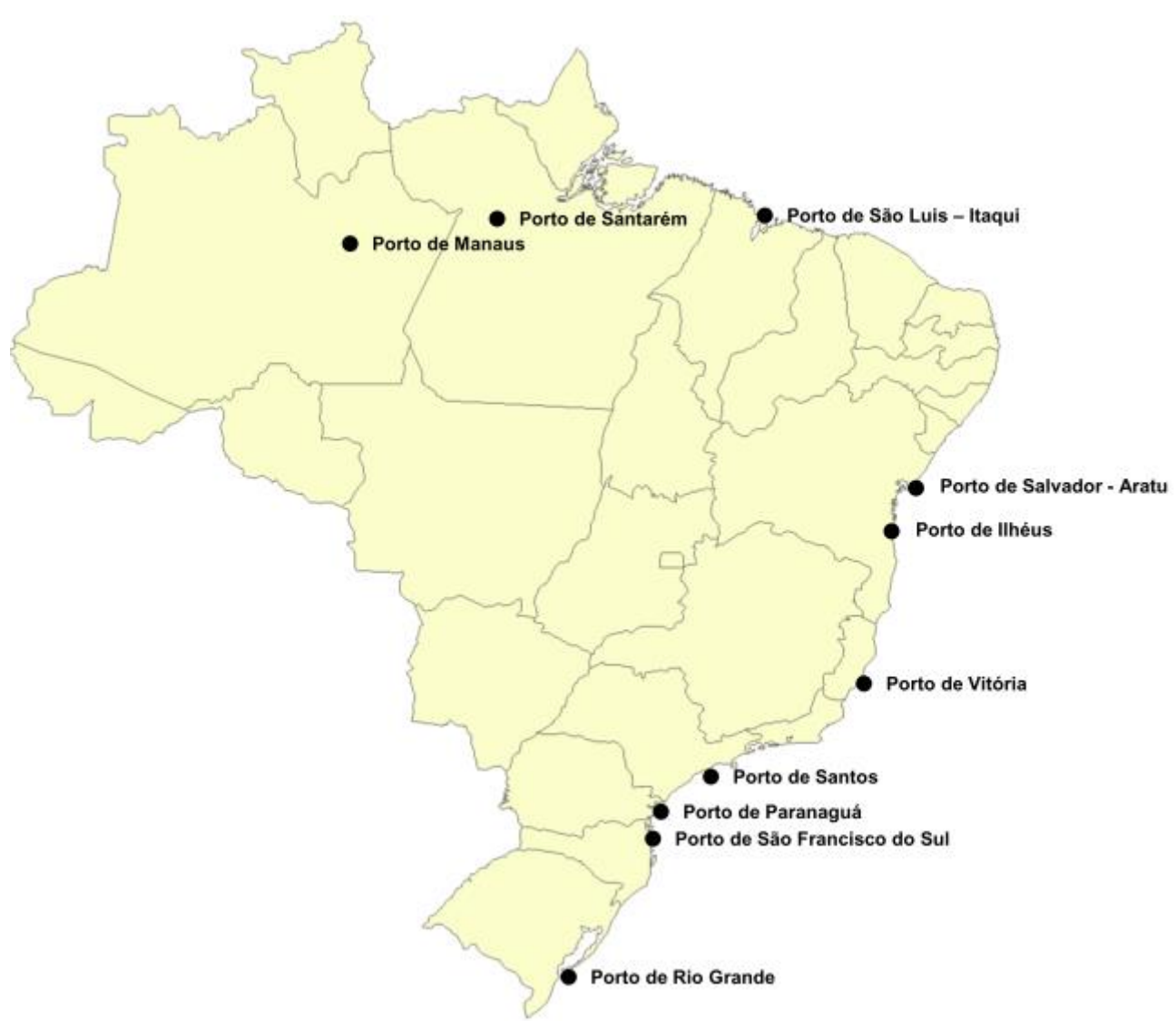

Figura 2: Portos utilizados para a movimentação de soja em 2011 Fonte: o Autor

Neste trabalho, foi utilizado o sistema intermodal de transporte que liga o porto de Vila do Conde, no estado do Pará, com os seguintes acessos rodoviários: pelas rodovias BR-135, BR-222, BR-316, BR-230, BR-226 e BR-010 e MA-230. O fluxo ferroviário compreende a EFC - Estrada de Ferro Carajás, com 809 km, a FNS - Ferrovia Norte-Sul, com 215 km de extensão, e a CFN - Companhia Ferroviária do Nordeste, com 453 km, ligando São Luís-MA à Teresina-PI. O acesso fluvial é realizado através dos Rios Mearim, Pindaré, dos Cachorros e Grajaú (CNT, 2012, ANTAQ, 2013 e BNDES 2012).

\subsection{ARMAZENAGEM}

Armazenamento é um conjunto de recursos usados para manter adequadamente os produtos em um local físico, ou seja, lida com questões 
referentes a dimensionamento de área, localização, configuração dos armazéns, tecnologia de movimentação interna, estocagem e sistemas (Ballou, 1993).

Para Weber (2005), os grãos precisam ser enviados à armazenagem após a colheita, que tem como objetivo, quando feita adequadamente, manter as qualidades biológicas, químicas e físicas desses produtos. Ou seja, a qualidade dos grãos pode ser melhorada durante o armazenamento, e poderá ser mantida assim pelo tempo que for necessário.

Junior e Tsunechiro (2011) afirmam que nos últimos anos os investimentos em infraestrutura para armazenagem não têm acompanhado o dinamismo da agricultura, causando problemas como congestionamento nas estradas, portos e pátios das instalações para recepção de mercadorias. Sendo assim, os problemas de como e onde guardar são questões importantes do agronegócio brasileiro e que devem merecer mais atenção dos agentes públicos e privados para permitir maior eficiência no deslocamento e comercialização das safras, tanto para garantir o abastecimento interno como para assegurar a competitividade no mercado externo.

Aldiqueri e Oliveira (2009) fizeram uma análise de trade-offs entre o escoamento direto da produção de soja desde o produtor até o porto, e a armazenagem intermediária dessa produção em silos localizados nas fazendas. Se o transporte de soja for controlado, uma vez que se tem capacidade de armazenagem dessa produção pelos produtores, conclui-se que ter silagem é o melhor cenário para o escoamento de grãos.

Scalabrin (2008), Jasper, Biaggioni e Ribeiro (2006) estudaram a viabilidade de se construir silos de armazenagem de grãos próximos às fazendas produtoras, bem como qual é o dimensionamento adequado dessa silagem. Além disso, avaliam a viabilidade econômica de aquisição dos silos.

Dambrosio et al. (2009) analisaram, em seu trabalho, os custos de padronização e armazenagem de soja e concluíram que é necessário o conhecimento de todos os custos que oneram a produção agrícola por parte do produtor rural.

Os autores compararam também a melhor alternativa para armazenagem de grãos: contratar armazenagem ou ter sua própria estrutura de armazenamento 
junto à fazenda. Com isso, concluíram que é menos custoso fazer o armazenamento próprio.

\subsection{SAZONALIDADE}

Segundo o dicionário Aurélio (2010), o verbete sazonalidade diz respeito às estações do ano, época do ano durante a qual comumente é executada determinada atividade agrícola.

Para analisar a sazonalidade, é adotado um modelo de séries temporais que, segundo Santana (2003), entende-se por um conjunto de dados numéricos que são obtidos por um período de tempo, no qual os fatos geradores desses dados incorporam influências do comportamento da economia, de fatores climáticos e de fatores aleatórios, nos quais o principal elemento é a sazonalidade ou estacionalidade dos dados. Ou seja, o comportamento sistemático que essa série de dados assume em um determinado período de tempo.

Buchberger e Wells (1996) estudaram o caráter sazonal da distribuição de água potável. Foi utilizado um sistema de simulação em rede para identificar a frequência, duração, volume e a média da intensidade da demanda de água.

Harrod (2006) mostrou algoritmos para chegadas sazonais, que podem ser aplicadas em transporte, finança e política social. Neste estudo, o autor comparou a acuracidade, velocidade e variabilidade entre algoritmos de chegada sazonal para diferentes arquiteturas de microprocessadores. $\mathrm{O}$ estudo mostrou que, sem conhecimento em arquitetura de computadores, não é possível escolher um algoritmo ótimo entre os testados.

Neste trabalho, serão utilizados como fatores de sazonalidade: a produção de grãos de soja pelas fazendas e, como segundo fator sazonal, a cota de nível de água das hidrovias, que serão utilizadas para o transporte de carga do porto fluvial até o porto de exportação.

Segundo a Agência Nacional de Águas - ANA (2014), os eventos naturais são inevitáveis, no entanto, é possível se preparar para enfrentá-los e, assim, minimizar as perdas. Com o propósito de contribuir para o planejamento de 
ações destinadas a prevenir ou minimizar os efeitos de secas e inundações, a ANA definiu um conjunto de estratégias para acompanhamento de eventos hidrológicos críticos. As estações de monitoramento de cota d'água formam uma rede que possibilita o acompanhamento da evolução dos níveis d'água dos principais rios da região em tempo real.

Nesse âmbito, foi feita a análise das cotas dos níveis d'água das três hidrovias que fazem parte da cadeia de abastecimento proposta. Foram extraídas as cotas das séries históricas dos pontos encontrados para esses rios. Na Figura 3, temse a localização das hidrovias e de cada ponto de coleta de dados pela ANA, 2014:

- Rio Madeira: Abunã; Balsa do Rio Abunã; Palmeiral; Salto Teotônio; Porto Velho; Porto Velho Jusante; Prosperidade; Calama; Manicoré; Novo Arupuranã; Fazenda Vista Alegre; Borba; Nova Olinda do Norte.

- Rio Tapajós: Barra do são Manuel; Fortaleza; Jatoba; Acará do Tapajós; Barreiras; Itaituba; Fordlândia; Santarém.

- Rio Tocantins: Baião; Cidade de Cameta; Fazenda Ipitinga; Fazenda São Tomé; Ipixuna; Itupiranga; Jatobal; Marabá; Nazaré dos Patos; Tucuruí.

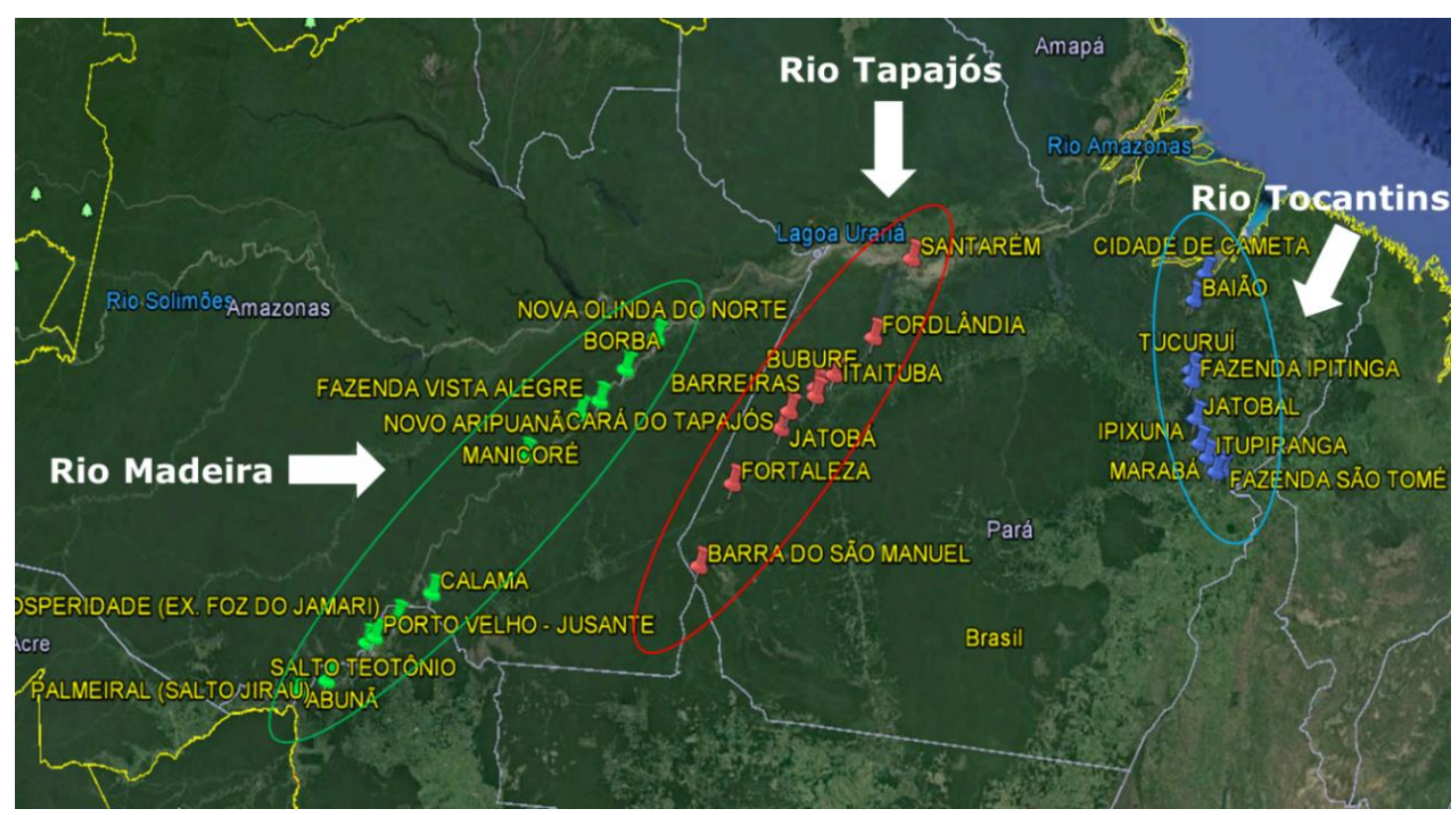

Figura 3: Hidrovias e Pontos de medida Fonte: o Autor 
A Figura 4 exemplifica um ponto de coleta de dados do Rio Madeira, onde se pode observar o comportamento do nível d'água ao longo do ano por aproximadamente 50 anos, assim como a frequência em que ocorreram. Note também que a linha em destaque é a média dos 50 anos analisados.
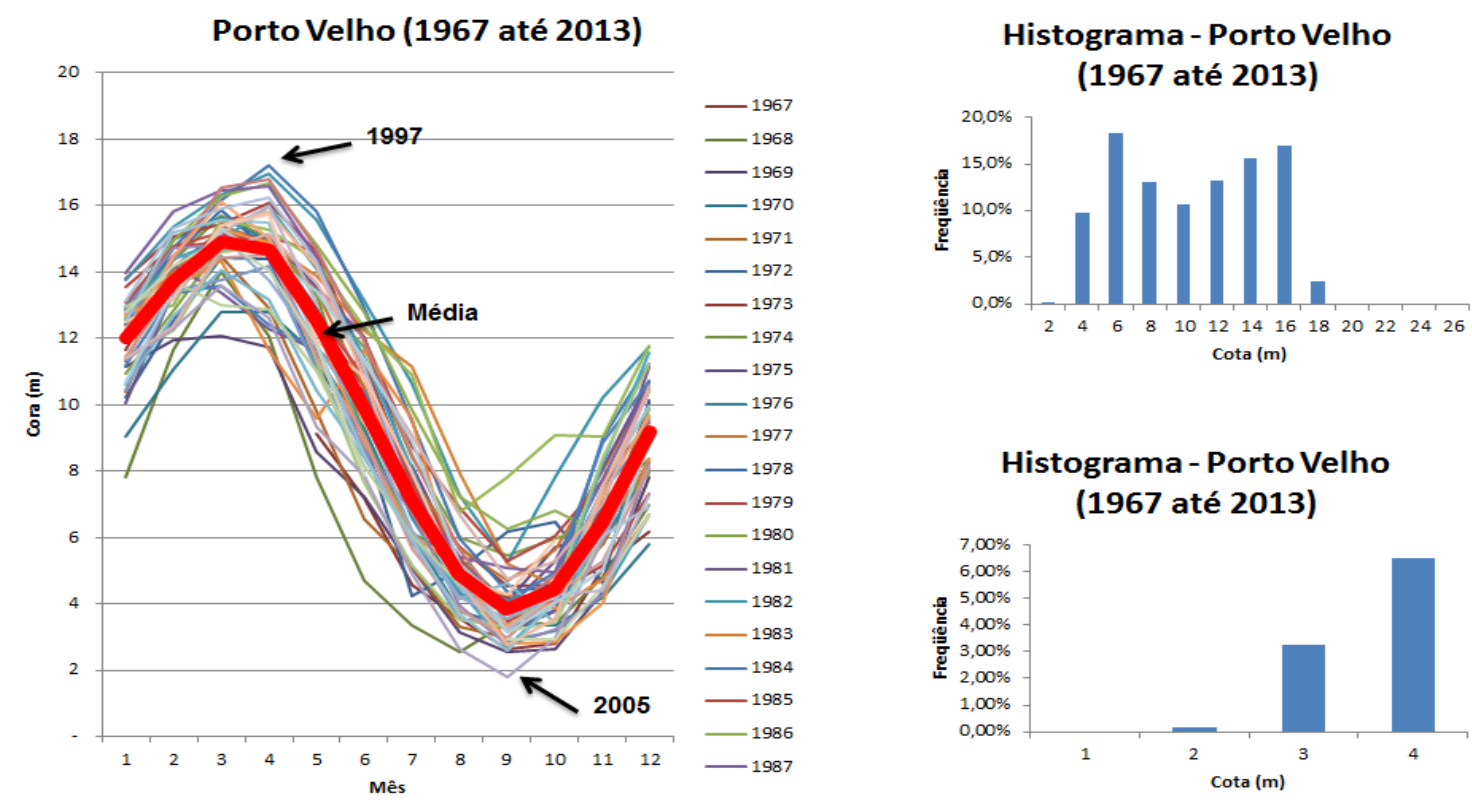

Figura 4: Cota de nível d'água em Porto Velho Fonte: dados ANA, 2014

Analogamente ao ponto de Porto Velho, localizado no Rio Madeira, tem-se o ponto de Itaituba, Rio Tapajós (Figura 5). 

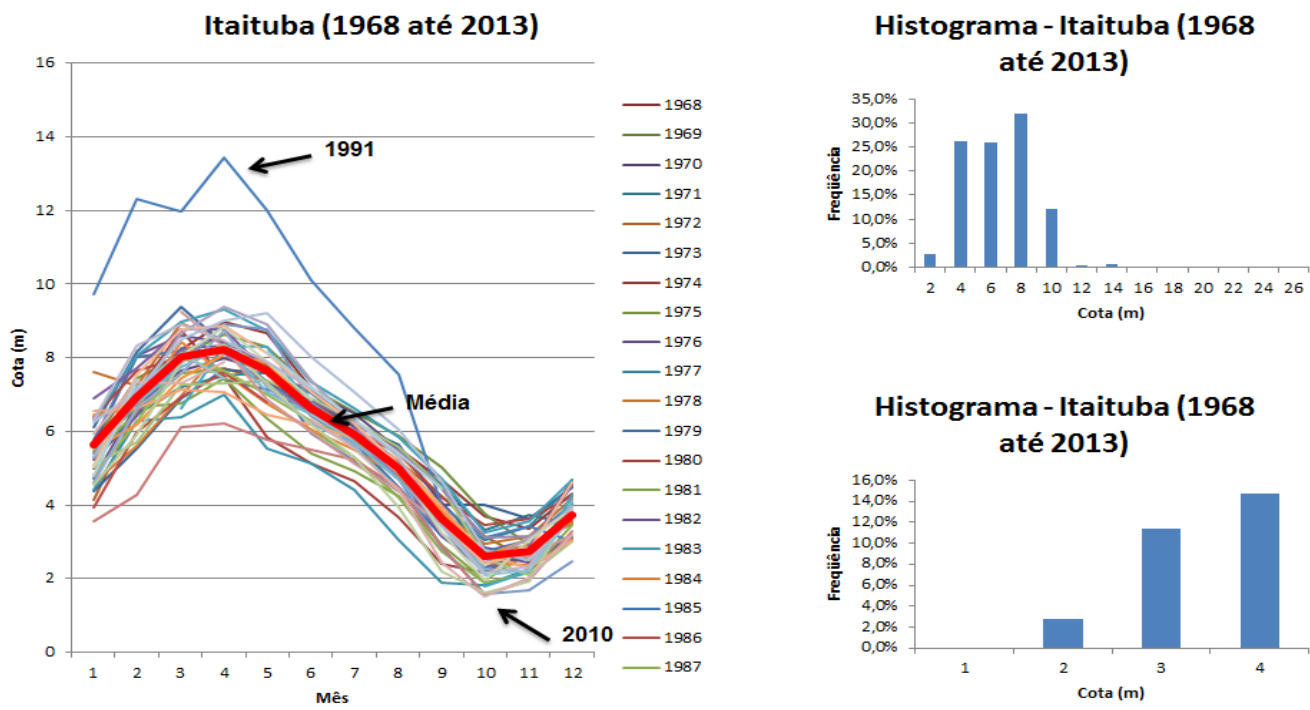

Figura 5: Cota de nível d'água em Itaituba Fonte: dados ANA, 2014

E, na mesma linha, tem-se, no Rio Tocantins, o ponto de Marabá (Figura 6).
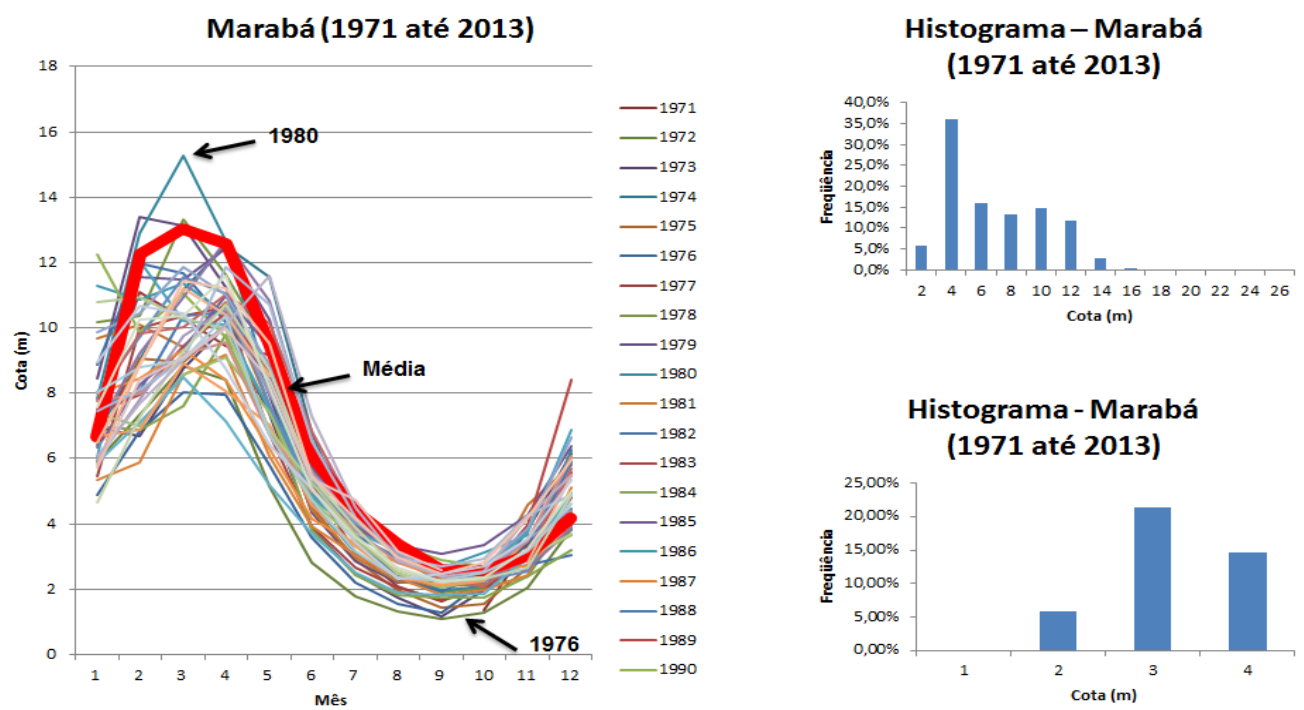

Figura 6: Cota de nível d'água em Itaituba Fonte: dados ANA, 2014

Com as análises feitas dos regimes de seca e cheia das hidrovias estudadas, será possível estabelecer qual a quantidade de carga a ser transportada ao longo do tempo em cada comboio fluvial de tais hidrovias.

No ANEXO 1, tem-se a mesma análise para todos os pontos onde a ANA coleta os dados de cotas de nível d’água. 


\section{O SETOR BRASILEIRO DE COMMODITIES DE GRÃOS}

Este capítulo contextualiza o setor no qual o problema estudado nessa dissertação se insere, ou seja, o panorama atual do mercado de commodities.

Foi realizada uma revisão sobre o mercado, transporte e armazenamento de grãos, um assunto de considerável relevância para o incremento da eficiência e da competitividade desse setor.

\subsection{DEFINIÇÕES DE COMMODITIES}

Para o Ministério do Desenvolvimento, Indústria e Comércio Exterior - MDIC, commodities são definidas como mercadorias provenientes do cultivo ou extração, produzidas em larga escala e comercializadas mundialmente. São produtos com características uniformes e produzidos por diferentes produtores, e podem ser estocados por certo período de tempo sem que ocorram perdas de qualidade. E, por serem mercadorias primárias, são comercializadas mundialmente.

Simplificadamente, Sinott (2010) define commodities como produtos com baixo processamento industrial e grande conteúdo de recursos naturais. Sendo assim, é um setor onde os produtores têm a capacidade de gerar altas rendas, ou seja, lucros associados aos ciclos de preços desses produtos.

Para Carneiro (2012), os malefícios desse setor decorrem de dois problemas distintos: do declínio em longo prazo dos termos de intercâmbio associados à perda de valor real dos preços das commodities ante as manufaturas, e da alta volatilidade desses preços em curto e médio prazo. Sendo assim, a primeira seria decorrente das características peculiares da oferta, como, por exemplo, a superprodução. Por sua vez, a segunda seria o resultado da volatilidade dos preços.

Ainda segundo Carneiro (2012), essas características teriam implicações desfavoráveis sobre o desenvolvimento de países que têm como principal atividade econômica a exploração de commodities. A volatilidade dos preços 
influenciaria diretamente sobre as decisões de investimentos e o aumento sustentado da produtividade.

O MDIC explica que, como as commodities são negociadas em bolsas, seus preços são definidos pelo mercado internacional, devido às oscilações de mercado em função de perdas e ganhos nos fluxos financeiros mundiais. Existem quatro tipos de commodities: Agrícolas: soja, suco de laranja congelado, trigo, algodão, borracha, café; Minerais: minério de ferro, alumínio, petróleo, ouro, níquel, prata; Financeiras: moedas negociadas em vários mercados, títulos públicos de governos federais; e Ambientais: créditos de carbono.

\subsection{COMMODITIES AGRÍCOLAS}

Para a economia brasileira, o setor de commodities contribui com uma parcela importante na geração de produtos, além de se caracterizar como estratégico quanto ao fornecimento de mercadorias para exportação (CONAB, 2015).

Segundo Sampaio et al. (2006), Brasil, Argentina e Estados Unidos são os três maiores produtores de grãos de soja. Pode-se verificar a produção mundial de grãos analisando a Figura 7, na qual se tem o histórico da soja produzida dos últimos 50 anos (FAOSTAT, 2014).

O Brasil se destaca nas exportações tanto de grãos quanto dos seus derivados (farelo e óleo de soja). Porém, os EUA são os maiores exportadores de grãos, com uma parcela pouco significativa no comércio de derivados, e a Argentina é especializada nas exportações de farelo e óleo de soja (SAMPAIO et al., 2006). 


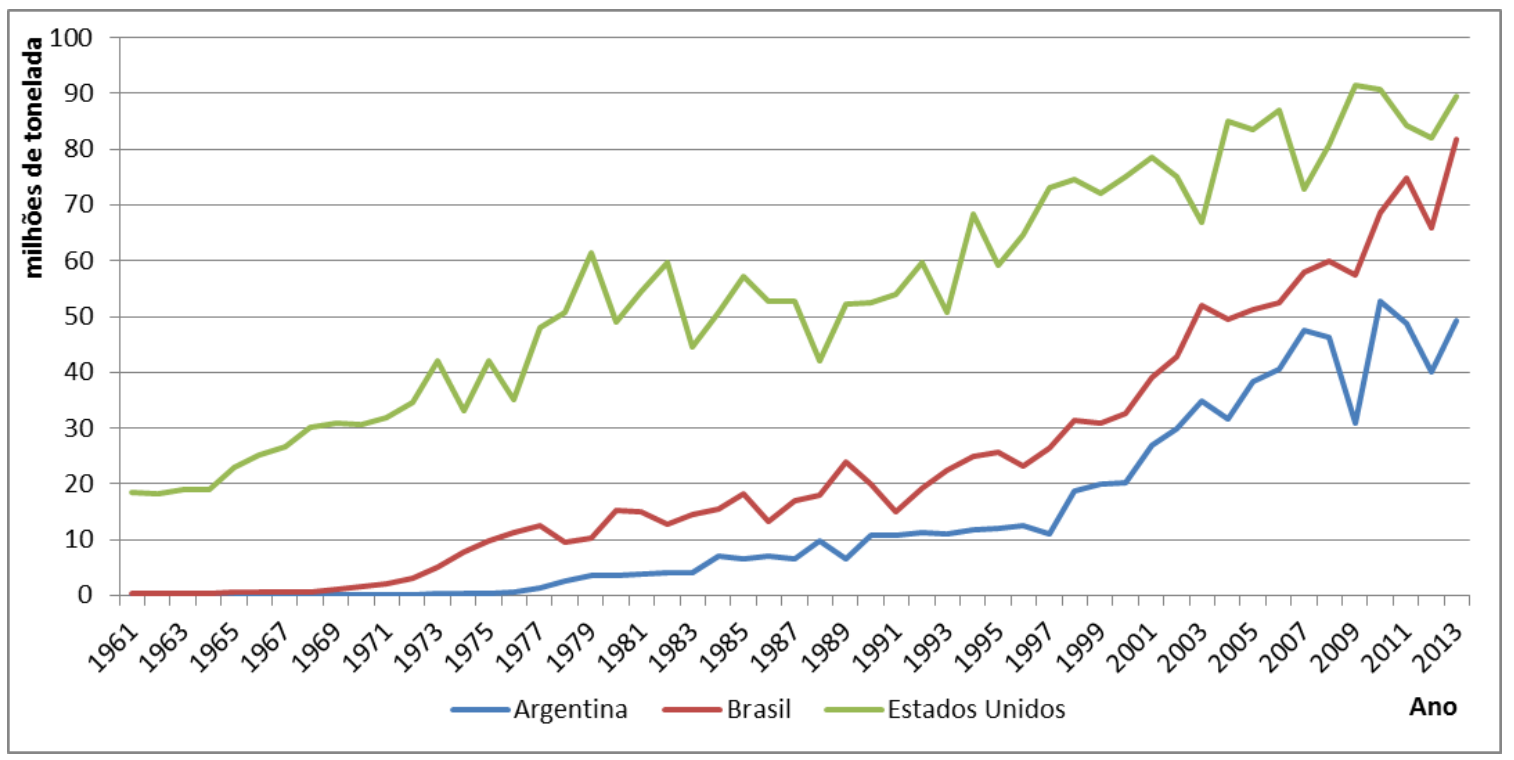

Figura 7: Histórico de Produção de Soja

Fonte: dados FAOSTAT (2014).

A produção de soja no mercado internacional é liderada pelos Estados Unidos, porém, com o recente aumento de áreas disponibilizadas para o cultivo de grãos no Brasil, o plantio está quase se equiparando ao produzido pelos Estados Unidos (Figura 7). A Argentina ainda segue atrás, porém com expressivo crescimento nos últimos anos.

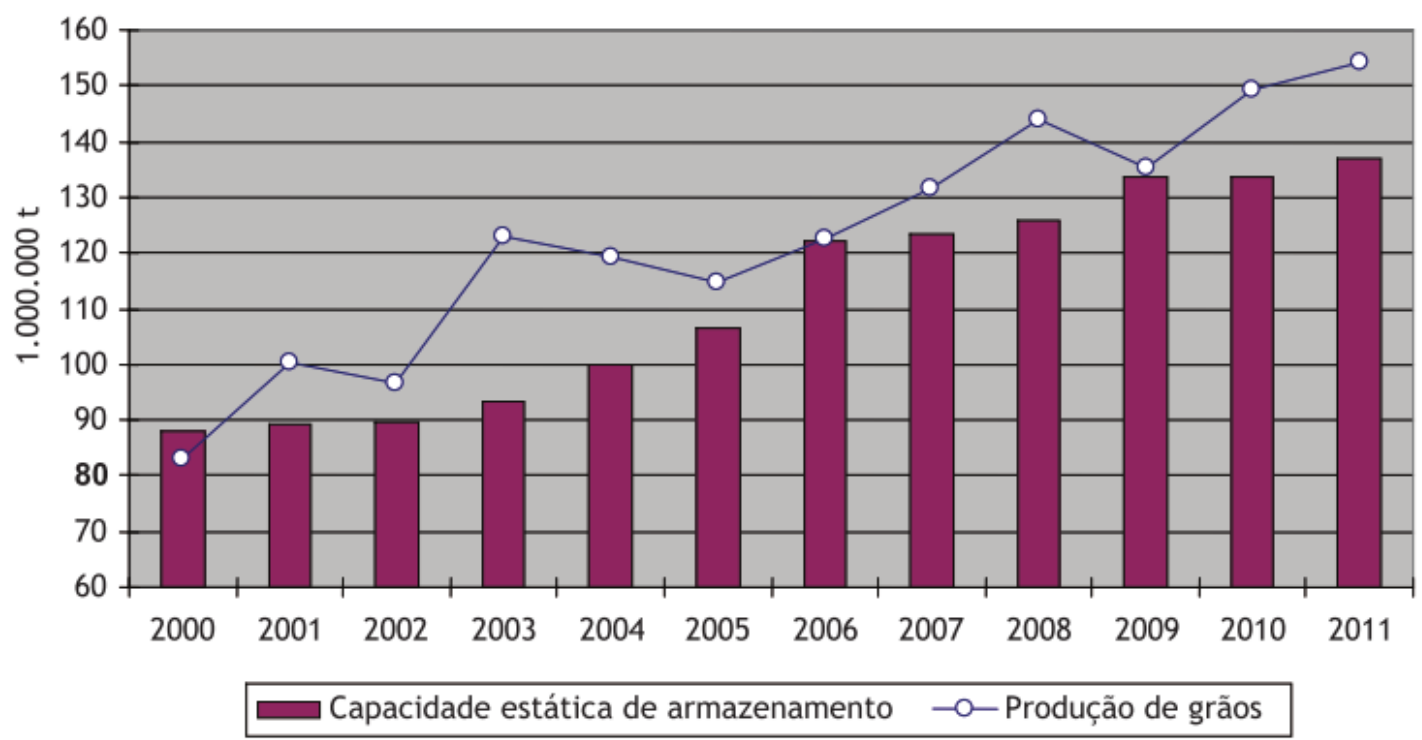

Figura 8: Capacidade de Armazenagem X Produção Fonte: Junior e Tsunechiro (2011) 
Em um cenário em que há ineficiência de transporte, é necessário ter capacidade de armazenar os produtos por maior tempo, sendo assim, a Figura 8 mostra a diferença entre a produção de grãos e a capacidade estática de armazenamento no Brasil, onde, no geral, não há paridade entre as capacidades de produção e de armazenagem.

Nos últimos anos, o agronegócio tem estado cada vez mais competitivo no mercado e vem passando por significativas mudanças. Para o MDIC, o mercado de alimentos vem crescendo e se diversificando, seguindo algumas tendências que são comuns aos mercados de outros setores.

Segundo a CONAB (2014), a China é a maior importadora de soja in natura no mundo. Os chineses passaram a investir em parcerias com as processadoras brasileiras a fim de garantir a exclusividade de compra de farelo e óleo de soja produzidos no Brasil.

Pode-se ver, na Figura 9, que a composição da dieta se modifica, diminuindo a proporção dos produtos de sobrevivência (como grãos e raízes) e aumentando em variedade e qualidade. Pode-se notar que os países emergentes com grande população, como China e Índia, estão no início da curva. Ou seja, países populosos, com alto potencial de crescimento e diversificação.

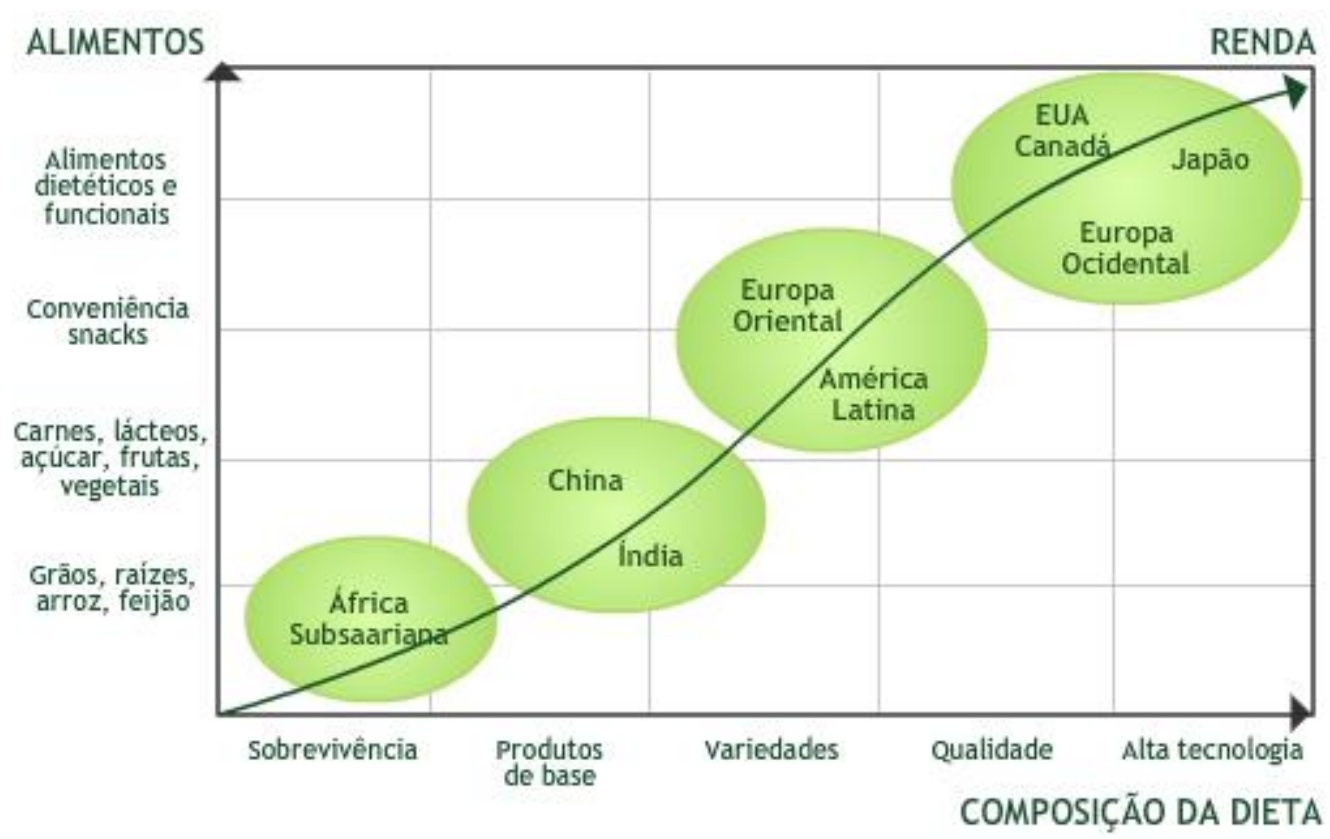

Figura 9: Padrão de consumo em função da renda Fonte: Ministério do Desenvolvimento, Indústria e Comércio Exterior - MDIC 
O Brasil é a oitava economia do mundo, com a soma das suas riquezas (PIB Produto Interno Bruto) em $R \$ 4,678$ trilhões em 2011. E, o agronegócio é responsável por aproximadamente $23 \%$ dessa riqueza. A Figura 10 mostra a participação do agronegócio no PIB brasileiro desde 1994 até 2013 (CEPEA, 2014).

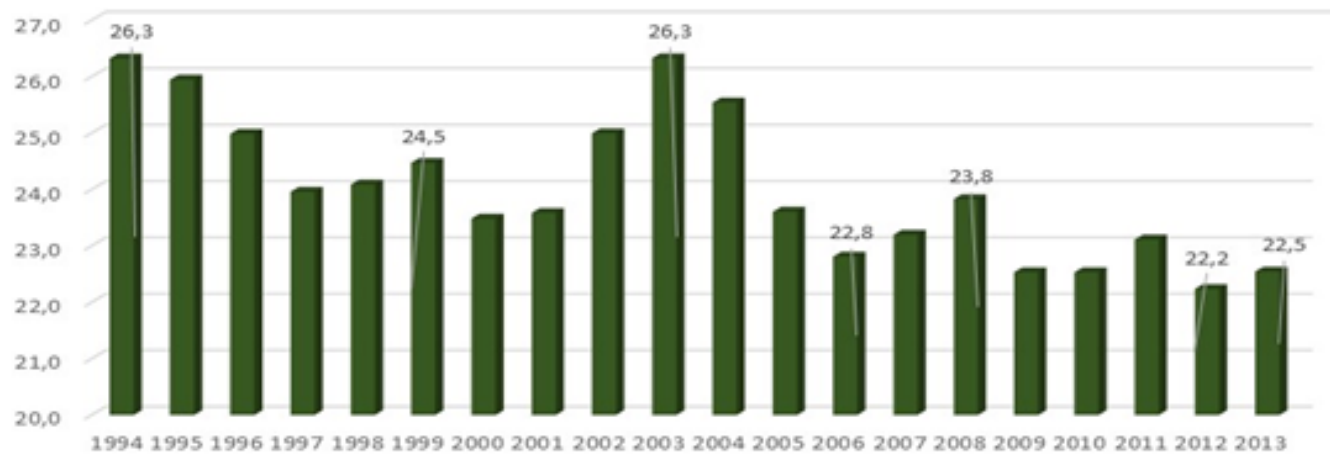

Figura 10: Participação do agronegócio no PIB Fonte: dados do CONAB, 2015

Para Sampaio et al. (2006), a dinâmica de competitividade e participação no mercado internacional de soja desses países é efeito de mudanças políticas. Os EUA aumentaram o subsídio a seus produtores de soja. Brasil e Argentina adotaram regimes de câmbio flutuantes.

No Brasil, foram feitas previsões de manutenção das taxas de substituição entre a área de pastagem, que vem sendo convertida em cultivo de soja, e de ocupação de novas áreas. Na Argentina, com a desvalorização de sua moeda, o setor agrícola reagiu rapidamente e os produtores de soja "foram beneficiados na medida em que haviam realizado os gastos com insumos". Nos EUA, aumentaram os subsídios para produtores de soja, que passaram a se basear na área e produtividade no cultivo dos grãos.

\subsection{ORIGEM E ROTAS DE TRANSPORTE DE CARGA}

A produtividade de grãos de soja no Brasil tem passado por grande expansão. Pode-se ver na Figura 11 a distribuição de produção de soja por região. 


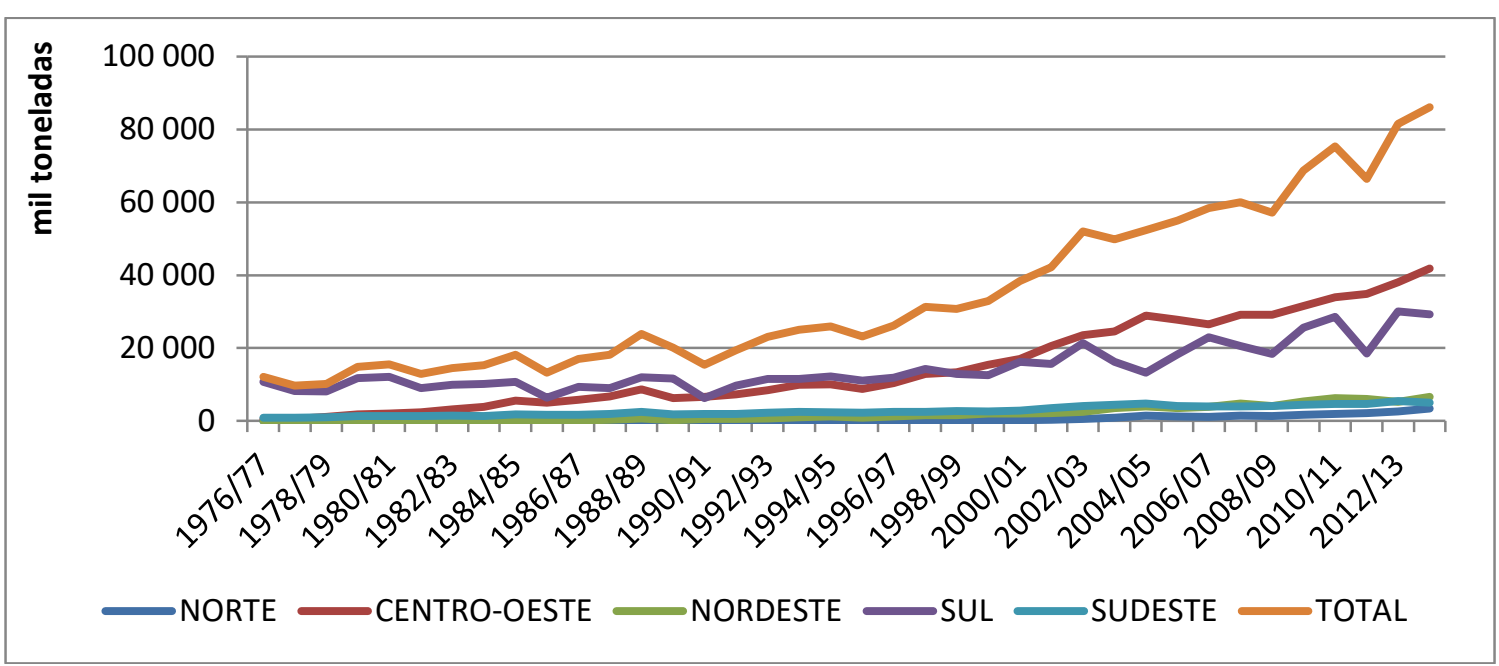

Figura 11: Produção de soja

Fonte: dados do CONAB, 2015

O Brasil, em 2011, produziu aproximadamente 75 milhões de toneladas de soja em grãos. As regiões Centro-Oeste e Sul representaram quase $84 \%$ de toda produção nesse período (Figura 12).

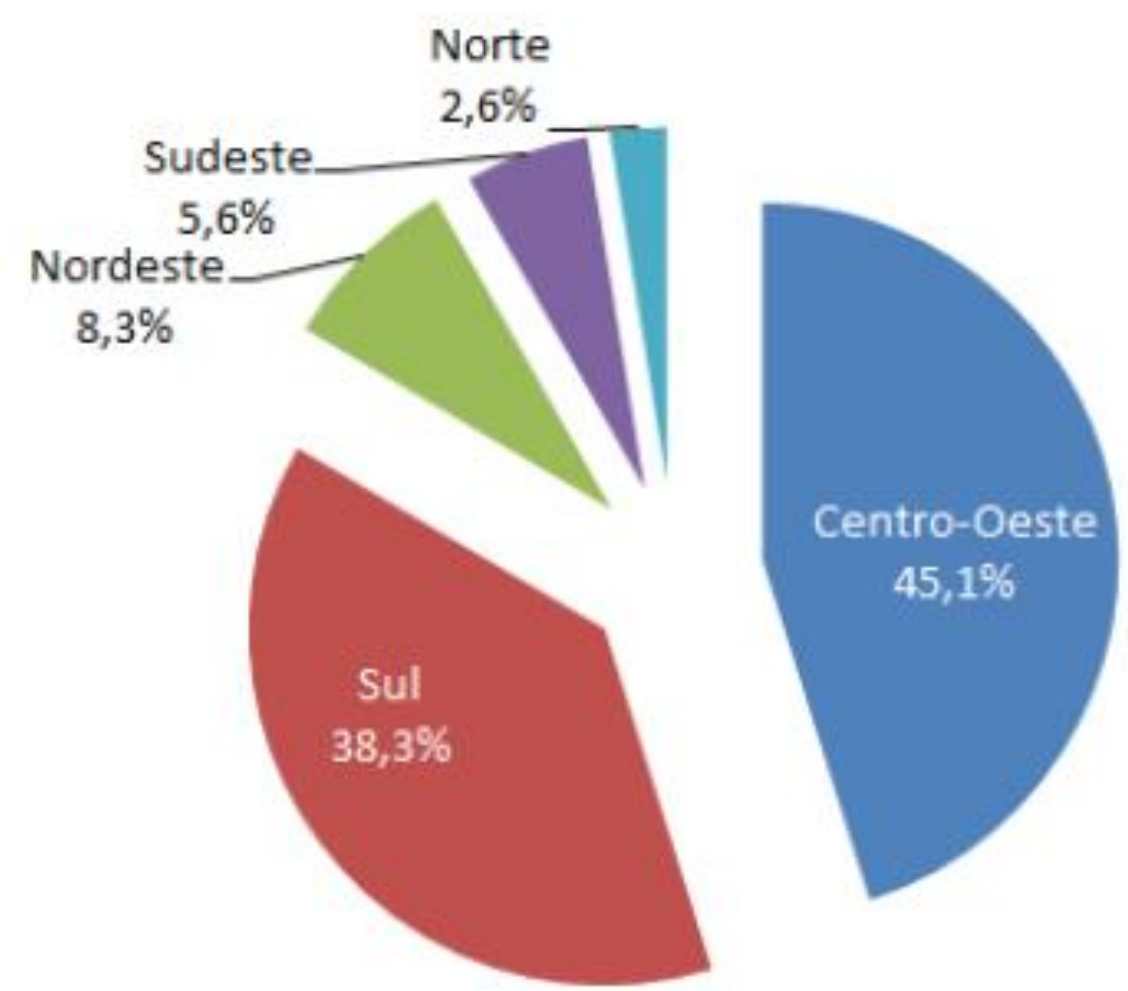

Figura 12: Participação das regiões na produção de soja em 2011 Fonte: SIDRA (2012) 
Note que a produção de grãos no Centro-Oeste e Sul, somadas, quase totaliza a produção do país. No entanto, o custo de transporte e estocagem desse produto, em comparação com outros grandes produtores, ainda é elevado. $\mathrm{Na}$ Figura 12, vê-se as áreas onde se dá o cultivo de grãos no Brasil.

A Figura 13 mostra a distribuição dos municípios produtores de soja no Brasil em 2011, onde se pode observar que há maior concentração nas regiões CentroOeste e Sul. É importante salientar que 33\% dos municípios brasileiros produziram soja nesse mesmo ano (SIDRA, 2013).

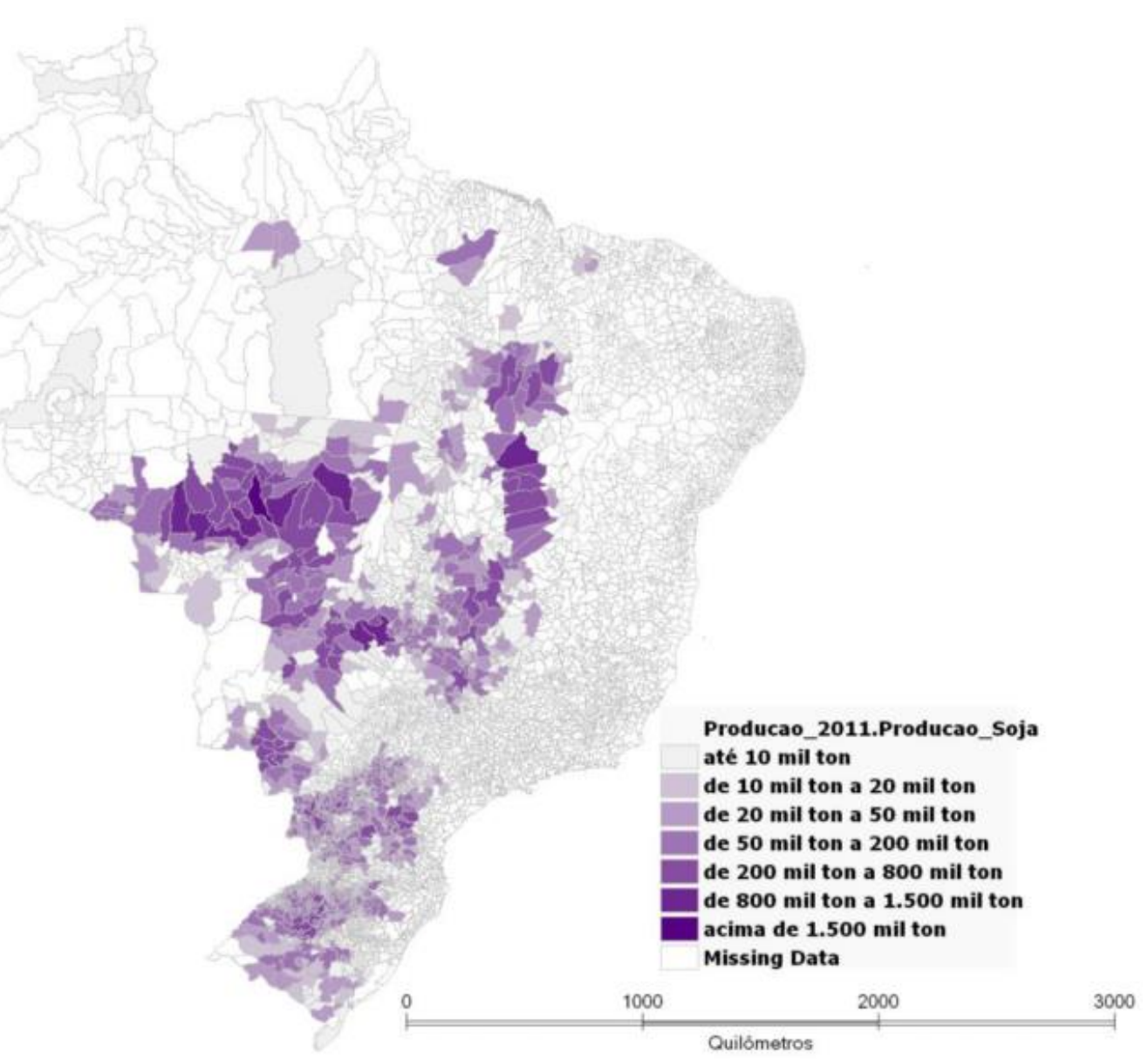

Figura 13: Distribuição da produção de soja por município Fonte: SIDRA, 2013

No Brasil, a janela de exportação mundial é diferente dos outros grandes exportadores como EUA e Argentina. Dessa forma, enquanto os outros países estão na entressafra, o Brasil está no auge da safra (CONABE, 2014). 
No entanto, a logística brasileira é a mais cara, se comparada aos grandes exportadores de grãos, pois o custo do transporte terrestre no Brasil chega a ser quase seis vezes mais alto que dos EUA e quatro vezes maior que na Argentina. Porém, no caso do transporte hidroviário, essa diferença praticamente não existe, conforme se vê na Figura 14 (SANTOS, 2014).

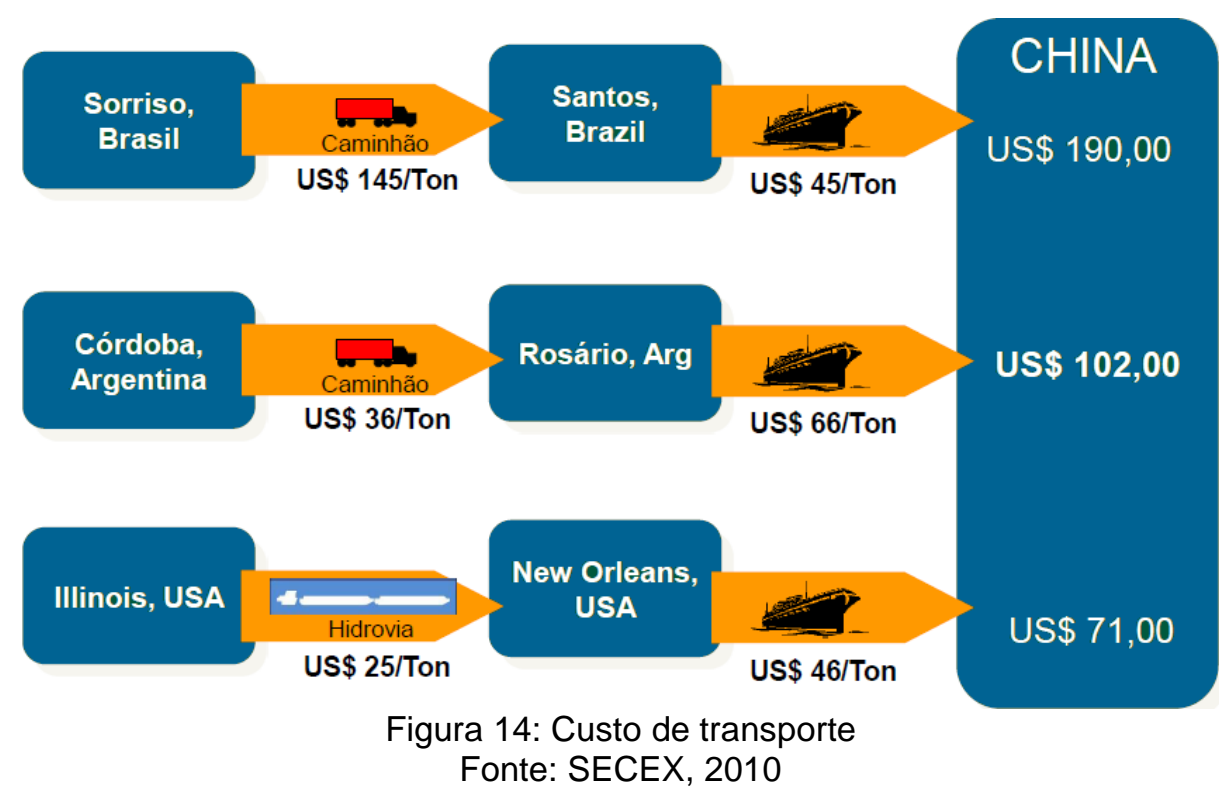

O SECEX (2010) comparou as malhas de transporte entre Brasil, Argentina e EUA, e se pode notar uma diferença clara de infraestrutura entre esses países. No Brasil, o transporte via rodovias é de aproximadamente $58 \%$, enquanto nos EUA gira em torno de 5\%. Já o modal ferroviário é de $28 \%$ contra $35 \%$, no Brasil e nos EUA, respectivamente. E, para as hidrovias é de $13 \%$ no Brasil contra $60 \%$ nos EUA.

A CNT (2012), de forma geral, considera $75.707 \mathrm{~km}$ de rodovias no Brasil, sendo $32 \%$ estaduais e $68 \%$ federais, onde $84 \%$ das rodovias são administradas pelo poder público e 16\% pelo poder privado, e são avaliadas conforme a Figura 15. 


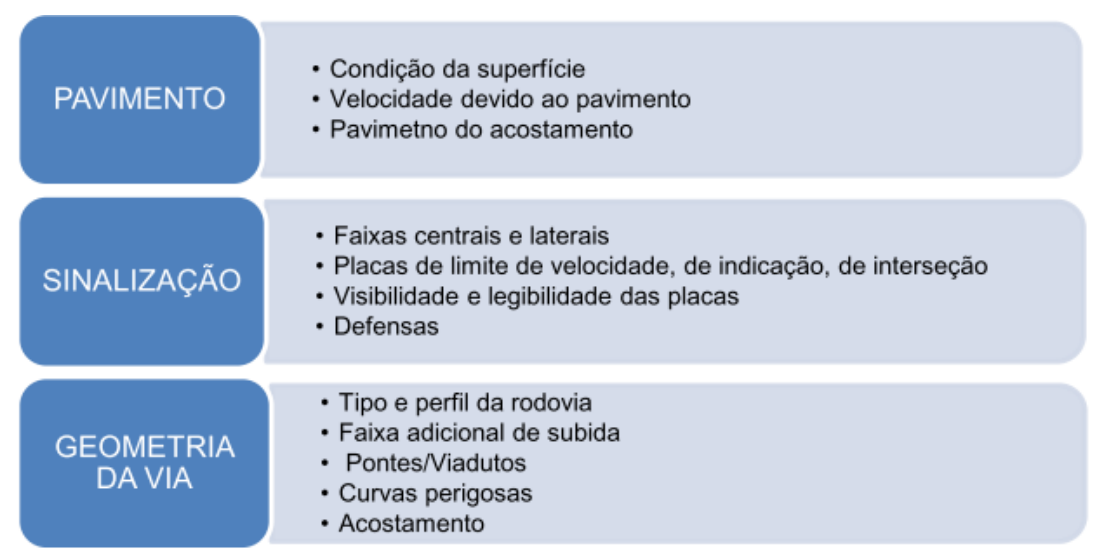

Figura 15: Critérios de avaliação das rodovias

Fonte: CNT, 2012

Santos (2014) determinou um centroide para cada região produtora, o qual se conecta à rede de transporte, permitindo identificar os caminhos percorridos pela carga desde a origem até o destino. Esses centroides foram determinados a partir do zoneamento definido pelo IBGE (2011) para os municípios brasileiros, mostrados na Figura 16.
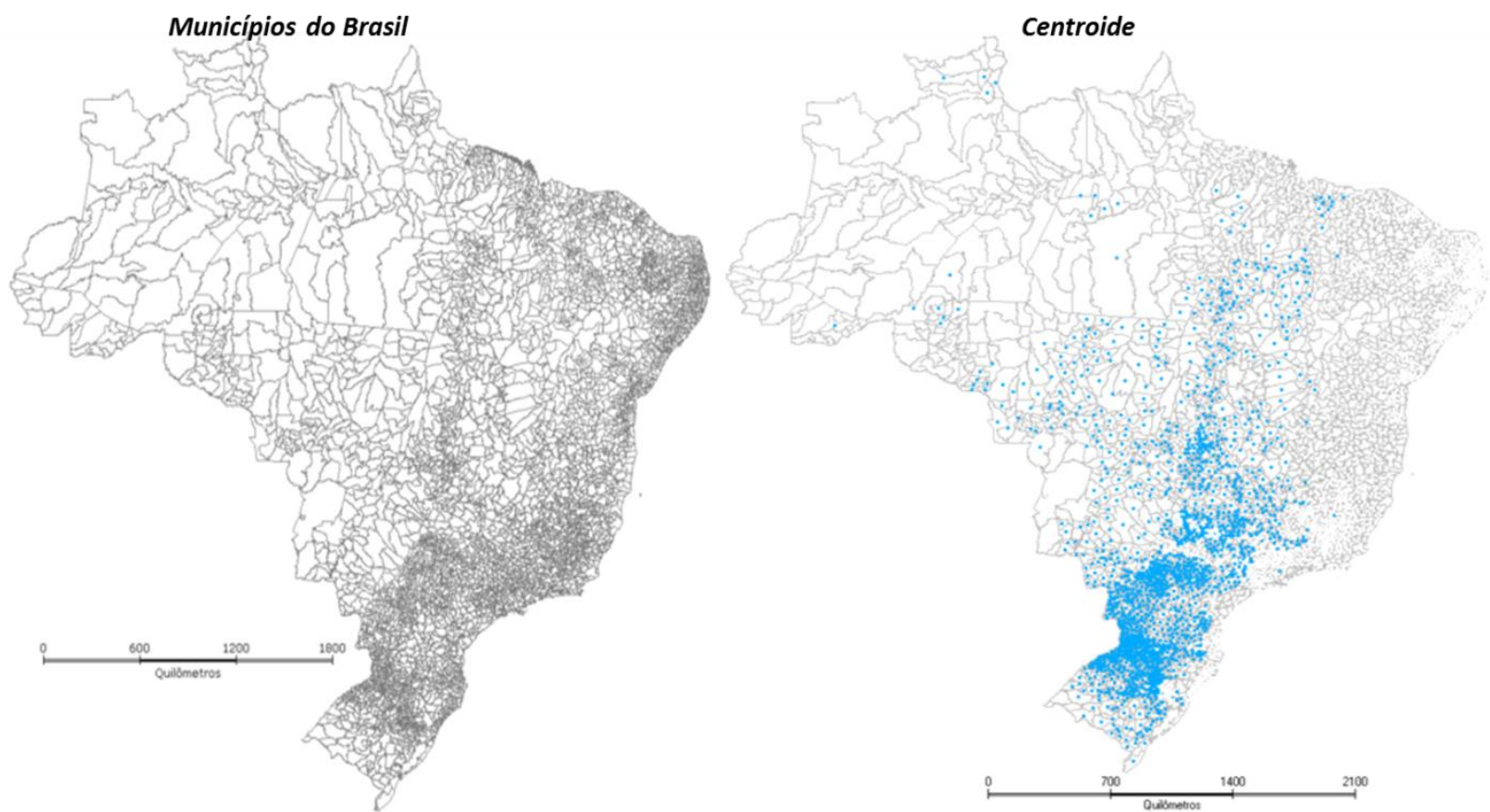

Figura 16: Municípios do Brasil X Centroide

Fonte: Adaptado de Santos, 2014

A Figura 17 apresenta a conexão dos centroides dos municípios à rede multimodal atual e futura do Brasil, onde se permite melhor visualização da malha de transporte multimodal atual e futura. 


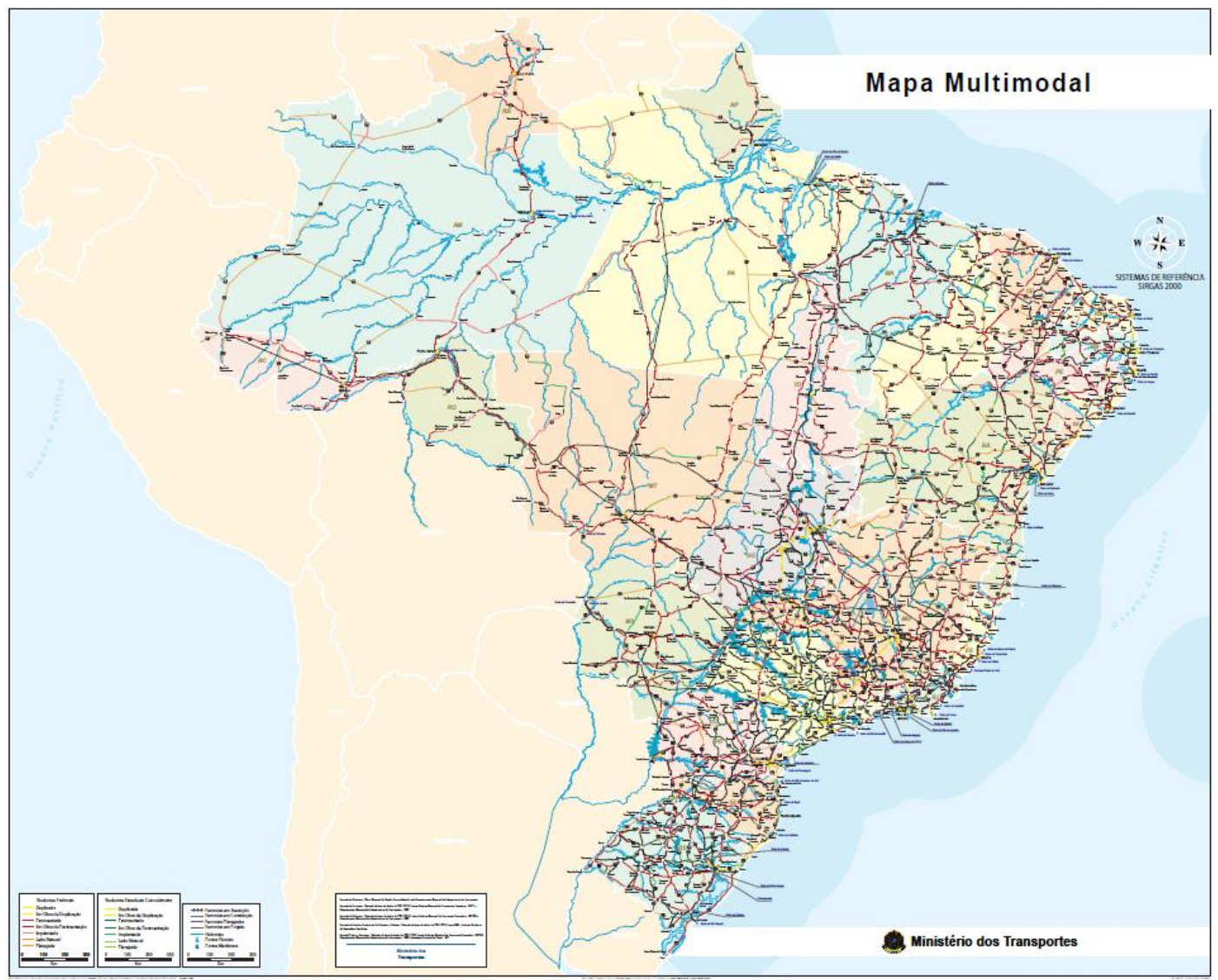

Figura 17: Mapa multimodal

Fonte: Ministério dos Transportes (2015)

No método de indução apresentado por Santos (2014) para determinar qual porto receberá grãos de qual município produtor, no entanto, são considerados apenas os dois extremos da cadeia produtiva, sendo feita essa escolha de acordo com o melhor custo logístico total.

O governo brasileiro está fazendo algumas melhorias nas matrizes de transporte do país. No entanto, ainda faltam serem construídas muitas estradas de ferro e hidrovias. Na Figura 18 tem-se uma comparação entre o que existe construído no Brasil e nos EUA, assim como o que ainda está previsto para ser construído no Brasil. 


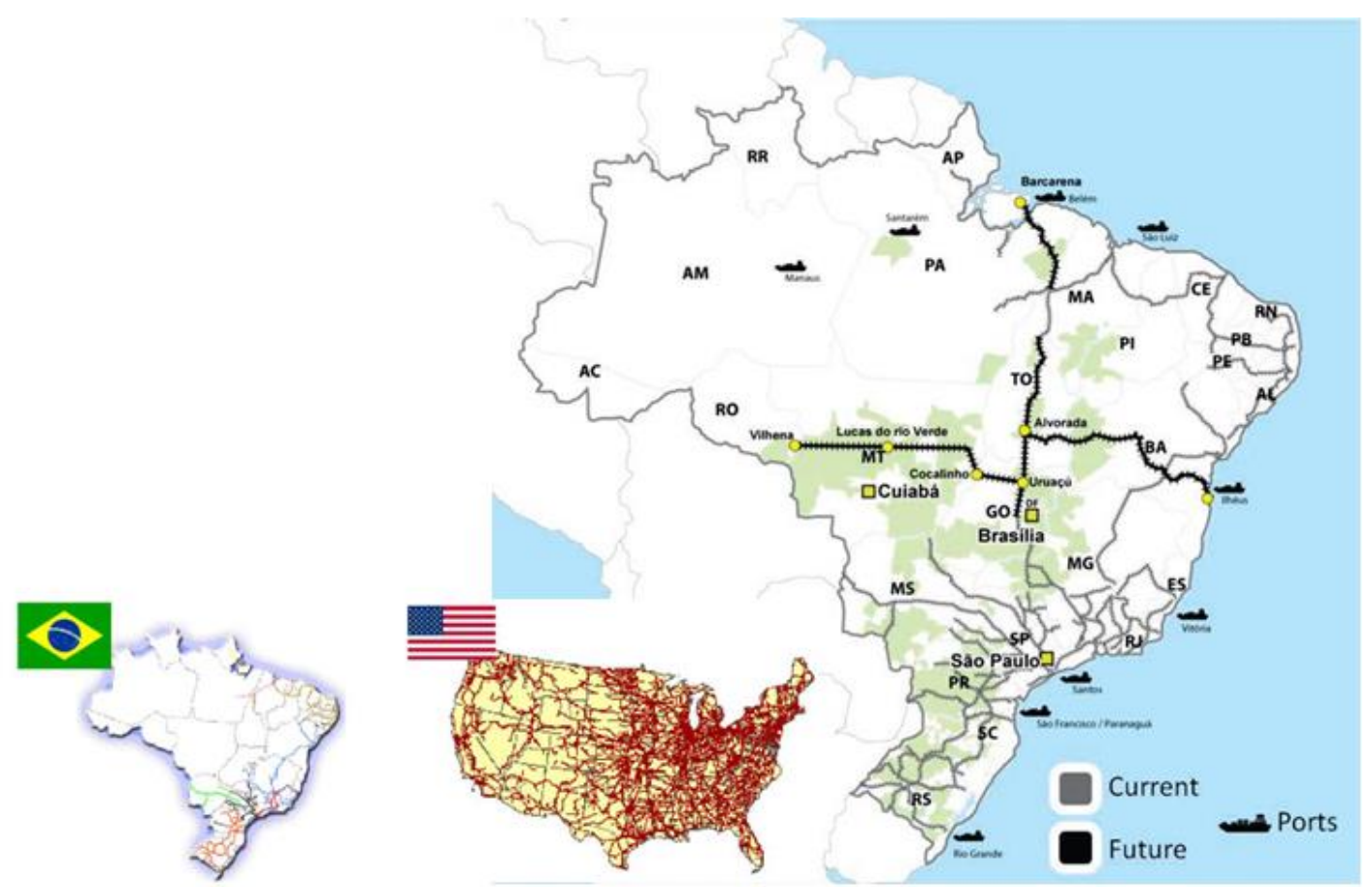

Figura 18: Comparação das ferrovias entre Brasil e EUA

Fonte: adaptado de SECEX, 2010

No entanto, o Brasil não utiliza seu potencial hídrico, que é o modal mais econômico e ecológico, apresentado na Figura 19.

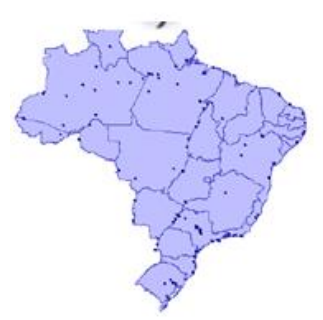

Figura 19: Comparação das hidrovias entre Brasil e EUA

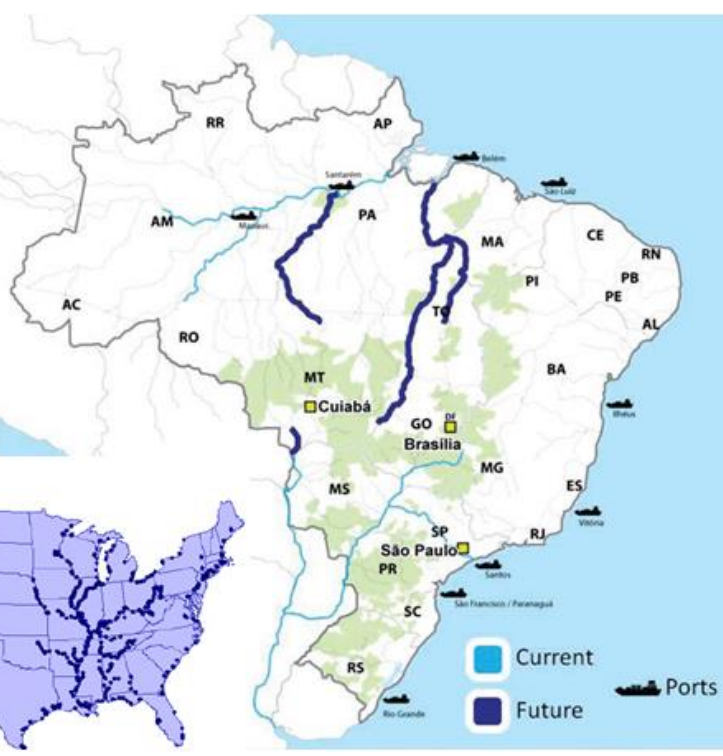

Fonte: adaptado de SECEX, 2010

Com base na revisão efetuada nesse capítulo, notou-se uma lacuna no que se refere aos efeitos sazonais da produção de grãos, em geral, considerada homogênea durante um certo período de tempo; e outra lacuna no que se refere 
aos efeitos das secas nos sistemas fluviais que podem ser utilizados como meio de transporte desse produto.

Pelo fato desses efeitos sazonais serem importantes para o dimensionamento dos sistemas de transportes e estoques intermediários, o objetivo dessa pesquisa foca na comparação de cenários com e sem sazonalidade, utilizando um modelo de simulação de eventos discretos. 


\section{METODOLOGIA DE SIMULAÇÃO}

O objetivo deste capítulo é, inicialmente, efetuar um breve levantamento bibliográfico sobre a metodologia de simulação de eventos discretos, justificando a utilização deste método para a elaboração dessa pesquisa.

\subsection{MODELO DE SIMULAÇÃO DE EVENTOS DISCRETOS}

Segundo Prado (1999), na década de 60 surgiram as primeiras aplicações para desenvolvimento de modelos de simulação. No entanto, na década de 80 , devido à maior capacidade computacional, começaram as aplicações visuais de simulação. Atualmente, a simulação é feita em computador pessoal, daí o nome simulação computacional. A Figura 20 mostra a evolução dos sistemas de simulação ao longo dos anos.

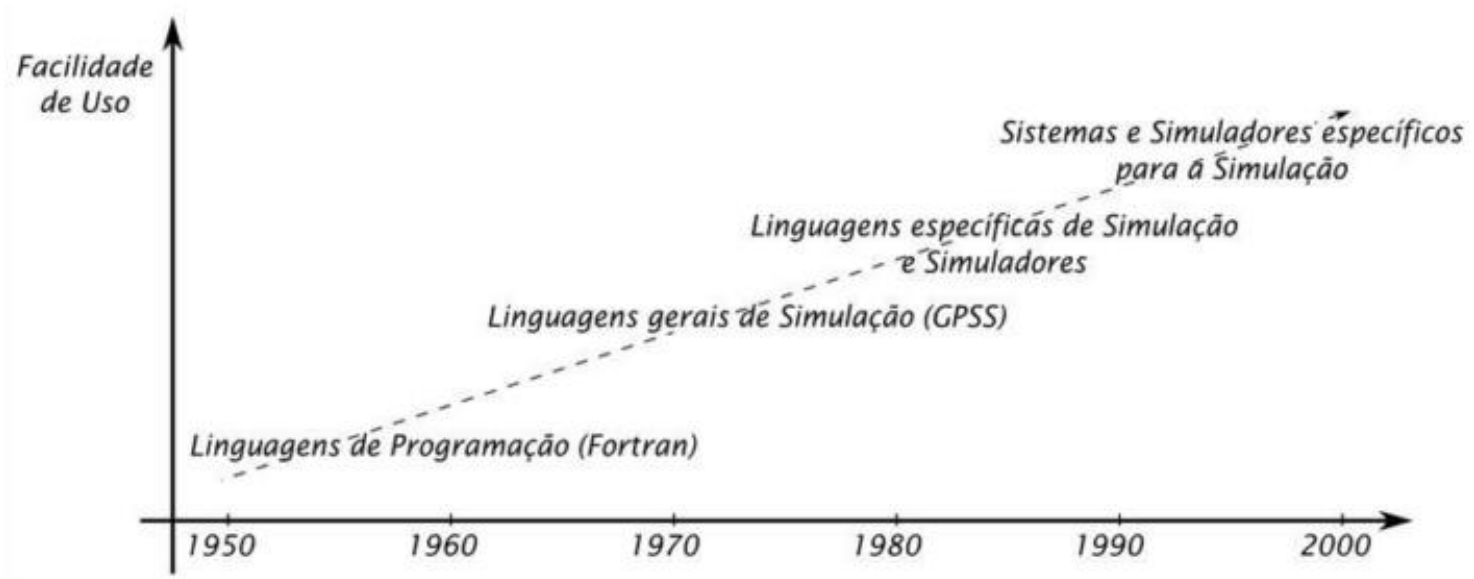

Figura 20: Evolução dos sistemas de simulação

Fonte: Chwif e Medina (2015)

Um modelo de simulação para Chwif e Medina (2015) é a representação de um processo ou sistema de modo a imitar as respostas do mundo real numa sucessão de eventos que ocorrem ao longo do tempo.

Para Pegden et al. (1995), a simulação pode ser definida como o processo de projetar um sistema real em um modelo computacional e fazer experimentos com 
este modelo afim de entender seu comportamento e avaliar estratégias ao longo do tempo, além de analisar o comportamento do sistema quando submetido a diversas alternativas operacionais diferentes.

Botter (2004) utiliza técnicas de simulação para tratar problemas grandes e complexos, em que há interação entre atividades que dificultam a modelagem analítica.

Devido à natureza dinâmica (que muda seu estado ao longo do tempo) e à natureza aleatória (que é regida por variáveis aleatórias), os sistemas reais apresentam maior complexidade. É possível capturar com fidelidade essas características com um modelo de simulação, na qual se busca repetir em um computador o mesmo comportamento que o sistema apresentaria se submetido às mesmas condições. Então, um modelo de simulação é utilizado para responder questões do tipo "o que ocorre se..." (Chwif e Medina, 2015).

Para a elaboração de um modelo de simulação de eventos discretos, foram consideradas as etapas propostas por Chwif e Medina (2015), que estratificam a elaboração do modelo em três grandes fases cíclicas (Figura 21):

1. Concepção: etapa na qual são definidos os sistemas e os objetivos, além de se realizar o levantamento de dados e a modelagem conceitual;

2. Implementação: nesta etapa é elaborado o modelo computacional propriamente dito;

3. Verificação e validação: fase onde os dados de saída são confrontados com os dados reais já analisados previamente. Após essa fase, pode-se dizer que o modelo de simulação representa a realidade;

4. Análise: etapa em que são realizadas as simulações desejadas, além das análises de sensibilidade e análises de resultados. 


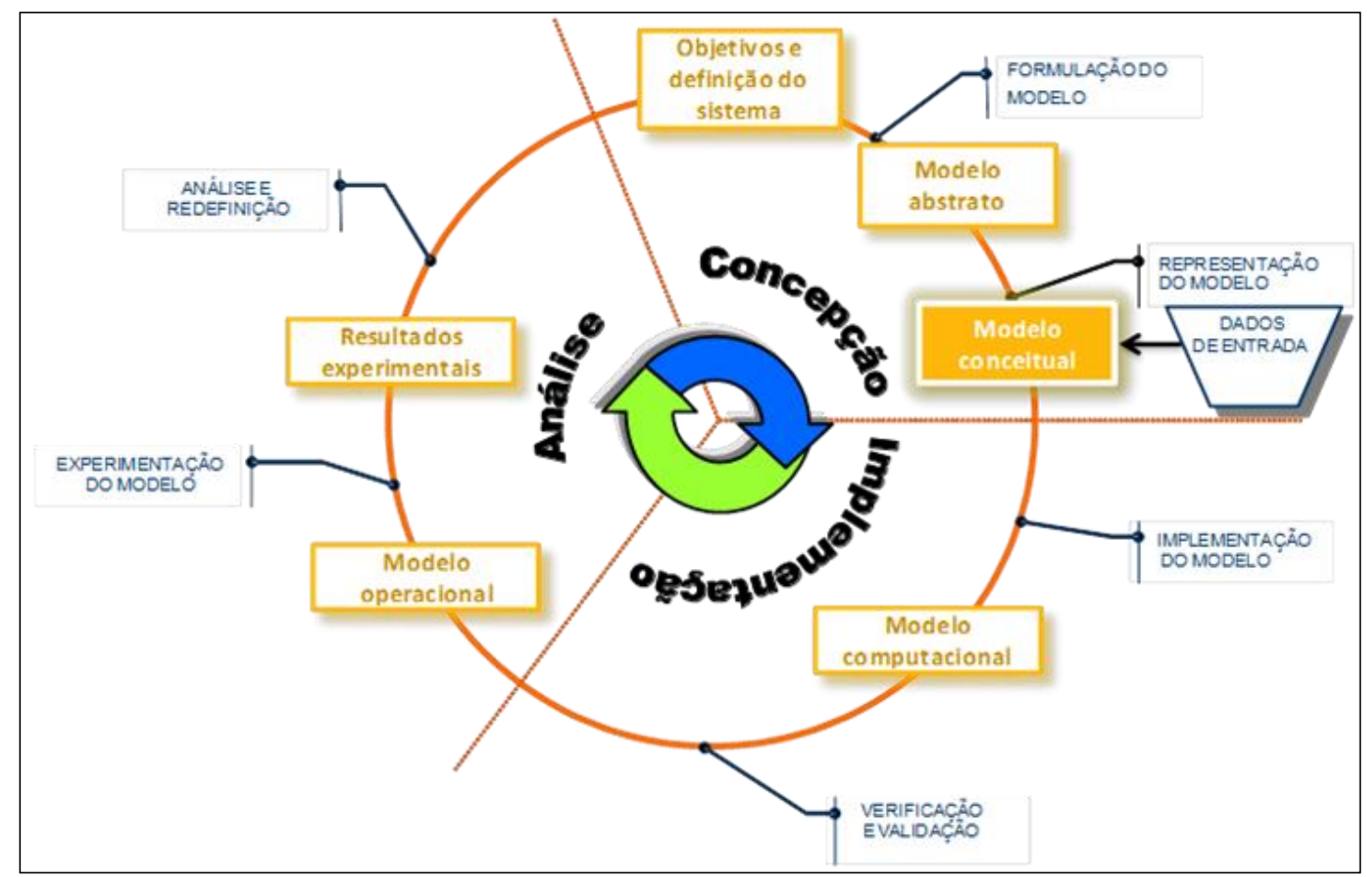

Figura 21: Etapas de um modelo de simulação Fonte: Chwif e Medina, 2015.

Cada uma dessas fases, ainda segundo os autores, é composta de outras subfases:

1. Definição dos objetivos e sistemas: determinação das fronteiras e restrições que serão utilizadas e investigação do funcionamento do sistema ou processo que se deseja estudar;

2. Elaboração do modelo abstrato: criação mental do modelo a ser construído;

3. Formulação do modelo conceitual: desenvolvimento de um modelo preliminar, de maneira gráfica ou em um pseudocódigo, para a definição dos componentes, descrição das variáveis e interações que constituem o sistema;

4. Levantamento de dados de entrada: realizado simultaneamente à construção do modelo conceitual. Dessa forma, segundo Chwif e Medina (2015), a coleta de dados é definida pelas necessidades do modelo conceitual;

5. Elaboração do modelo computacional: conversão do modelo conceitual em um modelo computacional, através de um software. Após essa etapa, 
são conduzidas as verificações e validações do modelo, que visam garantir que o mesmo está representando de maneira adequada 0 sistema;

6. Modelo operacional: com o modelo computacional devidamente validado, tem-se o modelo operacional com o qual podem ser conduzidos os experimentos e testados os cenários de simulação;

7. Resultados experimentais: referentes à execução da simulação para a geração dos dados desejados e execução da análise dos resultados. Após a geração dos dados, deve-se realizar a análise e interpretação dos mesmos.

Law e Kelton (2000) dizem que a verificação e validação são passos importantes na construção de um modelo válido, que tenha credibilidade e um nível de detalhamento apropriado. Sendo que verificação é o passo no qual se faz a checagem se o modelo conceitual foi corretamente implementado em um modelo computacional, e a validação é o processo que determina se o modelo de simulação tem representação acurada do sistema real, e se está de acordo com os objetivos do estudo proposto.

Kelton e Sadowski (1998), dizem que entradas aleatórias implicam em saídas aleatórias, portanto, não se pode tirar conclusões da simulação com uma única replicação. Sendo assim, é importante que se rode o modelo de simulação para um período de tempo adequado e uma quantidade de replicações que deem um resultado dentro do seu intervalo de confiança, que é um intervalo de valores que contém a média da população, com uma certa probabilidade e, quanto maior for a probabilidade, maior a confiança estatística de que a média da população esteja representada nesta média.

Este intervalo de confiança $100(1-\alpha) \%$ para a média da população é dado pela equação (Devore, 2000):

$$
P(\bar{x}-h \leq \mu \leq \bar{x}+h)=1-\alpha \quad \text { ou } \quad \bar{x} \pm t_{n-1, \alpha / 2} \frac{s}{\sqrt{n}}
$$

Onde:

$\bar{x}$ é a média da amostra;

$h=t_{n-1, \alpha / 2} \frac{s}{\sqrt{n}}$ é a metade do tamanho do intervalo de confiança (precisão); 
$t_{n-1, \alpha / 2}$ é o $(1-\alpha / 2)$ percentil da distribuição de t de Student com $n-1$ graus de liberdade;

s é o desvio padrão da amostra;

n é o número de dados da amostra.

Para Chwif e Medina (2015), para se aumentar a precisão dos dados, deve-se aumentar o tamanho da amostra, ou seja, o número de replicações. Esse número deverá ser compatível para que o modelo deixe o regime transitório e passe para o regime permanente. Onde o regime transitório é representado por uma esporácidade momentânea, sendo fortemente relacionado com as condições iniciais do sistema e o regime permanente não sofre essas influências, agindo conforme a normalidade do sistema.

Como, por exemplo, em um lançamento de dados de seis faces, não viciado, a média dos valores obtidos deveria ser 3,5, no entanto, se não for realizada um número de replicações necessárias, essa média não será representada no resultado final. A Figura 22 mostra o comportamento da média acumulada dos valores obtidos após 150 lançamentos desse dado. Como a primeira parte da figura mostra a média dos primeiros 50 lançamentos, que sofre influência do comportamento inicial do sistema, é o regime transitório; e a segunda parte, já faz parte do regime permanente. 


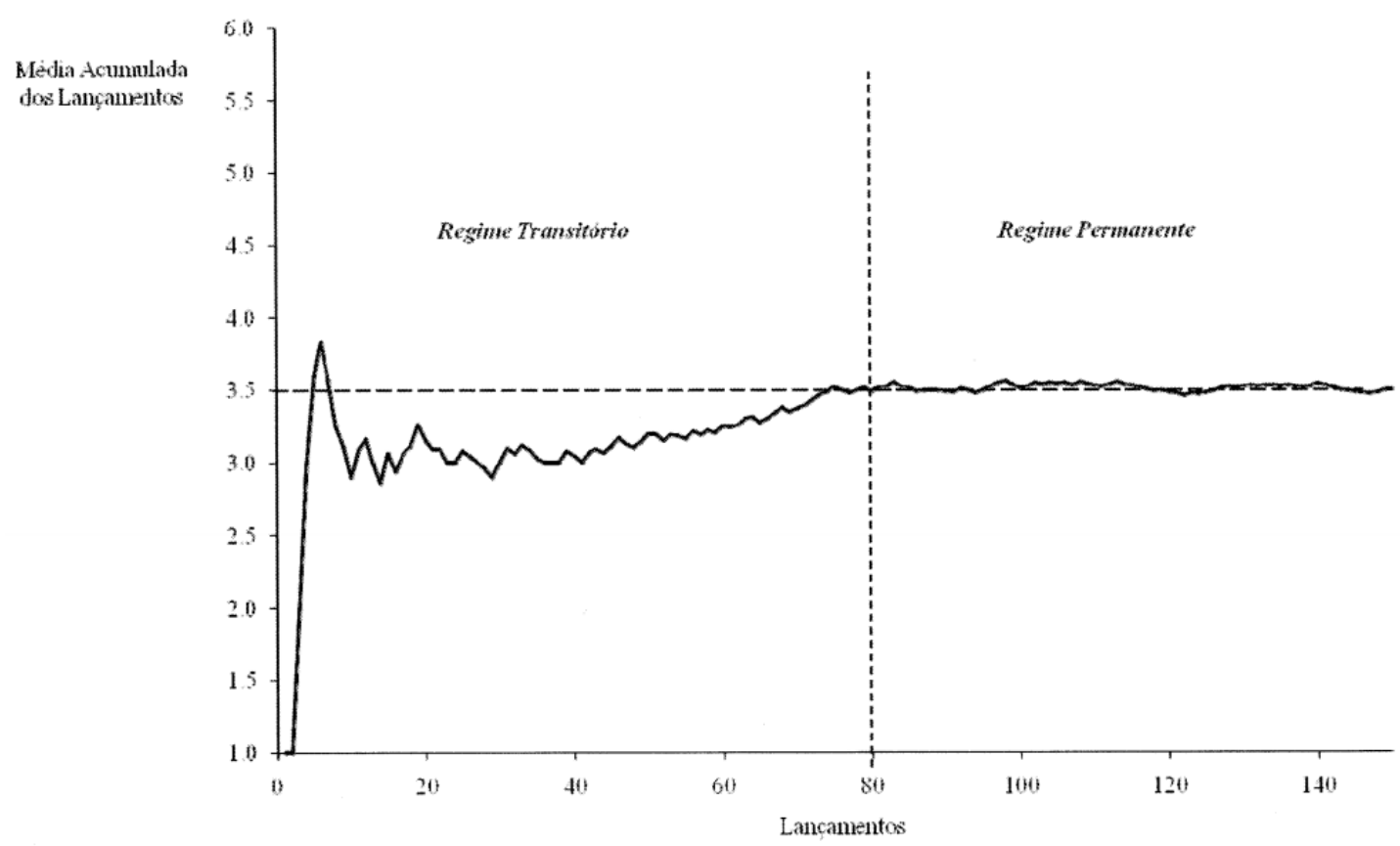

Figura 22: Comportamento da média acumulada dos valores após 150 lançamentos de um dado não viciado

Fonte: Chwif e Medina, 2015

Para Netto (2012), podem ser destacadas algumas vantagens em modelos de simulação de eventos discretos: a possibilidade de avaliar rapidamente a efetividade das estratégias propostas; facilidade para detalhamento de um sistema complexo (sendo possível levar em consideração um grande número de restrições e especificidades); melhor compreensão de quais variáveis têm real influência no sistema analisado; facilidade em identificar os "gargalos" do sistema; e uma representação bastante aproximada do cenário real.

Além disso, o autor afirma que em simulação de eventos discretos não é necessário fazer grandes simplificações do sistema real que, em linhas gerais, são adotadas para a resolução de modelos analíticos, que utilizam programação matemática.

O modelo de simulação de eventos discretos desenvolvido nessa dissertação permite avaliar os reais efeitos sobre os estoques quando o sistema é submetido às restrições de oferta de produto e capacidade de carregamento. 


\section{APLICAÇÃO PRÁTICA}

O objetivo desta seção é apresentar o modelo conceitual do problema em estudo. Busca-se, inicialmente, contextualizar o problema com uma breve descrição de um sistema de abastecimento de grãos em estudo. Posteriormente, é apresentado o modelo conceitual da solução proposta para a análise da impedância de duas sazonalidades sobrepostas em um único sistema de abastecimento, assim como a validação e cenários propostos para simulação.

\subsection{CONTEXTUALIZAÇÃO DO SISTEMA DE TRANSPORTE DE GRÃOS}

Foi desenvolvido um modelo de simulação de eventos discretos de um sistema intermodal de transporte de grãos para um terminal portuário localizado na região Norte do litoral brasileiro, no estado do Pará. Para este sistema, serão consideradas apenas três hidrovias ligadas ao porto de exportação. No entanto, a soja transportada neste sistema tem sua origem nas regiões brasileiras CentroOeste, Norte e Nordeste, ou seja, as fazendas de origem da carga encontramse distantes do porto de exportação em Vila do Conde, sendo assim, faz-se necessário a utilização dos modais de transporte rodoviário, hidroviário e marítimo para garantir que a carga seja transporta desde seus pontos de origem até o porto de destino, como mostrado na Figura 23. 


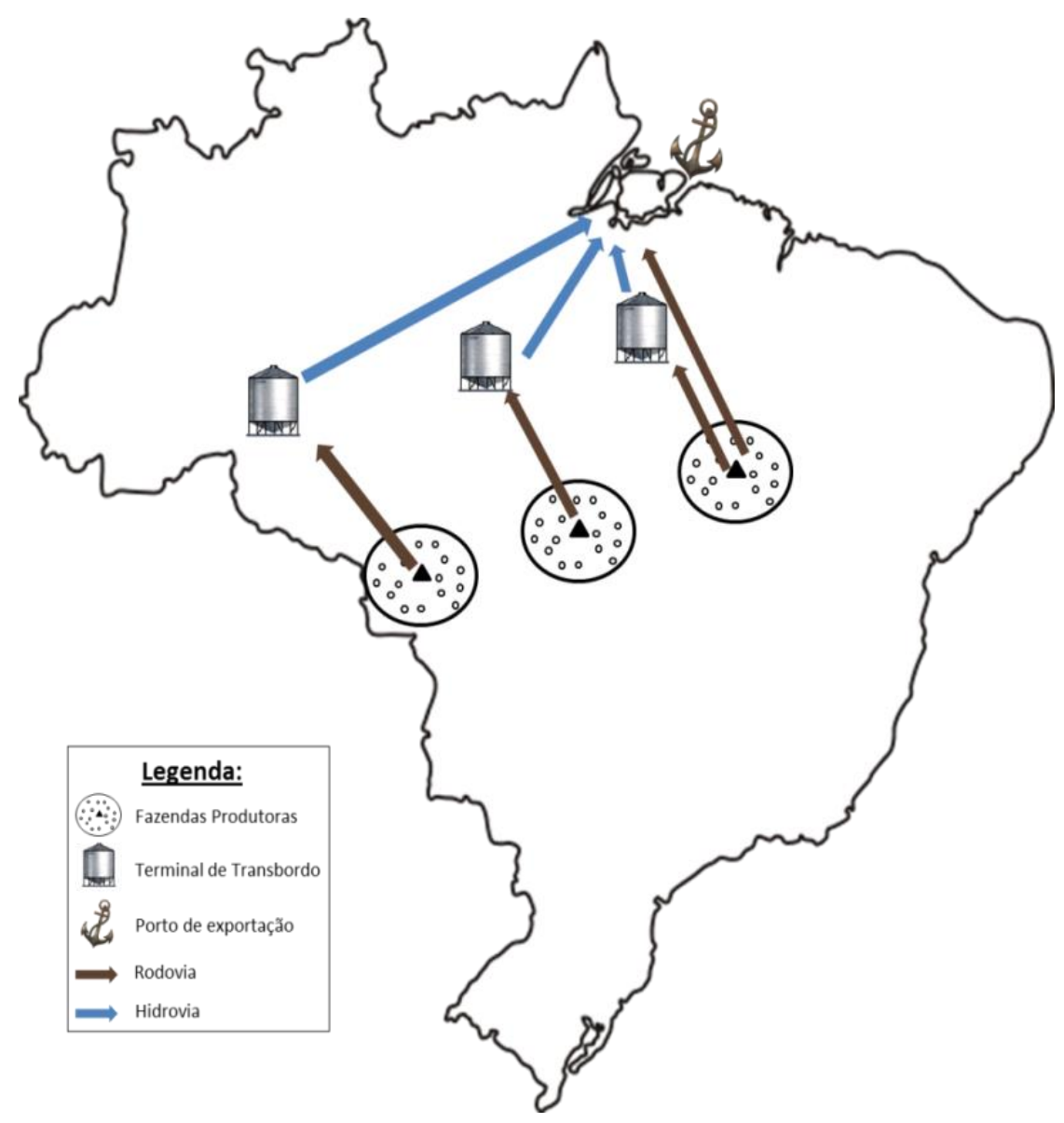

Figura 23: Localização geográfica do sistema

Fonte: o Autor

\subsection{MODELO CONCEITUAL}

Utilizando a metodologia de Chwif e Medina (2007) para desenvolvimento de um projeto de simulação, primeiro foi apresentado o objetivo e as definições do sistema proposto, como visto anteriormente neste trabalho; em seguida foi formulado o modelo abstrato e, depois, tem-se o modelo conceitual propriamente dito, como apresentado a seguir.

A modelagem de um sistema de transporte intermodal de cargas é mostrada na Figura 24. 


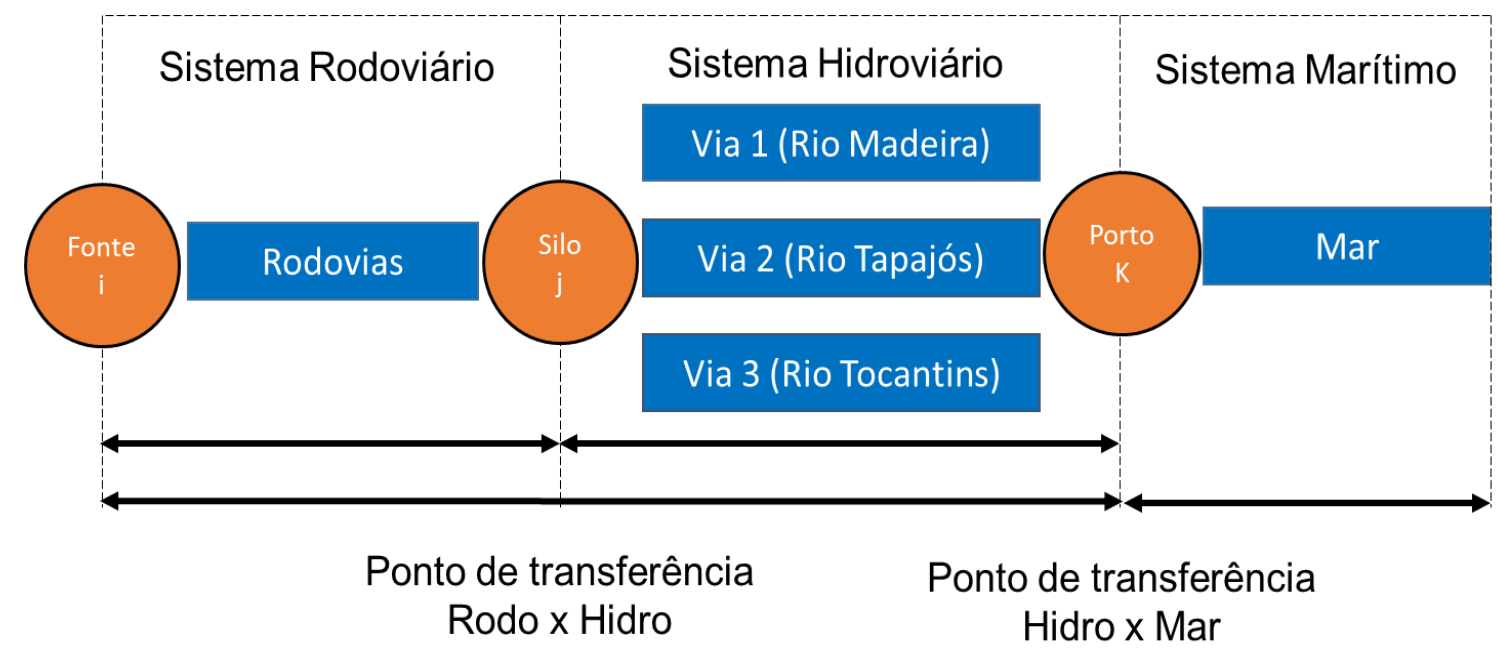

Figura 24: Modelo Conceitual Fonte: o Autor.

O transporte de grãos tem origem na fonte $i$, onde é originada a demanda de carga que deverá percorrer todo o sistema, e desloca-se por caminhões até os silos de armazenagem $j$. Sendo assim, o transporte rodoviário é dado entre as fontes $i$ e armazéns $j$, onde toda a oferta do sistema deverá ser retirada das fontes. Note que, genericamente, $i$ e $j$ podem assumir quaisquer valores diferentes de zero, no entanto, para a análise do sistema em questão, foi configurado um número de fazendas e silos reais deste sistema de abastecimento.

Sendo assim, todo material que chega aos armazéns $j$ deve ser estocado em silos até completar o lote de carga suficiente para preencher o próximo veículo do sistema, via transporte hidroviário. Assim como nas fontes geradoras de carga, toda a demanda que chega aos pontos de armazenagem deverá ser retirada, obedecendo às restrições de capacidade dos armazéns e o balanço de massa, respectivamente.

Analogamente aos armazéns $j$, o porto $k$ deverá receber toda a carga transportada pelo sistema hidroviário e respeitar as restrições de atendimento da demanda e balanço de massa. No entanto, foi modelado apenas um ponto de destino para as cargas, sendo assim, o porto ké o último elo entre os modais de transporte. 
Assim, pode-se verificar se os nós de armazenagem conseguem comportar uma quantidade de carga ofertada no sistema e quantos ativos serão necessários para a movimentação desta carga pelos arcos até seu destino.

No modelo de simulação de eventos discretos desenvolvido nesta pesquisa, o balanço de massa foi garantido internamente na codificação do modelo, uma vez que, para comparação entre cenários, é importante avaliar se a demanda foi atendida, ou seja, se toda a demanda produzida nas fontes $i$ fora transportada até o porto $k$.

Cada elo da cadeia foi modelado como sistemas independentes que se ligam via armazéns, sendo assim, cada subsistema rodoviário, hidroviário e marítimo apenas será movimentado quando tiver carga suficiente para seu funcionamento.

\subsubsection{SUBSISTEMA RODOVIÁRIO}

Toda a demanda gerada no sistema tem sua origem no subsistema rodoviário. Ou seja, a demanda mensal se origina nas fontes $i$, que será transportada por caminhões até os armazéns $j$. Assim que o caminhão for carregado, é decidido qual o destino da carga, que pode ser para um ponto de armazenagem $j$ ou diretamente para o porto $k$. Esta decisão se dá junto à origem dos grãos, quando é decidido qual modelo de transporte deve ser utilizado (neste projeto chamado de tiro direto quando não houver a integração com a hidrovia). Em seguida, o caminhão segue seu percurso até seu destino, onde aguarda em fila para 0 descarregamento. Após a descarga, os veículos retornam para o ponto de origem para iniciar um novo ciclo, mostrado na Figura 25.

A demanda é originada seguindo uma distribuição sazonal durante os 12 meses do ano e discretizada hora a hora, onde são transportadas por caminhões das fazendas até o silo de destino. 


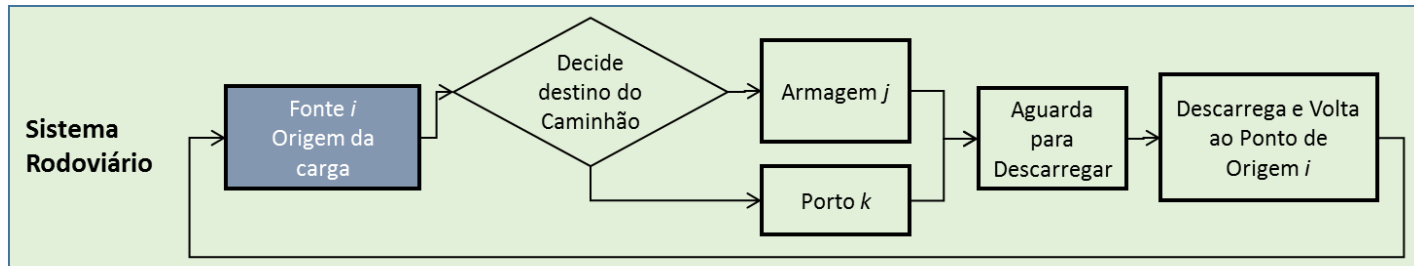

Figura 25: Subsistema Rodoviário

Fonte: o Autor

\subsubsection{SUBSISTEMA HIDROVIÁRIO}

Com a carga armazenada em $j$, dá-se início ao subsistema hidroviário. Os veículos aguardam a disponibilidade do berço para atracação em fila. Uma vez atracados, eles são carregados e farão a viagem até o porto $k$, onde, novamente, aguardam por disponibilidade de berço e de espaço no silo para descarregar os grãos. Este processo está ilustrado na Figura 26.

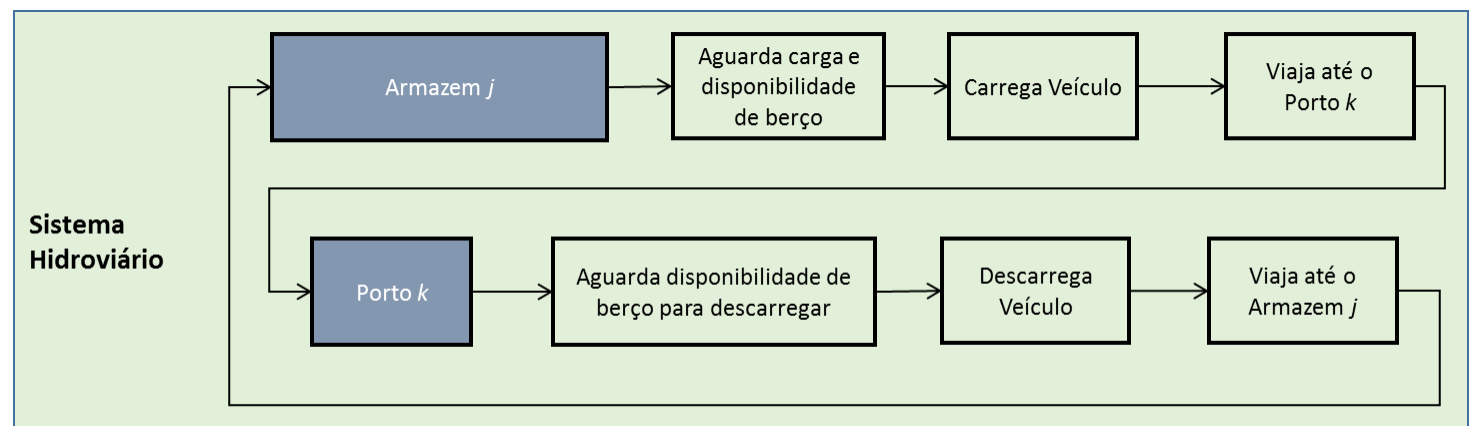

Figura 26: Subsistema Hidroviário

Fonte: o Autor

\subsubsection{SUBSISTEMA MARÍTIMO}

Assim como no subsistema hidroviário, que se liga com o rodoviário pela carga presente nos armazéns, o mesmo princípio é seguido no subsistema marítimo. O navio chega ao porto $k$, onde aguarda por disponibilidade de berço e material no silo. Logo após atracar, o navio é carregado, em seguida, desatraca e deixa o sistema, dando espaço para um novo navio, conforme a Figura 27. 


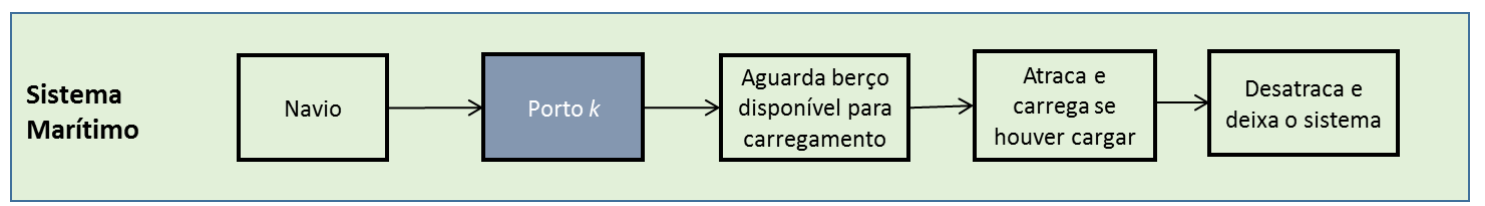

Figura 27: Subsistema Marítimo

Fonte: o Autor

Portanto, esses três subsistemas apresentados formam o sistema de abastecimento intermodal de transporte de soja.

\subsection{PREMISSAS E DADOS}

Foram consideradas algumas premissas para cada subsistema de transporte modelado. Premissas que são incorporadas ao modelo via uma interface de entrada de dados.

O dimensionamento da frota no sistema rodoviário será para atender uma demanda proposta de 5 milhões de toneladas por ano (Mtpa), distribuída entre fazendas nos estados de Mato Grosso, Tocantins, Pará, Piauí e Maranhão. Portanto, como o principal objetivo não é o dimensionamento da frota de caminhões, não há limitação para a quantidade de caminhões utilizados nesse sistema. A distribuição de carga segue uma sazonalidade na qual, ao decorrer do ano, há maior ou menor oferta de produto.

Este dimensionamento do sistema rodoviário é feito pelo próprio modelo de simulação, no qual é definido um número máximo de caminhões que poderão entrar no sistema e, toda vez que for necessário um novo veículo, o simulador adiciona um novo caminhão ao sistema, levando em consideração a carga a ser transportada e o tempo de ciclo dos veículos.

A Figura 28 mostra o comportamento da oferta de grãos gerada nas fazendas, sendo o eixo principal (eixo da esquerda) referente às cargas nas fazendas e o eixo secundário, com a curva tracejada (eixo da direita), ao total de carga oferecida para o sistema modelado. 


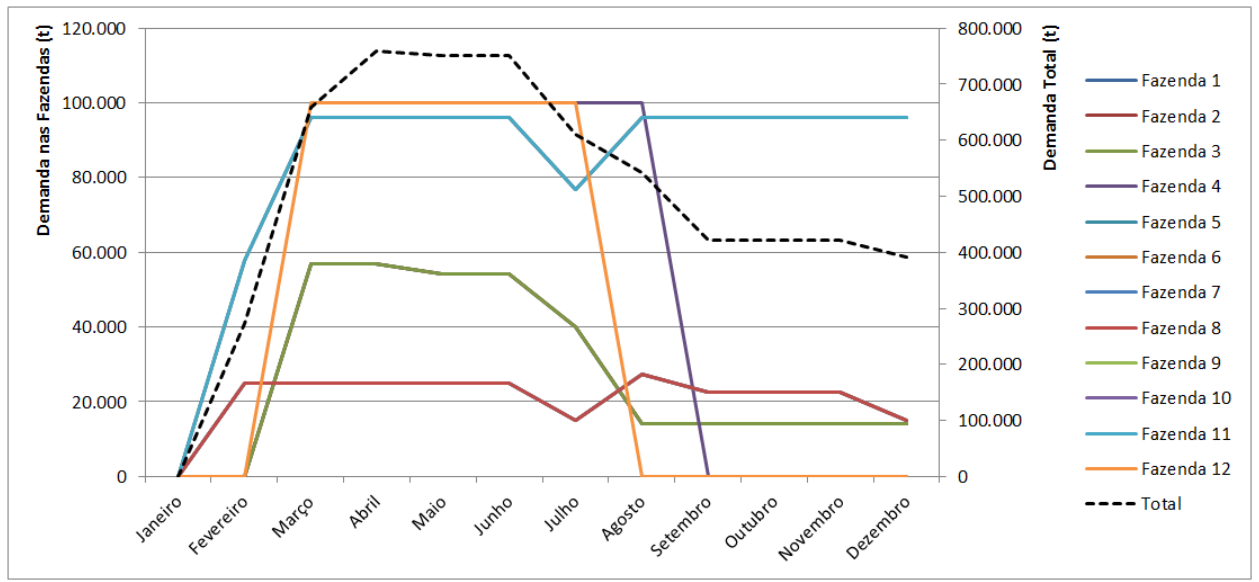

Figura 28: Distribuição da Oferta de grãos ao longo do ano Fonte: o Autor

Para o sistema hidroviário, a quantidade de comboios foi dimensionada (por cálculos determinísticos e tentativa e erro) para ter o menor número que atendesse à demanda que fora depositada nos silos. No entanto, a capacidade e velocidade das composições são diretamente afetadas pelo nível de água das hidrovias, portanto, afetando também o dimensionamento do número de embarcações necessárias, mostrado na Tabela 2:

Tabela 2: Premissas referente às hidrovias

\begin{tabular}{|c|c|}
\hline \multicolumn{2}{|c|}{ Características do comboio da hidrovia do Rio Madeira } \\
\hline Número de Empurradores & 1 \\
\hline Número de Chatas & 6 \\
\hline Capacidade no período de Cheia & $2417(\mathrm{t})$ \\
\hline Capacidade no período de Seca & $1000(\mathrm{t})$ \\
\hline Período de Seca & Agosto até Outubro \\
\hline \multicolumn{2}{|c|}{ Características do comboio da hidrovia do Rio Tapajós } \\
\hline Número de Empurradores & 1 \\
\hline Número de Chatas & 6 \\
\hline Capacidade no período de Cheia & $2150(\mathrm{t})$ \\
\hline Capacidade no período de Seca & $1000(\mathrm{t})$ \\
\hline Período de Seca & Agosto até Outubro \\
\hline \multicolumn{2}{|c|}{ Características do comboio da hidrovia do Rio Tocantins } \\
\hline Número de Empurradores & 1 \\
\hline Número de Chatas & 9 \\
\hline Capacidade no período de Cheia & $1700(\mathrm{t})$ \\
\hline Capacidade no período de Seca & $735(\mathrm{t})$ \\
\hline Período de Seca & Julho até Outubro \\
\hline
\end{tabular}


Já o sistema marítimo tem uma frota de navios operando em Vila do Conde com a capacidade necessária para atender à demanda proposta. Onde a capacidade média de cada tipo de navio é dada pela Tabela 3.

Tabela 3: Capacidade Média dos Navios

\begin{tabular}{c|c} 
Navio & Capacidade Média \\
\hline Handymax & $35.000,00(\mathrm{t})$ \\
\hline Panamax & $65.000,00(\mathrm{t})$ \\
\hline Capesize & $105.000,00(\mathrm{t})$ \\
\hline \multicolumn{2}{|c}{ Fonte: o Autor }
\end{tabular}

As taxas de embarque nos terminais de transbordo, descarga de barcaças e embarque de navios são 600 toneladas por hora (t/h), 750 toneladas por hora $(\mathrm{t} / \mathrm{h})$ e 1000 toneladas por hora $(\mathrm{t} / \mathrm{h})$, respectivamente.

Para as estocagens intermediárias, foram consideradas capacidades estáticas de estocagem nos pontos de transbordo (silos de armazenagem) de 36.000 toneladas ( $\mathrm{t}$ ) em Marabá e Porto Velho, 60.000 toneladas (t) em Miritituba e 144.000 toneladas ( $\mathrm{t}$ ) em Vila do Conde.

\subsection{INTERFACE DE ENTRADA DE DADOS}

Para que os cenários sejam configurados de forma rápida e eficiente, foi desenvolvida uma interface de entrada de dados utilizada como apoio para a entrada e saída de dados ao modelo de simulação.

Essa interface de entrada de dados foi desenvolvida em ambiente de planilha eletrônica do Microsoft Excel® e sua utilização é fácil e intuitiva, permitindo que sejam elaborados os mais diferentes cenários e realizadas as mais diversas análises. 
Para facilitar a navegação na interface, foi criado um menu para mudar as abas da planilha, mostrado na Figura 29.

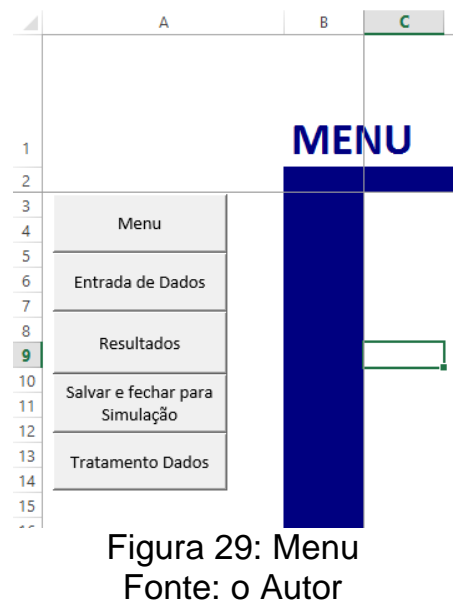

Os dados que devem ser alterados na interface para configuração dos cenários são:

Entrada de Dados: A primeira informação que se deve colocar na planilha referese aos parâmetros gerais do modelo, onde é informado o número de fazendas, silos, velocidade e capacidade dos caminhões, assim como a quantidade máxima de horas que os motoristas podem trabalhar por dia, produtividade dos equipamentos de carregamento e/ou descarregamento dos ativos ao longo da cadeia, duração em anos e número de replicações de cada rodada do modelo, além de outras informações, como se vê na Figura 30. 


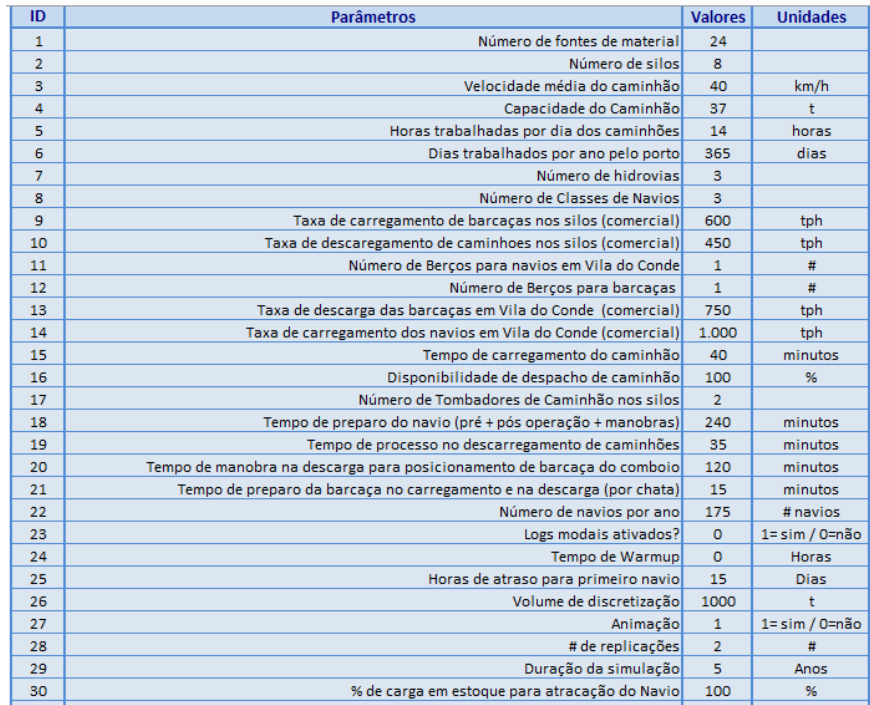

Figura 30: Parâmetros gerais

Fonte: o Autor

A quantidade de grãos inserida no sistema é definida em uma matriz de oferta de produtos em cada fazenda produtora, por mês, totalizando a oferta total de carga com a soma dos meses e fazendas, Figura 31.

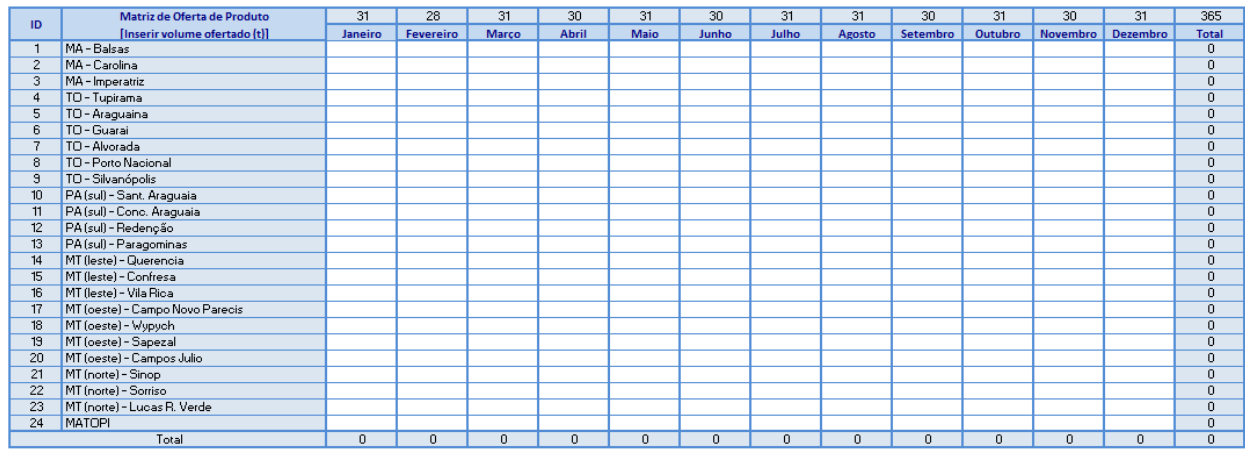

Figura 31: Matriz de oferta de grãos

Fonte: o Autor

Também são definidos, via interface, a capacidade de cada silo existente no sistema e seu estoque inicial (Figura 32). 


\begin{tabular}{|c|l|c|c|}
\hline \multirow{2}{*}{ ID } & \multicolumn{1}{|c|}{ Matriz de Armazenagem } & Estoque & Capacidade \\
\cline { 3 - 4 } & [ton] & [ton] \\
\hline 1 & Marabá & 18.000 & 36.000 \\
\hline 2 & Praia Norte & 18.000 & 36.000 \\
\hline 3 & Vila do Conde & 72.000 & 144.000 \\
\hline 4 & Porto Velho & 18.000 & 36.000 \\
\hline 5 & Miritituba & 30.000 & 60.000 \\
\hline 6 & Silo6 6 & & \\
\hline 7 & Silo 7 & & \\
\hline 8 & Silo 8 & & \\
\hline
\end{tabular}

Figura 32: Configuração dos silos

Fonte: o Autor

Matriz de distâncias: devem ser inseridas as distâncias entre as fazendas produtoras de grãos e os silos de armazenagem para o subsistema rodoviário, essas informações devem ser inseridas em quilômetros, Figura 33.

\begin{tabular}{|c|c|c|c|c|c|c|}
\hline \multirow{2}{*}{ ID } & \multirow{2}{*}{$\begin{array}{c}\text { Matriz de Distâncias } \\
\text { (Inserir distâncias [kml, } 0 \text { se não abastece) }\end{array}$} & Silo 1 & Silo 2 & Silo 3 & Silo 4 & Silo 5 \\
\hline & & Marabá & Praia Norte & Vila do Conde & Porto Velho & Miritituba \\
\hline 1 & MA - Balsas & 303 & 450 & 1.130 & & \\
\hline 2 & MA-Carolina & 360 & 260 & 850 & & \\
\hline 3 & MA - Imperatriz & 250 & 80 & 680 & & \\
\hline 4 & To - Tupirama & 530 & 500 & 1.180 & & \\
\hline 5 & To - Araguaina & 290 & 260 & 970 & & \\
\hline 6 & To-Guarai & 270 & 450 & 1.200 & & \\
\hline 7 & TO - Alvorada & 900 & 870 & 1.600 & & \\
\hline 8 & TO - Porto Nacional & 750 & 720 & 1.500 & & \\
\hline 9 & TO - Silvanópolis & 800 & 750 & 1.550 & & \\
\hline 10 & PA (sul) - Sant. Araguaia & 560 & 850 & 1.020 & & \\
\hline 11 & PA (sul) - Conc. Araguaia & 450 & 550 & 950 & & \\
\hline 12 & PA (sul) - Redenção & 400 & 650 & 850 & & \\
\hline 13 & PA (sul) - Paragominas & & & 400 & & \\
\hline 14 & MT (leste) - Querencia & 1.090 & 1.420 & 1.600 & & \\
\hline 15 & MT (leste) - Confresa & 872 & 1.200 & 1.300 & & \\
\hline 16 & MT (leste) - Vila Rica & 722 & 1.050 & 1.200 & & \\
\hline 17 & MT (oeste) - Campo Novo Parecis & & & & 1.058 & \\
\hline 18 & MT (oeste) - Wypych & & & & 1.180 & \\
\hline 19 & MT (oeste) - Sapezal & & & & 1.000 & \\
\hline 20 & MT (oeste) - Campos Julio & & & & 950 & \\
\hline 21 & MT (norte) - Sinop & & & & & 1.187 \\
\hline 22 & MT (norte) - Sorriso & & & & & 1.200 \\
\hline 23 & MT (norte) - Lucas R. Verde & & & & & 1.260 \\
\hline 24 & MATOPI & & & 875 & & \\
\hline
\end{tabular}

Figura 33: Matriz de Distâncias Fonte: O Autor

Ainda no subsistema rodoviário, é necessário inserir a frota máxima que será gerada no modelo, seguindo a mesma disposição da matriz de distância, tem-se a matriz de frota rodoviária, Figura 34. 


\begin{tabular}{|c|c|c|c|c|c|c|}
\hline \multirow{2}{*}{ ID } & \multirow{2}{*}{$\begin{array}{c}\text { Matriz de Frota } \\
\text { (Inserir número de veículos alocados, } 0 \text { se }\end{array}$} & Silo 1 & Silo 2 & Silo 3 & Silo 4 & Silo 5 \\
\hline & & Marabá & Praia Norte & Vila do Conde & Porto Velho & Miritituba \\
\hline 1 & MA-Balsas & 500 & 500 & 500 & & \\
\hline 2 & MA - Carolina & 500 & 500 & 500 & & \\
\hline 3 & MA - Imperatriz & 500 & 500 & 500 & & \\
\hline 4 & TO - Tupirama & 500 & 500 & 500 & & \\
\hline 5 & TO - Araguaina & 500 & 500 & 500 & & \\
\hline 6 & TO - Guarai & 500 & 500 & 500 & & \\
\hline 7 & TO - Alvorada & 500 & 500 & 500 & & \\
\hline 8 & TO - Porto Nacional & 500 & 500 & 500 & & \\
\hline 9 & TO - Silvanópolis & 500 & 500 & 500 & & \\
\hline 10 & PA (sul) - Sant. Araguaia & 500 & 500 & 500 & & \\
\hline 11 & PA (sul) - Conc. Araguaia & 500 & 500 & 500 & & \\
\hline 12 & PA (sul) - Redenção & 500 & 500 & 500 & & \\
\hline 13 & PA (sul) - Paragominas & & & 500 & & \\
\hline 14 & MT (leste) - Querencia & 500 & 500 & 500 & & \\
\hline 15 & MT (leste) - Confresa & 500 & 500 & 500 & & \\
\hline 16 & MT (leste) - Vila Rica & 500 & 500 & 500 & & \\
\hline 17 & MT (oeste) - Campo Novo Parecis & & & & 500 & \\
\hline 18 & MT (oeste) - Wypych & & & & 500 & \\
\hline 19 & MT (oeste) - Sapezal & & & & 500 & \\
\hline 20 & MT (oeste) - Campos Julio & & & & 500 & \\
\hline 21 & MT (norte) - Sinop & & & & & 500 \\
\hline 22 & MT (norte) - Sorriso & & & & & 500 \\
\hline 23 & MT (norte) - Lucas R. Verde & & & & & 500 \\
\hline 24 & MATOPI & & & 500 & & \\
\hline
\end{tabular}

Figura 34: Matriz de frota rodoviária Fonte: o Autor

As informações para o subsistema hidroviário têm algumas semelhanças com o subsistema rodoviário, no entanto, há outras informações necessárias para preencher esses campos.

Assim como no submodelo rodoviário, para as hidrovias também é definida uma matriz de distâncias, Figura 35.

\begin{tabular}{|c|l|c|c|c|}
\hline \multirow{2}{*}{ ID } & \multicolumn{1}{|c|}{$\begin{array}{c}\text { Matriz de Distância } \\
\text { (mn) }\end{array}$} & Via 1 & Via 2 & Via 3 \\
\cline { 3 - 5 } & \multicolumn{2}{|c|}{ Rio Madeira } & Rio Tapajós & Rio Tocantins \\
\hline 1 & Marabá & & & 300 \\
\hline 2 & Praia Norte & & & 500 \\
\hline 3 & Vila do Conde & & & \\
\hline 4 & Porto Velho & 1.400 & & \\
\hline 5 & Miritituba & & 600 & \\
\hline 6 & Silo 6 & & & \\
\hline 7 & Silo 7 & & & \\
\hline 8 & Silo 8 & & & \\
\hline
\end{tabular}

Figura 35: Matriz de distâncias das hidrovias Fonte: o Autor

Diferentemente da matriz de frota do subsistema rodoviário, nessa sessão é necessário inserir uma frota de empurradores e chatas, na qual é definido um conjunto de chatas para cada empurrador no sistema, por exemplo, para o Rio Madeira, em Porto velho, tem-se 9 empurradores com 6 chatas, ou seja, são 6 chatas para cada empurrador, Figura 36. 


\begin{tabular}{|c|l|c|c|c|}
\hline \multirow{2}{*}{ ID } & \multicolumn{1}{|c|}{$\begin{array}{c}\text { Matriz de Frota } \\
\text { (empurrador) }\end{array}$} & Via 1 & Via 2 & Via 3 \\
\cline { 3 - 5 } & Rio Madeira & Rio Tapajós & Rio Tocantins \\
\hline 1 & Marabá & & & 6 \\
\hline 2 & Praia Norte & & & \\
\hline 3 & Vila do Conde & & & \\
\hline 4 & Porto Velho & 9 & & \\
\hline 5 & Miritituba & & 17 & \\
\hline 6 & Silo 6 & & & \\
\hline 7 & Silo 7 & & & \\
\hline 8 & Silo 8 & & & \\
\hline & \multicolumn{1}{|c|}{ Matriz de Frota } & Via 1 & Via 2 & Via 3 \\
\hline ID & \multicolumn{1}{|c|}{ (chatas por empurrador) } & Rio Madeira & Rio Tapajós & Rio Tocantins \\
\hline 1 & Marabá & & & 9 \\
\hline 2 & Praia Norte & & & 9 \\
\hline 3 & Vila do Conde & & & \\
\hline 4 & Porto Velho & 6 & & \\
\hline 5 & Miritituba & & & \\
\hline 6 & Silo 6 & & & \\
\hline 7 & Silo 7 & & & \\
\hline 8 & Silo 8 & & & \\
\hline
\end{tabular}

Figura 36: Frota hidroviária

Fonte: o Autor

A velocidade de cada rio também é definida pela interface e é necessário definir as velocidades de subida e decida dos rios, assim como a velocidade do comboio nos períodos de seca e cheia, assim como mostrado na Figura 37.

\begin{tabular}{|l|l|c|c|c|c|c|c|c|c|c|c|c|c|}
\hline & Velocidade de subida (nós) & Fevereiro & Março & Abril & Maio & Junho & Julho & Agosto & Setembro & Outubro & Novembro & Dezembro & Janeiro \\
\hline $\mathbf{1}$ & Rio Madeira & 2,80 & 2,80 & 2,80 & 2,80 & 2,80 & 2,80 & 3,35 & 3,35 & 3,35 & 2,80 & 2,80 & 2,80 \\
\hline $\mathbf{2}$ & Rio Tapajós & 2,83 & 2,83 & 2,83 & 2,83 & 2,83 & 2,83 & 3,16 & 3,16 & 3,16 & 2,83 & 2,83 & 2,83 \\
\hline $\mathbf{3}$ & Rio Tocantins Araguaia & 2,83 & 2,83 & 2,83 & 2,83 & 2,83 & 3,16 & 3,16 & 3,16 & 3,16 & 2,83 & 2,83 & 2,83 \\
\hline
\end{tabular}

Figura 37: Velocidade das embarcações

Fonte: o Autor

Para coletar as estatísticas corretamente, há a necessidade de informar para o modelo quando são períodos de seca e cheia, definidos também na interface de entrada de dados, onde 1 representa o período de cheia e 2 o período de seca, Figura 38. 


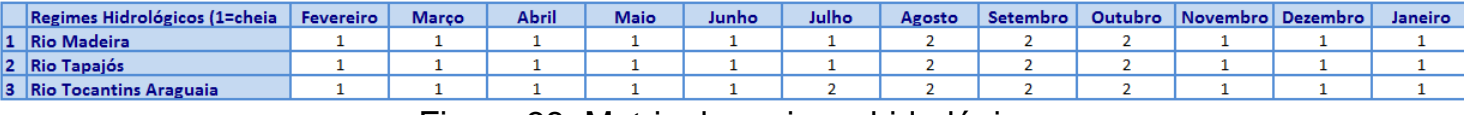

Figura 38: Matriz de regimes hidrológicos

Fonte: o Autor

Ainda no subsistema hidroviário, é preciso preencher a capacidade de cada chata no comboio em cada um dos rios, note também que, deve-se representar as capacidades diferentes nos períodos de seca e cheia, Figura 39.

\begin{tabular}{|c|c|c|c|c|c|c|c|c|c|c|c|c|c|}
\hline & Capacidade da chata ( $t$ ) & Fevereiro & Março & Abril & Maio & Junho & Julho & Agosto & Setembro & Outubro & Novembro & Dezembro & Janeiro \\
\hline 1 & Rio Madeira & 2.417 & 2.417 & 2.417 & 2.417 & 2.417 & 2.417 & 1.000 & 1.000 & 1.000 & 2.417 & 2.417 & 2.417 \\
\hline & Rio Tapajós & 2.150 & 2.150 & 2.150 & 2.150 & 2.150 & 2.150 & 1.000 & 1.000 & 1.000 & 2.150 & 2.150 & 2.150 \\
\hline & Rio Tocantins Ara & 1.700 & 1.700 & 1.700 & 1.700 & 1.700 & 735 & 735 & 735 & 735 & 1.700 & 1.700 & 1.700 \\
\hline
\end{tabular}

Figura 39: Capacidade das chatas

Fonte: o Autor

No subsistema marítimo, as únicas informações necessárias são a capacidade de navio e a porcentagem que esse tipo de navio vai representar na frota total de navios no sistema, Figura 40.

\begin{tabular}{|c|c|c|c|c|c|c|}
\hline ID & Classe do navio & $\begin{array}{c}\text { Carga } \\
(t)\end{array}$ & $\begin{array}{c}\text { Composição } \\
(\%)\end{array}$ & $\begin{array}{c}\text { \# de Navios Previstos } \\
\text { Caso } 100 \%\end{array}$ & $\begin{array}{l}\text { Volme por } \\
\text { Navio }\end{array}$ & $\begin{array}{c}\text { Capacidade } \\
\text { do Navio }\end{array}$ \\
\hline 1 & Handymax & $35.087,72$ & $100 \%$ & 171,00 & 6.000 .000 & 35.000 \\
\hline 2 & Panamax & 0 & $0 \%$ & 0,00 & 0 & 65.000 \\
\hline 3 & Capesize & 0 & $0 \%$ & 0,00 & 0 & 105.000 \\
\hline 4 & & & & & & \\
\hline & & & $100 \%$ & 171,00 & 6.000 .000 & \\
\hline
\end{tabular}

Figura 40: Entrada marítima

Fonte: o Autor

Além desses dados preenchidos diretamente, a planilha executa, ainda, alguns cálculos e informações que serão utilizadas na simulação.

A interface de dados deve ser utilizada para construir os cenários desejados e preparar o modelo para analisar o comportamento do sistema em função da variação de alguns parâmetros.

Considerando o objetivo deste trabalho, deve-se entender os mecanismos de análises gerados a partir dos outputs do modelo de simulação.

Uma vez finalizado o preenchimento da entrada de dados na interface com o modelo de simulação, e depois de rodar o cenário no simulador, pode-se 
importar os dados de saída do simulador para as planilhas, facilitando, assim, o entendimento dos resultados obtidos.

Essa integração entre modelo de simulação e interface se faz por rotinas desenvolvidas em VBA dentro das planilhas Excel. Através dessas rotinas são importados todos os dados gerados pelo modelo de simulação, Figura 41.

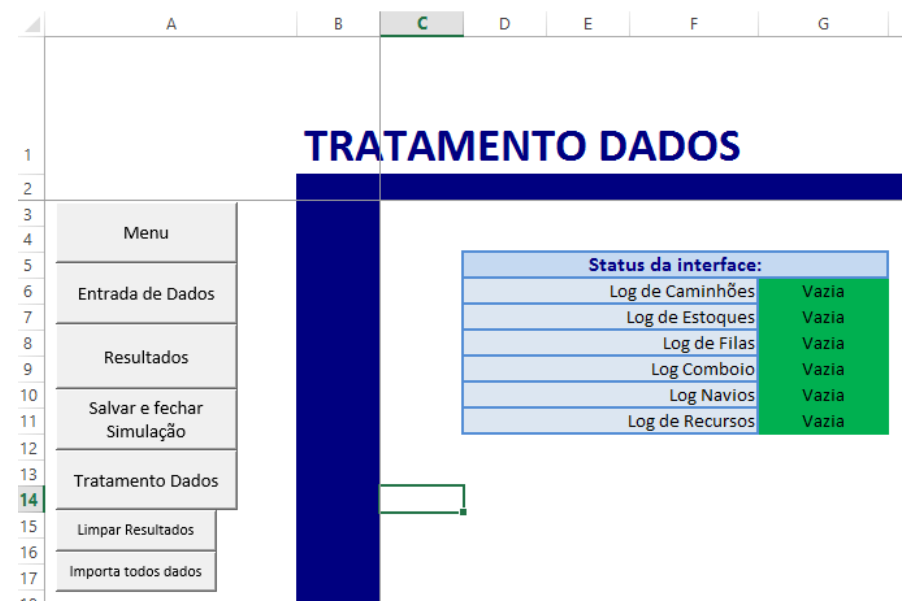

Figura 41: Importação de dados

Fonte: o Autor

Para visualizar os resultados obtidos, foi criada uma planilha com a carga total consolidada de grãos transportados por mês e modal de transporte, a fim de visualizar se toda a carga gerada foi transportada até seu destino e qual a distribuição dessa carga nos modais, Figura 42.

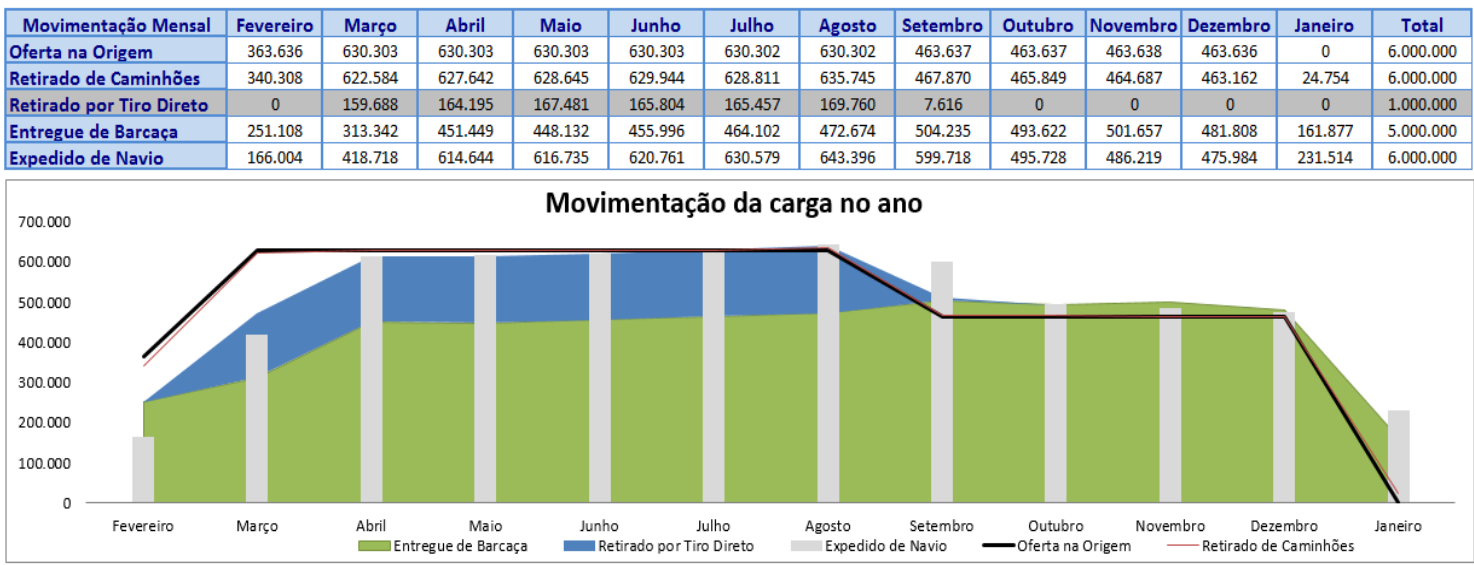

Figura 42: Resultado Consolidado

Fonte: o Autor 
Nessa imagem, pode-se ver a quantidade de grãos transportada por cada modal ao longo do ano. Note que o gráfico começa em fevereiro, isso devido ao cultivo da safra de soja, que se dá no início de fevereiro e se estende até meados de janeiro, quando já não há mais o cultivo, porém a carga ainda está em trânsito até o porto de exportação.

Os resultados do subsistema rodoviário são obtidos na Figura 43, onde se tem o número total de viagens realizadas de cada origem para cada destino, além dos volumes, tempo médio por rota e tempo de ciclo em cada região. Consolidado, ao lado da tabela, tem-se os tempos médio de ciclo dos caminhões e, abaixo, os principais indicadores de resultados.

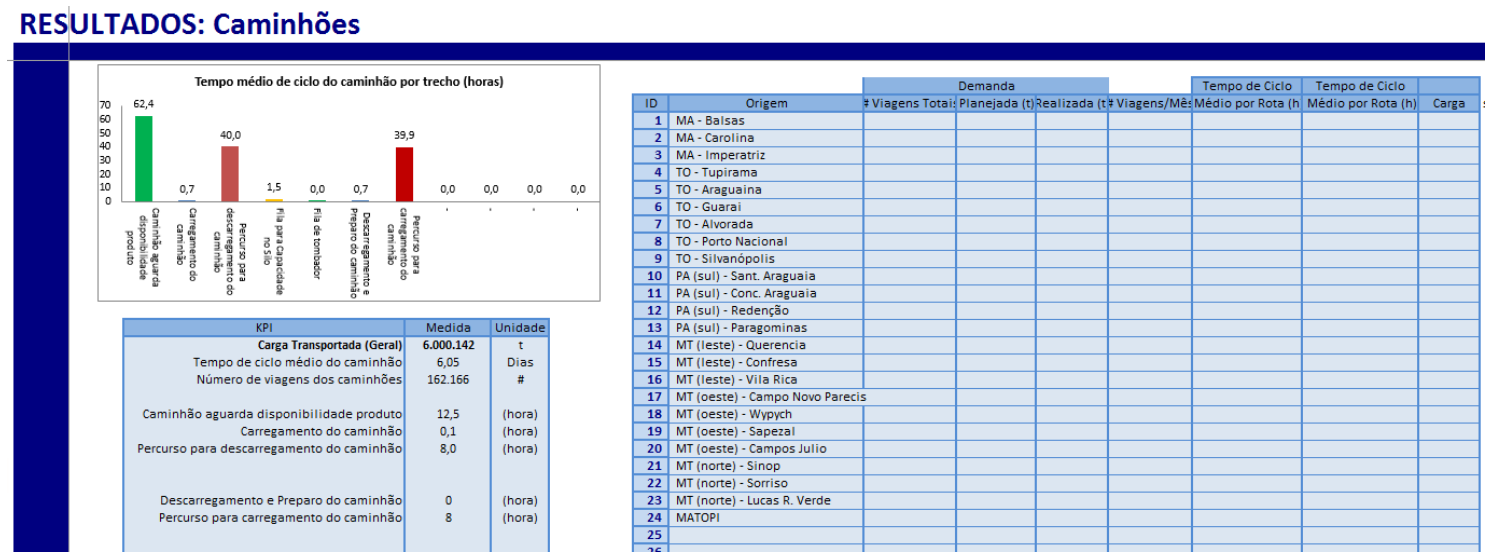

Figura 43: Resultados Rodoviários

Fonte: o Autor

No subsistema hidroviário, além de uma análise consolidada das hidrovias utilizadas, tem-se também as estatísticas dos comboios, divididas em períodos de seca e cheia, além dos tempos médios de ciclo mostrados no gráfico. Nessa seção, tem-se a avaliação dos ciclos dos comboios nos regimes de seca e cheia das hidrovias, a causa das filas em cada um dos regimes, quando elas ocorreram e, também, o resultado agregado para cada hidrovia no sistema em estudo, Figura 44.

Assim como no subsistema rodoviário, nesse subsistema tem-se um gráfico de tempo médio de ciclo dos comboios e os principais indicadores. 


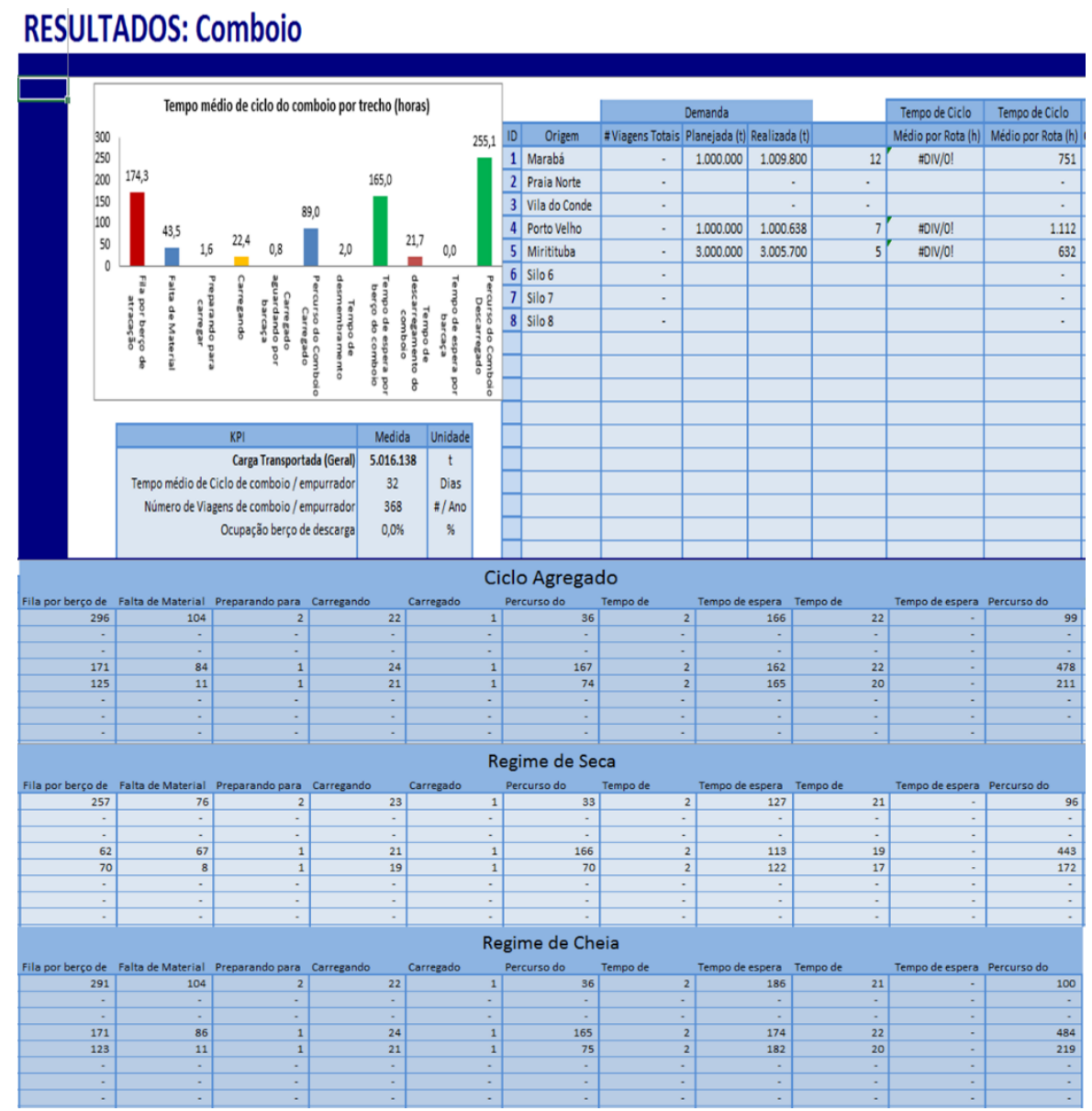

Figura 44: Resultados hidroviários

Fonte: o Autor

Analogamente aos subsistemas rodoviário e hidroviário, no subsistema marítimo tem-se também as mesmas análises de número de ciclos e tempos. Apontado no gráfico e com os principais indicadores de desempenho (Figura 45).

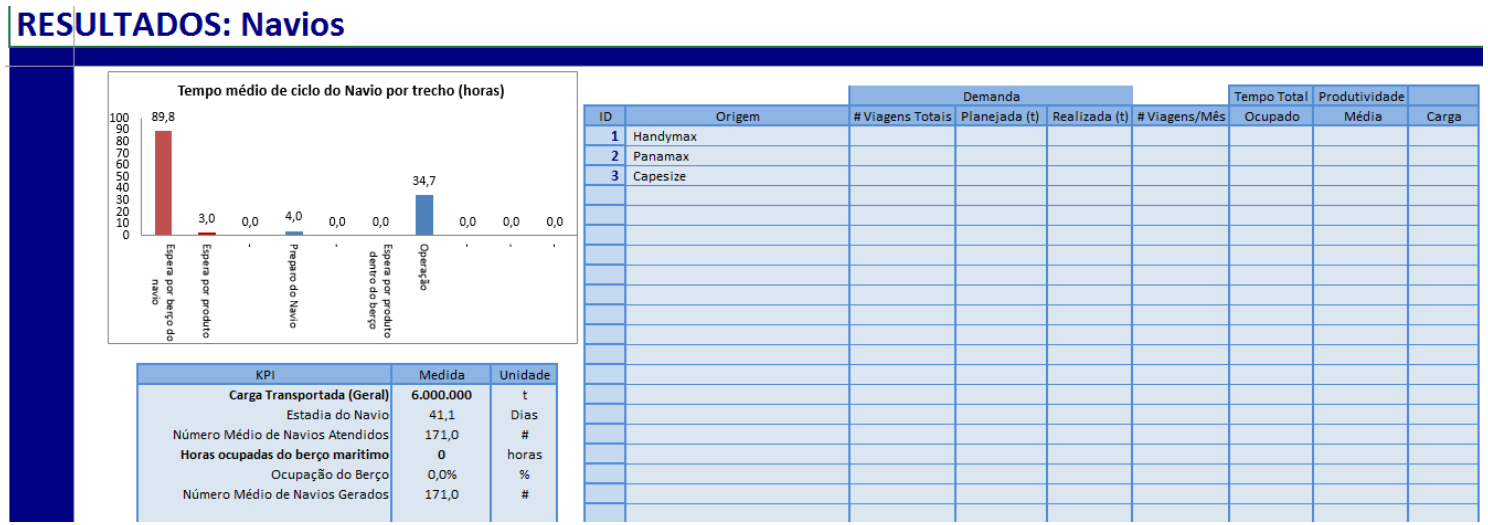

Figura 45: Resultado marítimo

Fonte: o Autor 
Um indicativo para avaliar o sistema estudado é o nível das filas. Essas filas são medidas nos pontos de carregamento e descarregamento de veículos nas fazendas, nos silos e no porto de exportação de grãos, onde se tem o tamanho médio da fila (em unidades) e o tempo médio que o veículo permaneceu esperando em fila (horas), Figura 46.

\begin{tabular}{|r|l|c|c|}
\hline \multicolumn{1}{|c|}{ ID Fila } & Tam. fila (\#) & Tempo Médio em fila (h) \\
\hline $\mathbf{1}$ & Marabá - Descarregamento Caminhão & 0,0 & 0,0 \\
\hline $\mathbf{2}$ & Praia Norte - Descarregamento Caminhão & 0,0 & 0,0 \\
\hline $\mathbf{3}$ & Vila do Conde - Descarregamento Caminhão & 10,2 & 3,3 \\
\hline $\mathbf{4}$ & Porto Velho - Descarregamento Caminhão & 0,0 & 0,0 \\
\hline $\mathbf{5}$ & Miritituba - Descarregamento Caminhão & 28,1 & 3,0 \\
\hline $\mathbf{6}$ & Silo 6- Descarregamento Caminhão & 0,0 & 0,0 \\
\hline $\mathbf{7}$ & Silo 7- Descarregamento Caminhão & 0,0 & 0,0 \\
\hline $\mathbf{8}$ & Silo 8- Descarregamento Caminhão & 0,0 & 0,0 \\
\hline $\mathbf{9}$ & Marabá - Carregamento Comboio & 0,8 & 11,6 \\
\hline $\mathbf{1 0}$ & Praia Norte - Carregamento Comboio & 0,0 & 0,0 \\
\hline $\mathbf{1 1}$ & Vila do Conde - Carregamento Comboio & 0,0 & 0,0 \\
\hline $\mathbf{1 2}$ & Porto Velho - Carregamento Comboio & 0,7 & 16,6 \\
\hline $\mathbf{1 3}$ & Miritituba - Carregamento Comboio & 0,3 & 2,7 \\
\hline $\mathbf{1 4}$ & Silo 6- Carregamento Comboio & 0,0 & 0,0 \\
\hline $\mathbf{1 5}$ & Silo 7- Carregamento Comboio & 0,0 & 0,0 \\
\hline $\mathbf{1 6}$ & Silo 8-Carregamento Comboio & 0,0 & 0,0 \\
\hline $\mathbf{1 7}$ & Descarregamento_comboio_1 (Vila do Conde) & 0,1 & 4,8 \\
\hline $\mathbf{1 8}$ & Descarregamento_comboio_2 & 0,0 & 0,0 \\
\hline $\mathbf{1 9}$ & Descarregamento_comboio_3 & 0,0 & 0,0 \\
\hline $\mathbf{2 0}$ & Berço de Exportação em Vila do Conde & 0,0 & 0,0 \\
\hline $\mathbf{2 1}$ & Disponibilidade de Material em Vila do Conde Atracado & 0,0 & 0,0 \\
\hline $\mathbf{2 2}$ & Fila tombador em Marabá & 0,0 & 0,0 \\
\hline $\mathbf{2 3}$ & Fila tombador em Praia Norte & 0,0 & 0,0 \\
\hline $\mathbf{2 4}$ & Fila tombador em Vila do Conde & 0,3 & 0,1 \\
\hline $\mathbf{2 5}$ & Fila tombador em Porto Velho & 0,0 & 0,0 \\
\hline $\mathbf{2 6}$ & Fila tombador em Miritituba & 0,8 & 0,1 \\
\hline $\mathbf{2 7}$ & Fila tombador em Silo 6 & 0,0 & 0,0 \\
\hline $\mathbf{2 8}$ & Fila tombador em Silo 7 & 0,0 & 0,0 \\
\hline $\mathbf{2 9}$ & Fila tombador em Silo 8 & 0,0 & 178,2 \\
\hline $\mathbf{3 0}$ & Fila Berço barcaça em Vila do Conde - Descarregamento de Comboio & 7,5 & 99,7 \\
\hline $\mathbf{3 1}$ & Fila Vila do Conde por Falta de Material Antes Atracação & 0,0 & \\
\hline $\mathbf{3 2}$ & Fila Berço Vila do Conde (Comercial) & 1,9 & \\
\hline & & & 0,0 \\
\hline
\end{tabular}

Figura 46: Tabela de filas

Fonte: o Autor

Além das filas, é importante avaliar a utilização dos recursos para o carregamento e descarregamento dos ativos necessários para transportar os grãos no sistema, Figura 47.

\begin{tabular}{|r|c|c|}
\hline \multicolumn{1}{|c|}{ ID } & Recurso & Utilização \\
\hline $\mathbf{1}$ & Berços de Exportação (efetiva) & $76,4 \%$ \\
\hline $\mathbf{2}$ & Berços de Barcaça (efetiva) & $90,2 \%$ \\
\hline $\mathbf{3}$ & Tombador em Marabá & $25,4 \%$ \\
\hline $\mathbf{4}$ & Tombador em Praia Norte & $0,0 \%$ \\
\hline $\mathbf{5}$ & Tombador em Vila do Conde & $25,4 \%$ \\
\hline $\mathbf{6}$ & Tombador em Porto Velho & $25,4 \%$ \\
\hline $\mathbf{7}$ & Tombador em Miritituba & $76,1 \%$ \\
\hline $\mathbf{8}$ & Tombador em Silo 6 & $0,0 \%$ \\
\hline $\mathbf{9}$ & Tombador em Silo 7 & $0,0 \%$ \\
\hline $\mathbf{1 0}$ & Tombador em Silo 8 & $0,0 \%$ \\
\hline $\mathbf{1 1}$ & Berço em Vila do Conde (Considerando espera por produto) & $79,8 \%$ \\
\hline
\end{tabular}

Figura 47: Utilização dos recursos

Fonte: o Autor 
Para que seja atingido o objetivo desse trabalho, é necessário avaliar o nível dos estoques ao longo do ano para cada silo existente no sistema. Note que se tem o estoque médio do silo ao final da simulação e o nível de cada silo hora a hora computado no gráfico, Figura 48.

RESULTADOS: Estoques

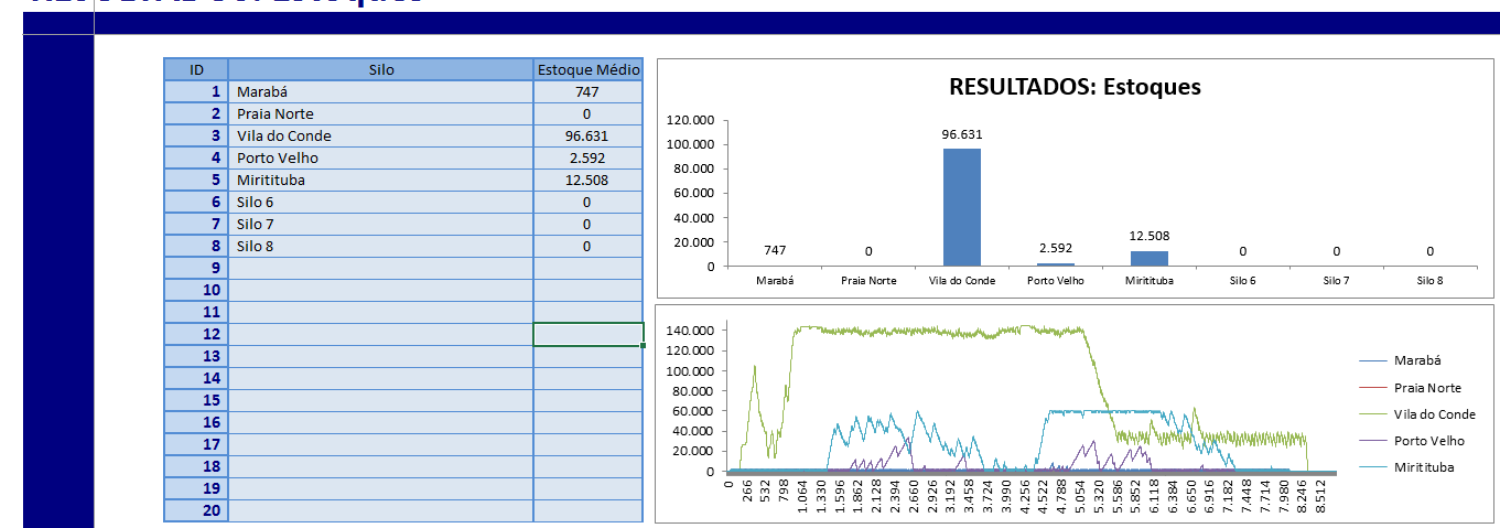

Figura 48: Nível dos estoques

Fonte: o Autor

\subsection{VERIFICAÇÃO E VALIDAÇÃO DO MODELO}

Como mostrado no capítulo anterior, a verificação de um modelo de simulação é uma etapa importante onde se busca apurar os possíveis erros e averiguar se o modelo computacional está de acordo com o modelo conceitual.

No entanto, a validação se dá no âmbito de verificar se os dados de saída do modelo condizem com o mundo real, ou seja, se o modelo tem representatividade real e pode ser utilizado para avaliar os cenários propostos.

O modelo deste trabalho foi validado pelos tempos de ciclos, número de veículos utilizados e carga total transportada por cada subsistema.

A Tabela 4 mostra a comparação entre o resultado simulado e o cálculo determinístico do número médio de veículos necessário para transportar a carga proposta, tempo de ciclo médio para cada região e o volume transportado em cada um dos subsistemas. 
Tabela 4: Validação de ciclos

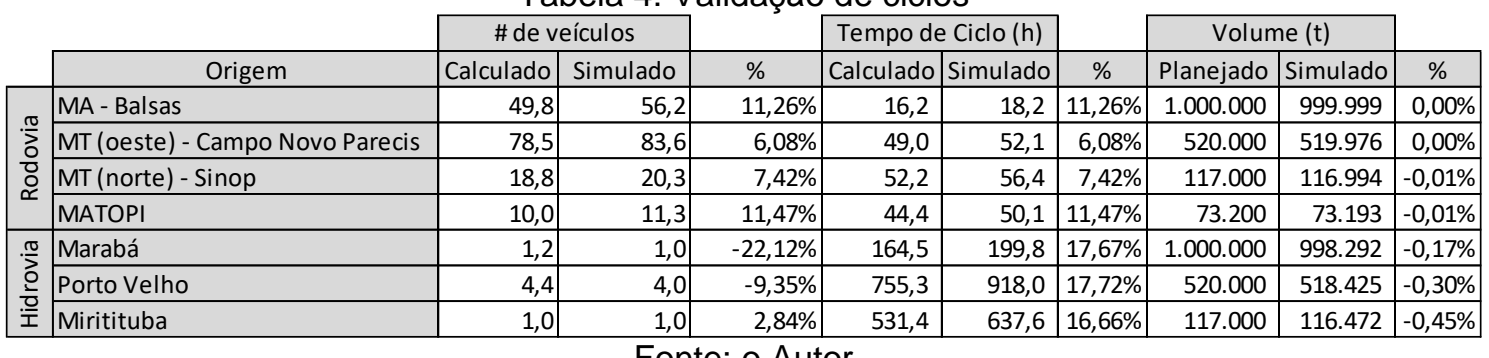

Fonte: o Autor

Note que, comparativamente, os valores simulados estão próximos ao valor calculado. No entanto, deve-se observar ambas as comparações, tanto a numérica quanto a diferença porcentual, já que, em alguns casos, tem-se a diferença porcentual perto de $22 \%$, mas ao se olhar para os valores, a diferença é de 0,2. Essa variação deve-se ao fato da aleatoriedade inserida ao sistema simulado.

Comparando os volumes totais calculados e simulados, tem-se uma diferença média de $0,43 \%$, ou seja, foi considerado que foi exportado por navios todo o volume gerado nas fazendas, mostrado na Tabela 5.

Tabela 5: Validação de volumes

\begin{tabular}{|r|r|r|r|}
\cline { 2 - 4 } \multicolumn{1}{c|}{} & Calculado & Simulado & \multicolumn{1}{c|}{$\%$} \\
\hline Ciclo total dos caminhoes (\#) & $46.033,0$ & $46.222,6$ & $0,41 \%$ \\
\hline Carga total transportada via Rodoviário (t) & 1.703 .220 & 1.710 .186 & $0,41 \%$ \\
\hline Ciclo total dos Comobios (\#) & 140,0 & 144,8 & $3,37 \%$ \\
\hline Carga total transportada via Hidroviário (t) & 1.660 .026 & 1.633 .290 & $-1,64 \%$ \\
\hline Carga total transportada via Maritimo (t) & 1.710 .200 & 1.703 .220 & $-0,41 \%$ \\
\hline
\end{tabular}

Fonte: o Autor

Considerando os valores obtidos pelo modelo, e comparado aos valores de tempo de ciclos, quantidade de carga transportada em cada região e quantidade de veículos utilizados, calculados deterministicamente, e a carga total de grãos que saiu das origens e chegou ao destino, este modelo foi considerado validado. Portanto, representa as condições do sistema real e pode ser utilizado para extrapolação de demanda para analisar qual será o comportamento do sistema real.

Para todos os cenários simulados neste projeto, foram utilizadas 10 replicações de 10 anos. A Figura 49 apresenta um cenário com 100 anos de simulação, que representa o intervalo médio entre chegadas do berço de barcaças em Vila do 
Conde. Pode-se observar que no período de 10 anos o sistema já entra em regime permanente, sendo que este período de tempo é suficiente para que os resultados convirjam.

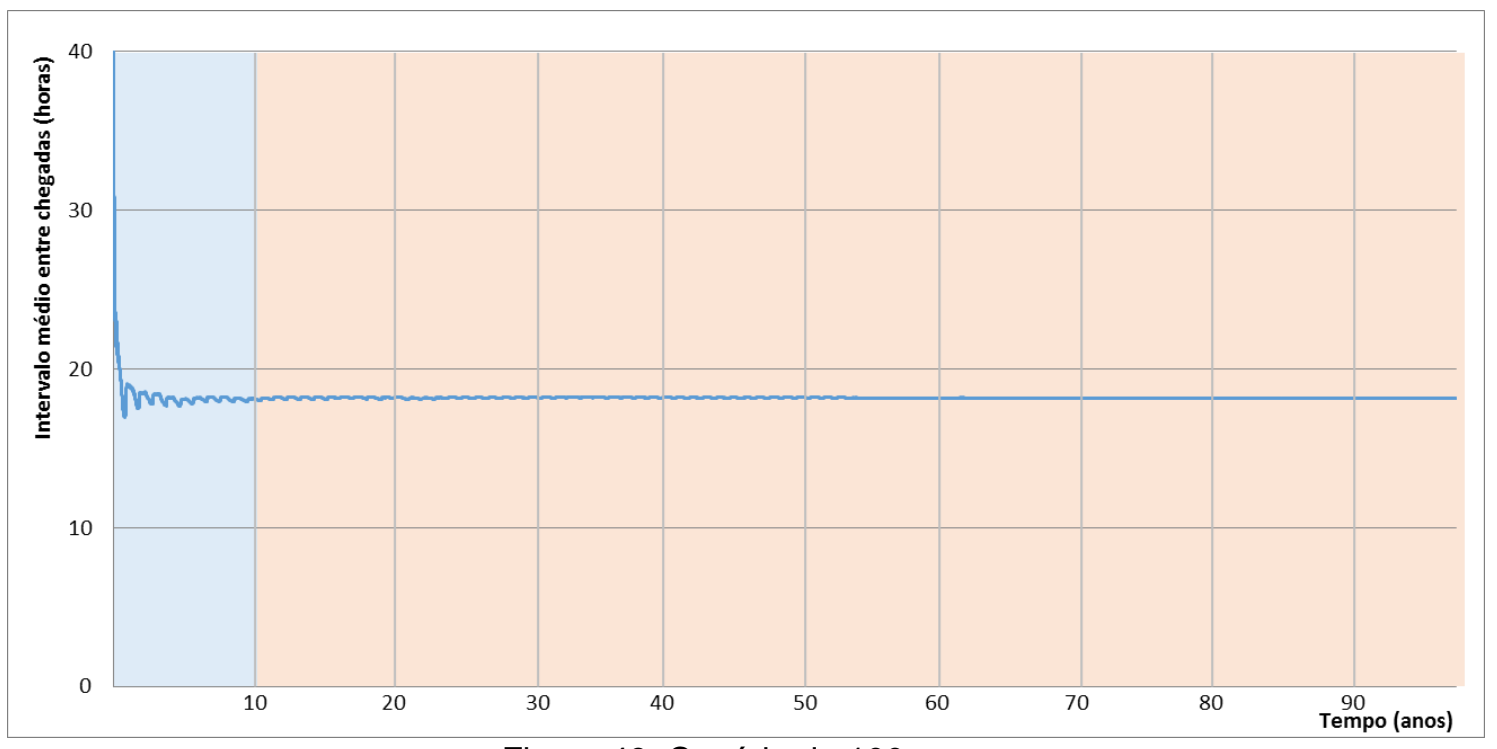

Figura 49: Cenário de 100 anos

Fonte: o Autor

Apesar de haver métodos matemáticos para o cálculo do número de replicações, há no mercado alguns softwares que já calculam este número utilizando 0 intervalo de confiança desejado. No entanto, neste projeto, foi utilizado empiricamente o número de 10 replicações.

\subsection{CENÁRIOS}

Foram definidos, inicialmente, quatro cenários para verificação da influência das restrições da hidrovia e oferta de carga sobre o sistema de armazenagem. Esses cenários são:

- CENÁRIO A "SEM RESTRIÇÕES" - Capacidade 5 Mtpa sem restrição de variação de capacidade de transporte dos comboios nas hidrovias, sem sazonalidade na demanda: neste cenário, a demanda para o transporte hidroviário foi distribuída igualmente ao longo dos meses. 
- CENÁRIO B - Capacidade 5 Mtpa com restrição de variação de capacidade de transporte dos comboios nas hidrovias, sem sazonalidade na demanda: neste cenário, a demanda para o transporte hidroviário foi distribuída igualmente ao longo dos meses.

- CENÁRIO C - Capacidade 5 Mtpa sem restrição de variação de capacidade de transporte dos comboios nas hidrovias e com sazonalidade na demanda: neste cenário, foi adotada a premissa de sazonalidade na demanda.

- CENÁRIO D - Sistema real de transporte, considerando as restrições das hidrovias e a sazonalidade na oferta de produtos.

Todos os cenários foram testados com três perfis de frota de navios distintos, sendo assim, para cada conjunto de cenários a frota de navio é definida como $100 \%$ dos navios do tipo Handymax, 100\% Panamax e um mix de navios onde se tem que $20 \%$ são do tipo Capesize e $80 \%$ Panamax.

Cabe ressaltar que em todos os cenários podem ser feitas análises de sensibilidade, no entanto, foi definido como sensibilidade a produtividade dos equipamentos de carregamento dos navios e descarregamento dos comboios no sistema, ou seja, variou-se as taxas para deixar o sistema mais eficiente e avaliar esse impacto no nível de estocagem dos silos:

- CENÁRIO E: Análises de sensibilidade das taxas de carga dos navios e descarga dos comboios, composto por um conjunto de variações. Os resultados destes cenários devem ser comparados sempre com o Cenário $D$, que é o cenário real de operação, para navios do tipo Panamax para avaliação do comportamento dos estoques em função da análise de sensibilidade.

E1: Aumento da taxa de descarga de barcaça para $1.000 \mathrm{t} / \mathrm{h}$ e mantém embarque a $1.000 \mathrm{t} / \mathrm{h}$

E2: Mantém taxa de descarga em $750 \mathrm{t} / \mathrm{h}$ e aumento da taxa de embarque de navios $1.250 \mathrm{t} / \mathrm{h}$

$>$ E3: Aumento da taxa de descarga de barcaça para $1.000 \mathrm{t} / \mathrm{h}$ e taxa de embarque $1.250 \mathrm{t} / \mathrm{h}$ 


\section{RESULTADOS OBTIDOS}

Este capítulo apresenta os resultados obtidos pelo modelo de simulação elaborado, através do qual foram simulados os diversos cenários descritos no capítulo cinco.

Inicialmente, foram testados quatro cenários para saber a real impedância dos fatores sazonais no sistema e, em seguida, foi feita uma análise de sensibilidade sobre o cenário $D$.

\subsection{CENÁRIO A}

Como mostrado no capítulo anterior, este cenário é livre de restrições, com âmbito de ter um cenário para comparação entre os cenários com algum tipo de restrição. Cabe relembrar que em todos os cenários foram testadas três frotas diferentes de navios, com 100\% Handymax, 100\% Panamax e o mix entre Panamax e Capesize, respectivamente.

A Tabela 6 mostra os principais resultados obtidos na simulação do cenário $A$, com navios do tipo Handymax. Observa-se que para cada cenário obtido se tem um grupo de cenários devido à variação da frota de navios de exportação.

Tabela 6: Resumo do cenário $\mathrm{A}$

\begin{tabular}{|c|c|c|c|c|c|c|c|c|c|}
\hline & \multicolumn{2}{|c|}{ Número médio em Fila } \\
\hline Origem & $\begin{array}{c}\text { Frota de } \\
\text { Barcaças (\#) }\end{array}$ & $\begin{array}{c}\text { Ciclo das } \\
\text { Barcaças (Dias) }\end{array}$ & Ociosidade (Dias) & Carga Total $(\mathrm{t})$ & $\begin{array}{c}\text { Ocupação das } \\
\text { Barcaças (\%) }\end{array}$ & $\begin{array}{c}\text { Ocupação dos } \\
\text { Navios (\%) }\end{array}$ & $\begin{array}{c}\text { Ocupação das } \\
\text { Barcaças (\%) }\end{array}$ & Navios (\#) & Barcaças (\#) \\
\hline \multicolumn{10}{|c|}{ Cenário 1 - Handymax } \\
\hline Marabá & 3 & 17,5 & 10,0 & 833.333 & 69,8 & - & - & - & - \\
\hline Miritituba & 9 & 21,7 & 4,2 & 2.500 .000 & 58,0 & - & - & - & - \\
\hline Porto Velho & 6 & 38,3 & 5,8 & 833.333 & 45,0 & - & - & - & - \\
\hline Vila do Conde & - & - & - & 833.333 & - & 70,7 & 73,3 & 1,8 & 1,7 \\
\hline \multicolumn{2}{|r|}{ Navio Atendidos: } & 143 & Total: & 5.000 .000 & & & & & \\
\hline \multicolumn{10}{|c|}{ Cenário 2 - Panamax } \\
\hline Marabá & 3 & 25,8 & 10,0 & 833.333 & 71,1 & - & - & - & - \\
\hline Miritituba & 9 & 21,7 & 4,2 & 2.500 .000 & 57,4 & - & - & - & - \\
\hline Porto Velho & 6 & 39,2 & 5,8 & 833.333 & 48,0 & - & - & - & - \\
\hline Vila do Conde & - & - & - & 833.333 & - & 70,2 & 73,7 & 1,2 & 1,7 \\
\hline \multicolumn{2}{|r|}{ Navio Atendidos: } & 77 & Total: & 5.000 .000 & & & & & \\
\hline \multicolumn{10}{|c|}{ Cenário 3 - 80\% Panamax / 20\% Capesize } \\
\hline Marabá & 3 & 25,8 & 8,3 & 841.500 & 62,6 & - & - & - & - \\
\hline Miritituba & 9 & 22,5 & 3,3 & 2.504 .750 & 54,4 & - & - & - & - \\
\hline Porto Velho & 6 & 39,2 & 5,0 & 833.865 & 39,6 & - & - & - & - \\
\hline Vila do Conde & - & - & - & 833.363 & - & 71,9 & 75,8 & 1,3 & 2,3 \\
\hline \multicolumn{2}{|r|}{ Navio Atendidos: } & 71 & Total: & 5.013 .478 & & & & & \\
\hline
\end{tabular}


Note que conforme as taxas de ocupação no descarregamento das barcaças e no carregamento dos navios estão diretamente relacionadas, isso se dá devido ao tamanho dos navios de exportação.

No caso do cenário 3 - 80\% Panamax / 20\% Capesize - a ocupação está maior que no cenário anterior, com $100 \%$ da frota de navios do tipo Panamax. Isso devido ao tempo que se espera para chegada de carga suficiente para completar o carregamento do navio, que é maior.

Os tempos de ciclo descritos na Tabela 7 mostram segregados os tempos obtidos no subsistema hidroviário para o transporte das barcaças no cenário onde se tem apenas navios do tipo Handymax para atendimento do porto de Vila do Conde.

Tabela 7: Tempos de ciclo cenário A para Handymax

\begin{tabular}{|c|c|c|c|c|c|c|c|c|c|c|}
\hline Origem & $\begin{array}{l}\text { Fila por } \\
\text { berço (h) }\end{array}$ & $\begin{array}{c}\text { Falta de } \\
\text { Material (h) }\end{array}$ & Carregando (h) & $\begin{array}{c}\text { Carregado aguardando } \\
\text { por barcaça (h) }\end{array}$ & $\begin{array}{l}\text { Percurso } \\
\text { Carregado (h) }\end{array}$ & $\begin{array}{c}\text { Tempo de } \\
\text { desmembramento ( } \mathrm{h} \text { ) }\end{array}$ & $\begin{array}{c}\text { Tempo de espera } \\
\text { por berço (h) }\end{array}$ & $\begin{array}{c}\text { Tempo de } \\
\text { descarregamento }(\mathrm{h})\end{array}$ & \begin{tabular}{|c|} 
Percurso \\
Descarregado (h)
\end{tabular} & $\begin{array}{l}\text { Tempo totalde } \\
\text { ciclo (dias) }\end{array}$ \\
\hline \multicolumn{11}{|c|}{ Tempo de Ciclo Agregado } \\
\hline Marabá & 50,0 & 75,0 & 18,3 & 0,8 & 30,8 & $\begin{array}{r}1,7 \\
\end{array}$ & 35,8 & 18,3 & 84,2 & 13,1 \\
\hline Porto Velho & 63,3 & 40,0 & 20,0 & 0,8 & 136,7 & 1,7 & 38,3 & 17,5 & 409,2 & 30,3 \\
\hline \begin{tabular}{|l|} 
Miritituba \\
\end{tabular} & 26,7 & 2,5 & 17,5 & 0,8 & 61,7 & \begin{tabular}{|l|}
1,7 \\
\end{tabular} & 38,3 & 16,7 & 174,2 & 14,2 \\
\hline \multicolumn{11}{|c|}{ Tempo de Ciclo durante o Regime de Seca } \\
\hline Marabá & 23,3 & 61,7 & 19,2 & 0,8 & 27,5 & \begin{tabular}{|c|}
1,7 \\
\end{tabular} & 25,0 & 17,5 & 75,8 & 1,0 \\
\hline Porto Velho & 17,5 & 29,2 & 17,5 & 0,8 & 130,8 & 1,7 & 25,0 & 15,0 & 367,5 & 0,7 \\
\hline Miritituba & 10,8 & 0,0 & 15,8 & 0,8 & 55,8 & 1,7 & 24,2 & 15,8 & 180,0 & 0,5 \\
\hline \multicolumn{11}{|c|}{ Tempo de Ciclo durante o Regime de Cheia } \\
\hline Marabá & 50,0 & 74,2 & 19,2 & 0,8 & 30,8 & 1,7 & 44,2 & 18,3 & 85,8 & 2,1 \\
\hline Porto Velho & 62,5 & 38,3 & 20,0 & 0,8 & 137,5 & 1,7 & 45,0 & 17,5 & 413,3 & 2,6 \\
\hline Miritituba & 26,7 & 2,5 & 17,5 & 0,8 & 63,3 & 1,7 & 45,0 & 16,7 & 175,8 & 1,1 \\
\hline
\end{tabular}

Fonte: o Autor

Tem-se, também, para o cenário de navios do tipo Panamax, o mesmo tipo de dados segregados, como mostrado na Tabela 8.

Tabela 8: Tempos de ciclo cenário A para Panamax

\begin{tabular}{|c|c|c|c|c|c|c|c|c|c|c|}
\hline Origem & $\begin{array}{l}\text { Fila por } \\
\text { berço }(\mathrm{h})\end{array}$ & $\begin{array}{c}\text { Falta de } \\
\text { Material (h) }\end{array} \mid$ & Carregando (h) & $\begin{array}{c}\text { Carregado aguardando } \\
\text { por barcaça (h) }\end{array}$ & $\begin{array}{l}\text { Percurso } \\
\text { Carregado (h) }\end{array}$ & $\begin{array}{c}\text { Tempo de } \\
\text { desmembramento (h) }\end{array}$ & $\begin{array}{c}\text { Tempo de espera } \\
\text { por berço }(\mathbf{h})\end{array}$ & $\begin{array}{c}\text { Tempo de } \\
\text { descarregamento }(\mathrm{h})\end{array}$ & \begin{tabular}{|c|} 
Percurso \\
Descarregado (h)
\end{tabular} & $\begin{array}{l}\text { Tempo totalde } \\
\text { ciclo (dias) }\end{array}$ \\
\hline \multicolumn{11}{|c|}{ Tempo de Ciclo Agregado } \\
\hline Marabá & 50,0 & 75,0 & 18,3 & 0,8 & 30,8 & 1,7 & 35,8 & 18,3 & 84,2 & 13,1 \\
\hline Porto Velho & 63,3 & 40,0 & 20,0 & 0,8 & 136,7 & 1,7 & 38,3 & 17,5 & 409,2 & 30,3 \\
\hline Miritituba & 26,7 & 2,5 & 17,5 & 0,8 & 61,7 & 1,7 & 38,3 & 16,7 & 174,2 & 14,2 \\
\hline \multicolumn{11}{|c|}{ Tempo de Ciclo durante o Regime de Seca } \\
\hline Marabá & 23,3 & 61,7 & 19,2 & 0,8 & 27,5 & 1,7 & 25,0 & 17,5 & 75,8 & 1,0 \\
\hline Porto Velho & 17,5 & 29,2 & 17,5 & 0,8 & 130,8 & 1,7 & 25,0 & 15,0 & 367,5 & 0,7 \\
\hline Miritituba & 10,8 & 0,0 & 15,8 & 0,8 & 55,8 & 1,7 & 24,2 & 15,8 & 180,0 & 0,5 \\
\hline \multicolumn{11}{|c|}{ Tempo de Ciclo durante o Regime de Cheia } \\
\hline Marabá & 50,0 & 74,2 & 19,2 & 0,8 & 30,8 & 1,7 & 44,2 & 18,3 & 85,8 & 2,1 \\
\hline Porto Velho & 62,5 & 38,3 & 20,0 & 0,8 & 137,5 & 1,7 & 45,0 & 17,5 & 413,3 & 2,6 \\
\hline Miritituba & 26,7 & 2,5 & 17,5 & 0,8 & 63,3 & 1,7 & 45,0 & 16,7 & 175,8 & 1,1 \\
\hline
\end{tabular}

Fonte: o Autor 
E, finalizando essa coleta de dados de ciclos, tem-se para o mix de navios Panamax e Handymax os dados descritos na Tabela 9.

Tabela 9: Tempos de ciclo cenário A para o mix Panamax e Handymax

\begin{tabular}{|c|c|c|c|c|c|c|c|c|c|c|}
\hline Origem & $\begin{array}{l}\text { Fila por } \\
\text { berço (h) }\end{array}$ & \begin{tabular}{|c} 
Falta de \\
Material (h)
\end{tabular} & Carregando (h) & $\begin{array}{c}\text { Carregado aguardando } \\
\text { por barcaça (h) }\end{array}$ & $\begin{array}{l}\text { Percurso } \\
\text { Carregado (h) }\end{array}$ & $\begin{array}{c}\text { Tempo de } \\
\text { desmembramento (h) }\end{array}$ & $\begin{array}{c}\text { Tempo de espera } \\
\text { por berço }(\mathrm{h})\end{array}$ & $\begin{array}{c}\text { Tempo de } \\
\text { descarregamento (h) }\end{array}$ & $\begin{array}{c}\text { Percurso } \\
\text { Descarregado (h) }\end{array}$ & $\begin{array}{l}\text { Tempo totalde } \\
\text { ciclo (dias) }\end{array}$ \\
\hline \multicolumn{11}{|c|}{ Tempo de Ciclo Agregado } \\
\hline Marabá & 60,0 & 56,7 & 18,3 & 0,8 & 30,8 & 1,7 & 48,3 & 19,2 & 85,8 & 13,4 \\
\hline Porto Velho & 55,8 & 30,0 & 20,0 & 0,8 & 140,0 & 1,7 & 50,0 & 18,3 & 406,7 & 30,1 \\
\hline Miritituba & 15,8 & 1,7 & 17,5 & 0,8 & 62,5 & 1,7 & 52,5 & 18,3 & 173,3 & 14,3 \\
\hline \multicolumn{11}{|c|}{ Tempo de Ciclo durante o Regime de Seca } \\
\hline Marabá & 15,0 & 53,3 & 20,0 & 0,8 & 29,2 & 1,7 & 23,3 & 17,5 & 75,0 & 9,8 \\
\hline Porto Velho & 10,8 & 20,0 & 17,5 & 0,8 & 123,3 & 1,7 & 23,3 & 15,8 & 401,7 & 25,6 \\
\hline Miritituba & 7,5 & \#VALOR! & 15,8 & 0,8 & 58,3 & 1,7 & 19,2 & 13,3 & 163,3 & 11,7 \\
\hline \multicolumn{11}{|c|}{ Tempo de Ciclo durante o Regime de Cheia } \\
\hline Marabá & 58,3 & 51,7 & 18,3 & 0,8 & 29,2 & 1,7 & 63,3 & 19,2 & 86,7 & 13,7 \\
\hline Porto Velho & 59,2 & 31,7 & 20,0 & 0,8 & 138,3 & 1,7 & $\frac{05,0}{65,0}$ & 18,3 & 414,2 & 31,2 \\
\hline Miritituba & 15,8 & 1,7 & 17,5 & 0,8 & 62,5 & 1,7 & 67,5 & 18,3 & 177,5 & 15,1 \\
\hline
\end{tabular}

Fonte: o Autor

Observa-se para este cenário que a frota, Tabela 10, de veículos terrestres é pequena quando comparada aos cenários em que as restrições da hidrovia e da oferta de produtos estão presentes. Existe um trade-off claro entre a disponibilidade da carga $\mathrm{x}$ a curva de sazonalidade $\mathrm{x}$ restrições da hidrovia. Quando as restrições são retiradas, o reflexo se dá, principalmente, na frota de veículos terrestres para realizar o transporte, pois as restrições de armazenagem e capacidade de transporte dos comboios são reduzidas.

Tabela 10: Frota de caminhões - Cenário A

\begin{tabular}{|l|c|c|c|c|c|c|c|c|c|c|c|c|c|c|c|}
\hline \multicolumn{1}{|c|}{ Origem } & Janeiro & Fevereiro & Março & Abril & Maio & Junho & Julho & Agosto & Setembro & Outubro & Novembro & Dezembro \\
\hline \multicolumn{8}{|c|}{ Frota utilizada para Handymax } \\
\hline Marabá & 0 & 0 & 63 & 300 & 60 & 58 & 59 & 58 & 58 & 60 & 58 & 60 \\
\hline Vila do Conde & 0 & 0 & 1039 & 587 & 640 & 660 & 868 & 523 & 0 & 0 & 0 & 0 \\
\hline Porto Velho & 0 & 218 & 241 & 457 & 497 & 360 & 527 & 385 & 493 & 269 & 220 & 225 \\
\hline Miritituba & 0 & 860 & 1218 & 2540 & 3012 & 3297 & 3407 & 3495 & 3583 & 3392 & 3340 & 3285 \\
\hline \multicolumn{8}{|c|}{ Frota utilizada para Panamax } \\
\hline Marabá & 0 & 0 & 63 & 178 & 271 & 58 & 295 & 227 & 58 & 59 & 58 & 59 \\
\hline Vila do Conde & 0 & 0 & 820 & 1457 & 525 & 908 & 853 & 428 & 0 & 0 & 0 & 0 \\
\hline Porto Velho & 0 & 217 & 242 & 222 & 689 & 478 & 518 & 568 & 568 & 448 & 364 & 417 \\
\hline Miritituba & 0 & 862 & 1193 & 2258 & 3357 & 3578 & 4168 & 4385 & 4210 & 4545 & 4372 & 4252 \\
\hline
\end{tabular}

Fonte: o Autor

Para ver o comportamento dos estoques intermediários e final no sistema de abastecimento de grãos, é necessário plotar o gráfico desses silos, mostrado na Figura 50. 


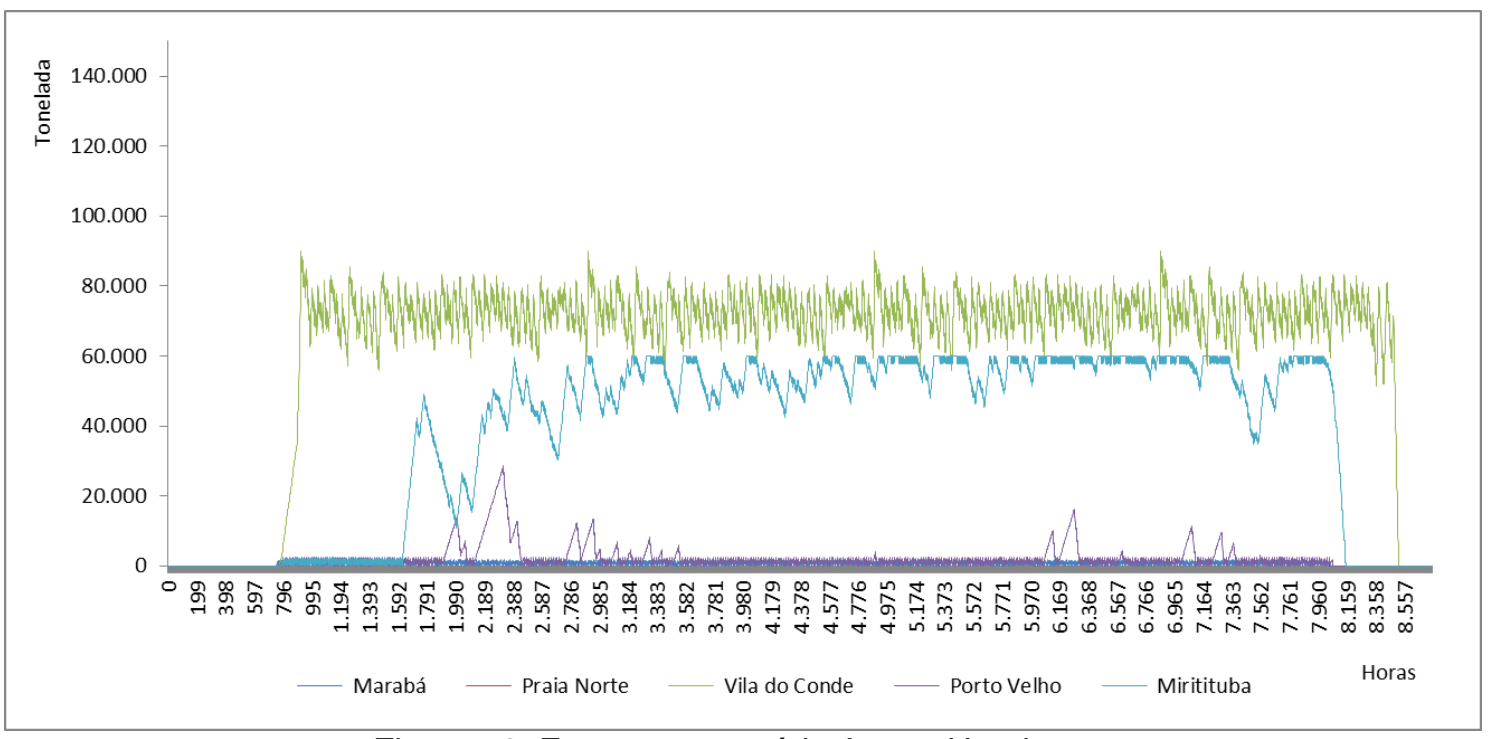

Figura 50: Estoques - cenário A com Handymax

Fonte: o Autor

Para o cenário de frota de navios do tipo Panamax, o comportamento dos estoques ao longo da simulação foi semelhante, porém a média foi um pouco superior, já que é necessário esperar mais por navios, pois com um navio maior, o número de embarcações é reduzido, Figura 51.

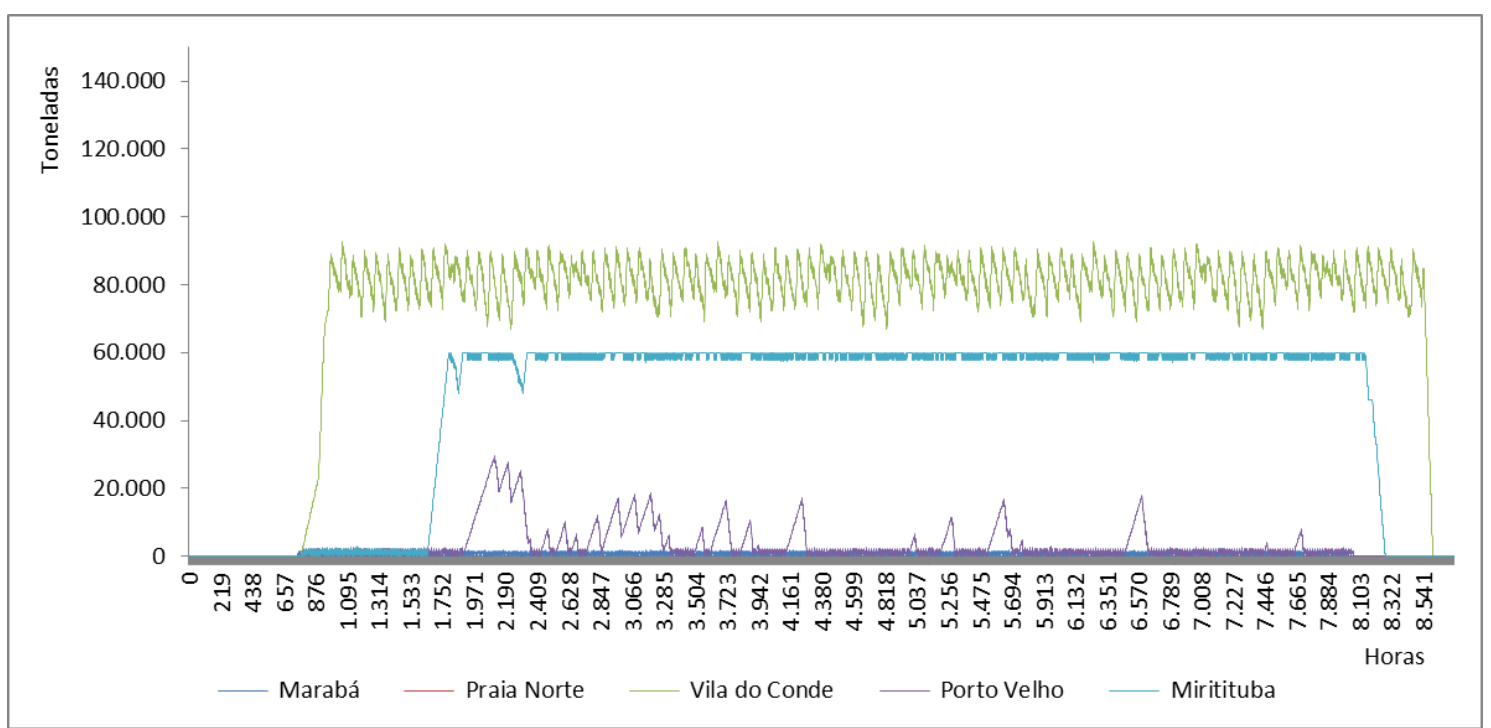

Figura 51: Estoques - cenário A com Panamax

Fonte: o Autor 
No entanto, o comportamento dos estoques quando se tem um mix na frota de navios é diferente dos observados anteriormente, isso se deve pela espera maior por navios e também pelo tamanho dos navios, Figura 52.

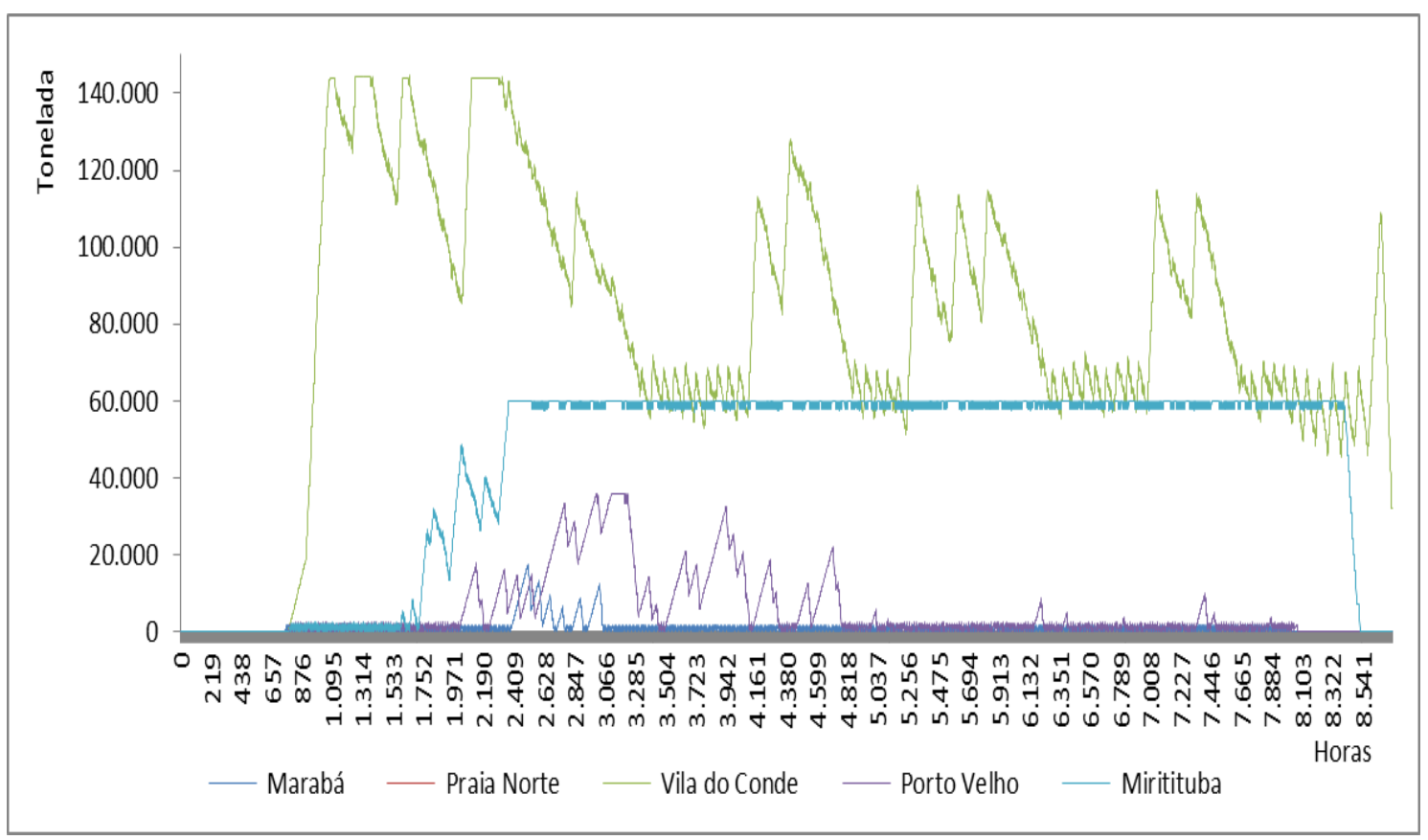

Figura 52: Estoques - cenário A com mix de navios Fonte: o Autor

\subsection{CENÁRIO B}

Este cenário é também para capacidade de $5 \mathrm{Mtpa}$. No entanto, foi adicionada a restrição de variação de capacidade de transporte dos comboios nas hidrovias, ou seja, agora a cota do nível d'água nos rios utilizados para o transporte de grãos influencia diretamente na quantidade que será transportada, bem como na velocidade dos comboios. Contudo, continua sem sazonalidade nas fazendas produtoras de grãos, deixando a oferta de grãos constante ao longo do ano.

A Tabela 11 apresenta, assim como no cenário anterior, os principais resultados obtidos na simulação do cenário $B$. 
Tabela 11: Resumo do cenário $B$

\begin{tabular}{|c|c|c|c|c|c|c|c|c|c|}
\hline \multirow[b]{2}{*}{ Origem } & \multirow[b]{2}{*}{$\begin{array}{c}\text { Frota de } \\
\text { Barcaças (\#) }\end{array}$} & \multirow[b]{2}{*}{$\begin{array}{c}\text { Ciclo das } \\
\text { Barcaças (Dias) }\end{array}$} & \multirow[b]{2}{*}{ Ociosidade (Dias) } & \multirow[b]{2}{*}{ Carga Total (t) } & \multirow[b]{2}{*}{$\begin{array}{l}\text { Ocupação das } \\
\text { Barcaças (\%) }\end{array}$} & \multirow[b]{2}{*}{$\begin{array}{c}\text { Ocupação dos } \\
\text { Navios (\%) }\end{array}$} & \multirow[b]{2}{*}{$\begin{array}{l}\text { Ocupação das } \\
\text { Barcaças (\%) }\end{array}$} & \multicolumn{2}{|c|}{ Número médio em Fila } \\
\hline & & & & & & & & Navios (\#) & Barcaças (\#) \\
\hline \multicolumn{10}{|c|}{ Cenário 1 - Handymax } \\
\hline Marabá & 5 & 22,5 & 8,3 & 841.500 & 72,5 & - & - & - & - \\
\hline Miritituba & 14 & 18,9 & 2,8 & 2.504 .750 & 43,8 & - & - & - & - \\
\hline Porto Velho & 8 & 32,8 & 3,0 & 833.865 & 63,8 & - & - & - & - \\
\hline Vila do Conde & - & - & - & 833.333 & - & 73,3 & 76,2 & 2,8 & 5,7 \\
\hline & Navio Atendidos: & 143 & Total: & 5.013 .448 & & & & & \\
\hline \multicolumn{10}{|c|}{ Cenário 2 - Panamax } \\
\hline Marabá & 5 & 22,2 & 8,3 & 841.500 & 71,5 & - & - & - & - \\
\hline Miritituba & 14 & 19,2 & 2,7 & 2.504 .750 & 42,3 & - & - & - & - \\
\hline Porto Velho & 8 & 32,8 & 2,8 & 833.865 & 61,4 & - & - & - & - \\
\hline \begin{tabular}{|l|} 
Vila do Conde \\
\end{tabular} & - & - & - & 833.333 & - & 71,5 & 77,1 & 1,7 & 6,1 \\
\hline & Navio Atendidos: & 77 & Total: & 5.013 .448 & & & & & \\
\hline \multicolumn{10}{|c|}{ Cenário 3 - 80\% Panamax / 20\% Capesize } \\
\hline Marabá & 5 & 22,6 & 7,4 & 841.500 & 67,0 & - & - & - & - \\
\hline Miritituba & 14 & 19,3 & 2,0 & 2.504 .750 & 35,2 & - & - & - & - \\
\hline Porto Velho & 8 & 32,8 & 1,9 & 833.865 & 58,6 & - & - & - & - \\
\hline Vila do Conde & - & - & - & 833.363 & - & 71,1 & 79,3 & 1,7 & 7,0 \\
\hline \multicolumn{2}{|r|}{ Navio Atendidos: } & 71 & Total: & 5.013 .478 & & & & & \\
\hline
\end{tabular}

Fonte: o Autor

Cabe ressaltar que, neste cenário, pela adição da restrição das hidrovias, houve a necessidade de adicionar mais comboios ao sistema, onde eram 3, 11 e 7 agora são 6, 17 e 9 para Marabá, Miritituba e Porto Velho, respectivamente.

Note também que os tempos de ciclo nestes cenários são maiores que dos cenários anteriores devido à mudança nas hidrovias.

Com relação aos tempos de ciclos das barcaças utilizadas nesse conjunto de cenários, podem ser observados com relação à frota de navios do tipo Handymax, Panamax e mix entre Panamax e Capesize, nas Tabela 12, Tabela 13 e Tabela 14, respectivamente.

Tabela 12: Tempos de ciclo cenário B para Handymax

\begin{tabular}{|c|c|c|c|c|c|c|c|c|c|c|}
\hline Origem & $\begin{array}{l}\text { Fila por } \\
\text { berço (h) }\end{array}$ & $\begin{array}{c}\text { Falta de } \\
\text { Material (h) }\end{array}$ & Carregando $(\mathrm{h})$ & $\begin{array}{c}\text { Carregado aguardando } \\
\text { por barcaça (h) }\end{array}$ & $\begin{array}{c}\text { Percurso } \\
\text { Carregado (h) }\end{array}$ & $\begin{array}{c}\text { Tempo de } \\
\text { desmembramento (h) }\end{array}$ & $\begin{array}{c}\text { Tempo de espera } \\
\text { por berço (h) }\end{array}$ & $\begin{array}{c}\text { Tempo de } \\
\text { descarregamento }(\mathrm{h})\end{array}$ & \begin{tabular}{|c|} 
Percurso \\
Descarregado (h)
\end{tabular} & $\begin{array}{l}\text { Tempo totalde } \\
\text { ciclo (dias) }\end{array}$ \\
\hline \multicolumn{11}{|c|}{ Tempo de Ciclo Agregado } \\
\hline Marabá & 199,2 & 72,5 & 15,8 & 0,0 & 31,7 & $\begin{array}{r}1,7 \\
\end{array}$ & 123,3 & 15,8 & 80,8 & 22,5 \\
\hline \begin{tabular}{|l|} 
Porto Velho \\
\end{tabular} & 71,7 & 34,2 & 16,7 & 0,0 & 143,3 & 1,7 & 111,7 & 16,7 & 390,8 & 32,8 \\
\hline Miritituba & 66,7 & 4,2 & 15,8 & 0,0 & 63,3 & \begin{tabular}{|l|}
1,7 \\
\end{tabular} & 116,7 & 15,8 & 170,0 & 18,9 \\
\hline \multicolumn{11}{|c|}{ Tempo de Ciclo durante o Regime de Seca } \\
\hline Marabá & 88,3 & 38,3 & 12,5 & 0,0 & 30,8 & \begin{tabular}{|c|}
1,7 \\
\end{tabular} & 48,3 & 12,5 & 74,2 & 12,8 \\
\hline Porto Velho & 0,8 & 0,0 & 7,5 & 0,0 & 147,5 & 1,7 & 16,7 & 6,7 & 350,0 & 22,2 \\
\hline Miritituba & 9,2 & 0,0 & 8,3 & 0,0 & 66,7 & 1,7 & 16,7 & 7,5 & 161,7 & 11,3 \\
\hline \multicolumn{11}{|c|}{ Tempo de Ciclo durante o Regime de Cheia } \\
\hline Marabá & 200,8 & 78,3 & 16,7 & 0,0 & 30,8 & 1,7 & 176,7 & 15,8 & 83,3 & 25,2 \\
\hline Porto Velho & 74,2 & 42,5 & 19,2 & 0,0 & 139,2 & 1,7 & 146,7 & 18,3 & 422,5 & 36,1 \\
\hline Miritituba & 69,2 & 5,0 & 16,7 & 0,0 & 62,5 & 1,7 & 154,2 & 17,5 & 177,5 & 21,0 \\
\hline
\end{tabular}

Fonte: o Autor 
Tabela 13: Tempos de ciclo cenário B para Panamax

\begin{tabular}{|c|c|c|c|c|c|c|c|c|c|c|}
\hline Origem & $\begin{array}{l}\text { Fila por } \\
\text { berço }(h)\end{array}$ & $\left|\begin{array}{c}\text { Falta de } \\
\text { Material (h) }\end{array}\right|$ & Carregando $(\mathrm{h})$ & $\begin{array}{c}\text { Carregado aguardando } \\
\text { por barcaça }(\mathrm{h})\end{array}$ & $\begin{array}{l}\text { Percurso } \\
\text { Carregado (h) }\end{array}$ & $\begin{array}{c}\text { Tempo de } \\
\text { desmembramento }(\mathrm{h})\end{array}$ & $\begin{array}{c}\text { Tempo de espera } \\
\text { por berço }(\mathrm{h})\end{array}$ & $\begin{array}{c}\text { Tempo de } \\
\text { descarregamento }(h)\end{array}$ & \begin{tabular}{|c|} 
Percurso \\
Descarregado (h)
\end{tabular} & $\begin{array}{l}\text { Tempo totalde } \\
\text { ciclo (dias) }\end{array}$ \\
\hline \multicolumn{11}{|c|}{ Tempo de Ciclo Agregado } \\
\hline Marabá & 198,3 & 59,2 & 15,8 & 0,0 & 30,8 & \begin{tabular}{|r|}
1,7 \\
\end{tabular} & 130,8 & 15,0 & 80,8 & 22,2 \\
\hline \begin{tabular}{|l} 
Porto Velho \\
\end{tabular} & 68,3 & 32,5 & 16,7 & 0,0 & 141,7 & 1,7 & 116,7 & 16,7 & 391,7 & 32,8 \\
\hline \begin{tabular}{|l|} 
Miritituba \\
\end{tabular} & 65,0 & 4,2 & 15,0 & 0,0 & 62,5 & \begin{tabular}{c|}
1,7 \\
\end{tabular} & 123,3 & 15,8 & 172,5 & 19,2 \\
\hline \multicolumn{11}{|c|}{ Tempo de Ciclo durante o Regime de Seca } \\
\hline Marabá & 60,0 & 34,2 & 11,7 & 0,0 & 28,3 & \begin{tabular}{|c|}
1,7 \\
\end{tabular} & 44,2 & 11,7 & 75,0 & 11,1 \\
\hline Porto Velho & 1,7 & 0,8 & 7,5 & 0,0 & 145,0 & 1,7 & 19,2 & 7,5 & 363,3 & 22,8 \\
\hline Miritituba & 6,7 & 0,0 & 7,5 & 0,0 & 65,0 & 1,7 & 20,8 & 7,5 & 156,7 & 11,1 \\
\hline \multicolumn{11}{|c|}{ Tempo de Ciclo durante o Regime de Cheia } \\
\hline Marabá & 214,2 & 65,0 & 15,8 & 0,0 & 30,8 & 1,7 & 174,2 & 15,0 & 84,2 & 25,1 \\
\hline Porto Velho & 73,3 & 44,2 & 18,3 & 0,0 & 138,3 & 1,7 & 145,8 & 19,2 & 410,8 & 35,6 \\
\hline Miritituba & 66,7 & 4,2 & 17,5 & 0,0 & 60,8 & 1,7 & 160,0 & 16,7 & 180,8 & 21,3 \\
\hline
\end{tabular}

Fonte: o Autor

Tabela 14: Tempos de ciclo cenário B para o mix de navios

\begin{tabular}{|c|c|c|c|c|c|c|c|c|c|c|}
\hline Origem & $\begin{array}{l}\text { Fila por } \\
\text { berço (h) }\end{array}$ & $\begin{array}{c}\text { Falta de } \\
\text { Material (h) }\end{array}$ & Carregando (h) & $\begin{array}{c}\text { Carregado aguardando } \\
\text { por barcaça }(\mathrm{h})\end{array}$ & $\begin{array}{c}\text { Percurso } \\
\text { Carregado (h) }\end{array}$ & $\begin{array}{c}\text { Tempo de } \\
\text { desmembramento (h) }\end{array}$ & $\begin{array}{c}\text { Tempo de espera } \\
\text { por berço (h) }\end{array}$ & $\begin{array}{c}\text { Tempo de } \\
\text { descarregamento (h) }\end{array}$ & $\begin{array}{c}\text { Percurso } \\
\text { Descarregado (h) }\end{array}$ & $\begin{array}{l}\text { Tempo totalde } \\
\text { ciclo (dias) }\end{array}$ \\
\hline \multicolumn{11}{|c|}{ Tempo de Ciclo Agregado } \\
\hline Marabá & 178,3 & 65,8 & 15,8 & 0,0 & 30,8 & 1,7 & 151,7 & 16,7 & 80,8 & 22,6 \\
\hline Porto Velho & 46,7 & 23,3 & 16,7 & 0,0 & 144,2 & 1,7 & 141,7 & 17,5 & 394,2 & 32,8 \\
\hline \begin{tabular}{|l|} 
Miritituba \\
\end{tabular} & 48,3 & 3,3 & 15,8 & 0,0 & 62,5 & 1,7 & 143,3 & 16,7 & 171,7 & 19,3 \\
\hline \multicolumn{11}{|c|}{ Tempo de Ciclo durante o Regime de Seca } \\
\hline Marabá & 66,7 & 27,5 & 11,7 & 0,0 & 30,8 & 1,7 & 50,8 & 10,8 & 70,8 & 11,3 \\
\hline Porto Velho & 0,8 & 0,0 & 6,7 & 0,0 & 140,0 & 1,7 & 21,7 & 7,5 & 357,5 & 22,4 \\
\hline Miritituba & 5,0 & 0,0 & 7,5 & 0,0 & 65,0 & 1,7 & 17,5 & 7,5 & 170,0 & 11,5 \\
\hline \multicolumn{11}{|c|}{ Tempo de Ciclo durante o Regime de Cheia } \\
\hline Marabá & 183,3 & 72,5 & 16,7 & 0,0 & 30,0 & 1,7 & 205,0 & 17,5 & 82,5 & 25,4 \\
\hline Porto Velho & 47,5 & 29,2 & 19,2 & 0,0 & 141,7 & 1,7 & 185,8 & 20,0 & 422,5 & 36,2 \\
\hline Miritituba & 51,7 & 4,2 & 17,5 & 0,0 & 62,5 & 1,7 & 190,8 & 18,3 & 180,8 & 22,0 \\
\hline
\end{tabular}

Fonte: o Autor

No caso da frota de veículos rodoviários, pode-se observar que há um considerável aumento no número de caminhões utilizados para transportar a mesma quantidade de grãos do cenário anterior, Tabela 15.

Tabela 15: Frota de caminhões - Cenário B

\begin{tabular}{|l|c|c|c|c|c|c|c|c|c|c|c|c|c|c|c|}
\hline \multicolumn{1}{|c|}{ Origem } & Janeiro & Fevereiro & Março & Abril & Maio & Junho & Julho & Agosto & Setembro & Outubro & Novembro & Dezembro \\
\hline \multicolumn{8}{|c|}{ Frota utilizada para Handymax } \\
\hline Marabá & 0 & 0 & 63 & 58 & 60 & 58 & 218 & 693 & 330 & 59 & 58 & 59 \\
\hline Vila do Conde & 0 & 0 & 1043 & 568 & 832 & 691 & 827 & 542 & 0 & 0 & 0 & 0 \\
\hline Porto Velho & 0 & 218 & 240 & 223 & 225 & 218 & 225 & 790 & 1537 & 2197 & 2143 & 1408 \\
\hline Miritituba & 0 & 859 & 948 & 945 & 975 & 1506 & 1952 & 3747 & 4718 & 5694 & 4124 & 2840 \\
\hline \multicolumn{8}{|c|}{ Frota utilizada para Panamax } \\
\hline Marabá & 0 & 0 & 64 & 58 & 59 & 58 & 60 & 697 & 868 & 165 & 58 & 60 \\
\hline Vila do Conde & 0 & 0 & 945 & 1058 & 862 & 741 & 822 & 1294 & 0 & 0 & 0 & 0 \\
\hline Porto Velho & 0 & 218 & 242 & 221 & 227 & 378 & 225 & 805 & 1697 & 2203 & 1900 & 1472 \\
\hline Miritituba & 0 & 860 & 1117 & 1540 & 2053 & 2045 & 2144 & 4142 & 5520 & 6362 & 4973 & 3920 \\
\hline
\end{tabular}

Fonte: o Autor

Assim como no cenário anterior, é necessário plotar o gráfico de comportamento dos silos ao longo do sistema para ter uma melhor visualização desses estoques ao longo da simulação, Figura 53. 


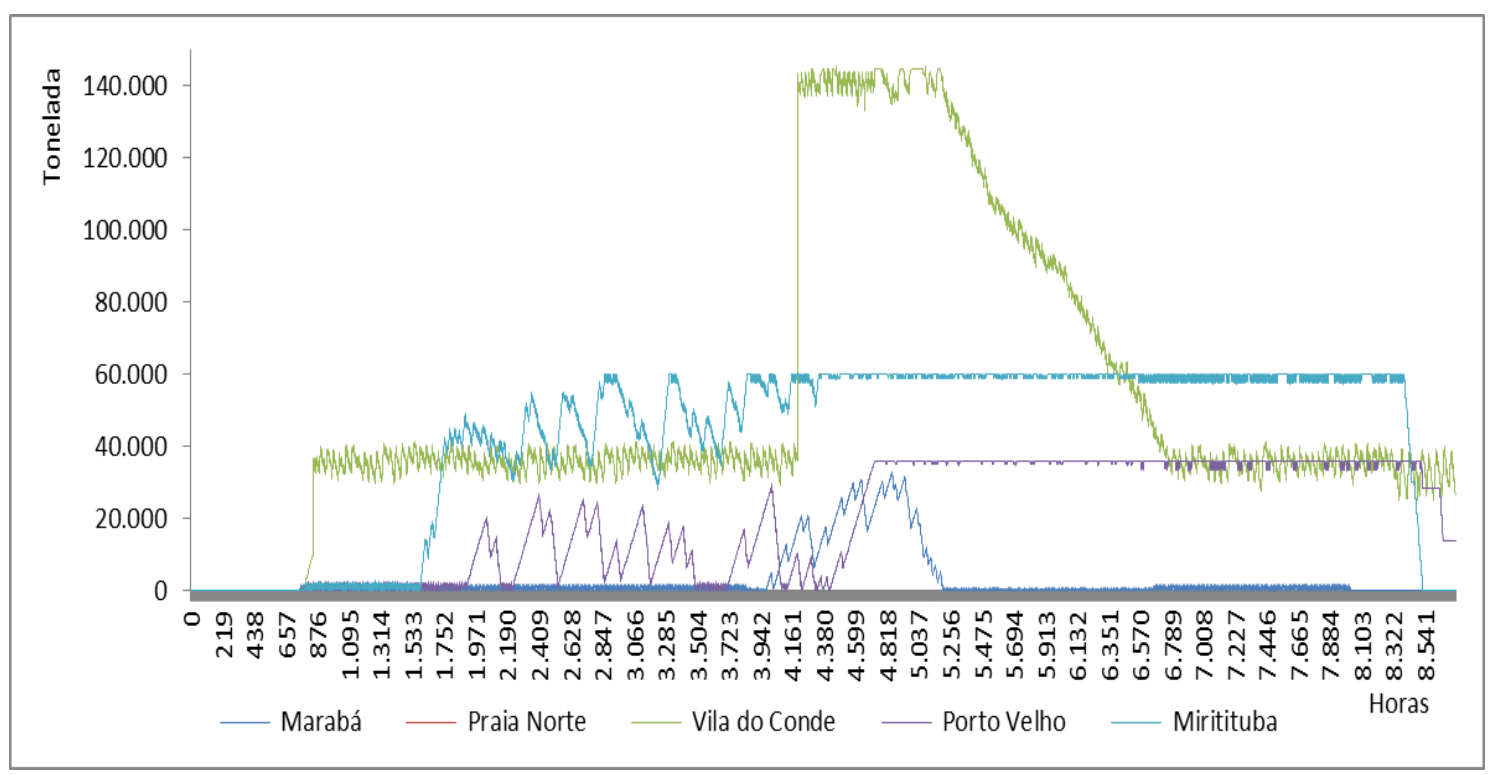

Figura 53: Estoques - cenário B com Handymax

Fonte: o Autor

Note que diferentemente do cenário $\mathrm{A}$, com o mesmo tipo de navio, agora se tem um pico na utilização do silo em Vila do Conde. Isso se dá devido à sazonalidade imposta pela hidrovia no transporte dos comboios.

No caso do cenário para navios do tipo Panamax, pode-se observar o comportamento na Figura 54.

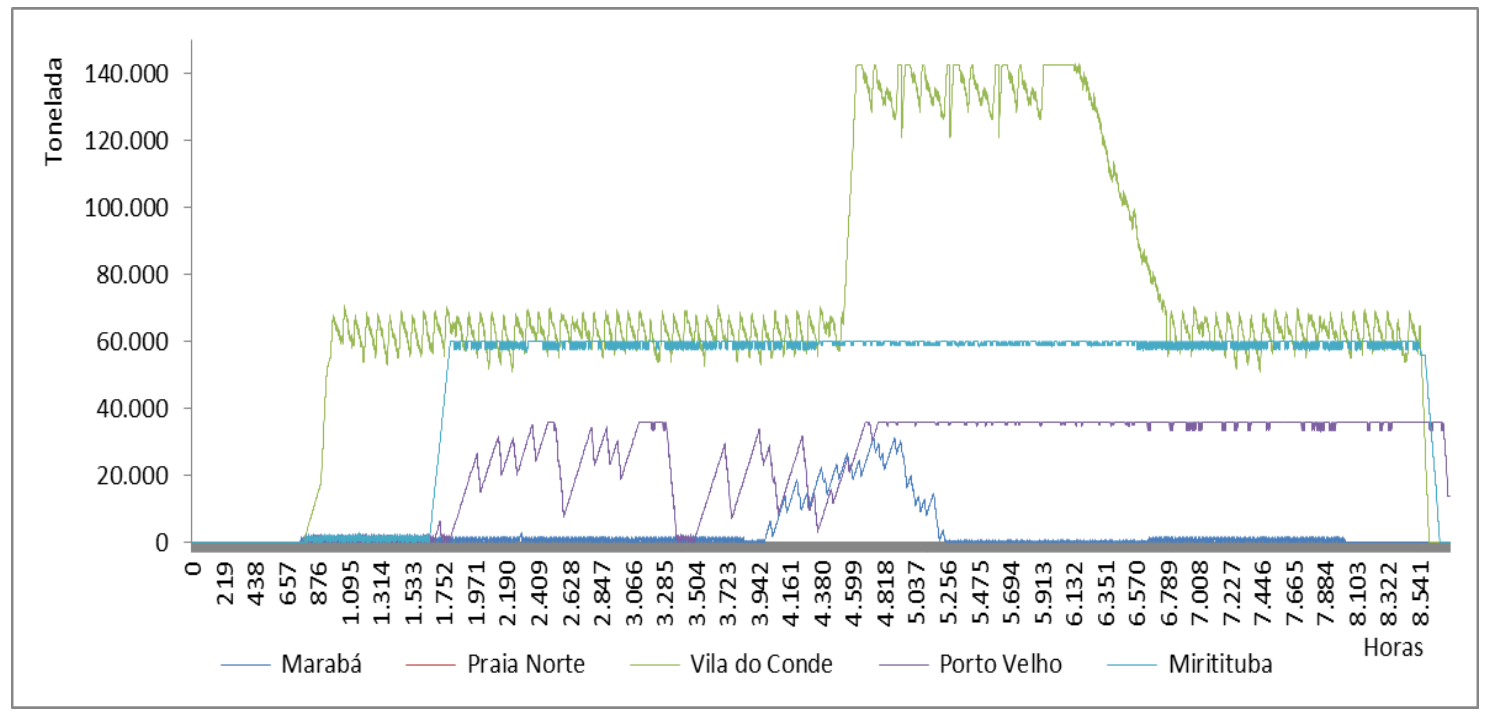

Figura 54: Estoques - cenário B com Panamax Fonte: o Autor

Em seguida, para o cenário do mix de navios com Panamax e Capesize, observa-se o comportamento como mostrado na Figura 55. 


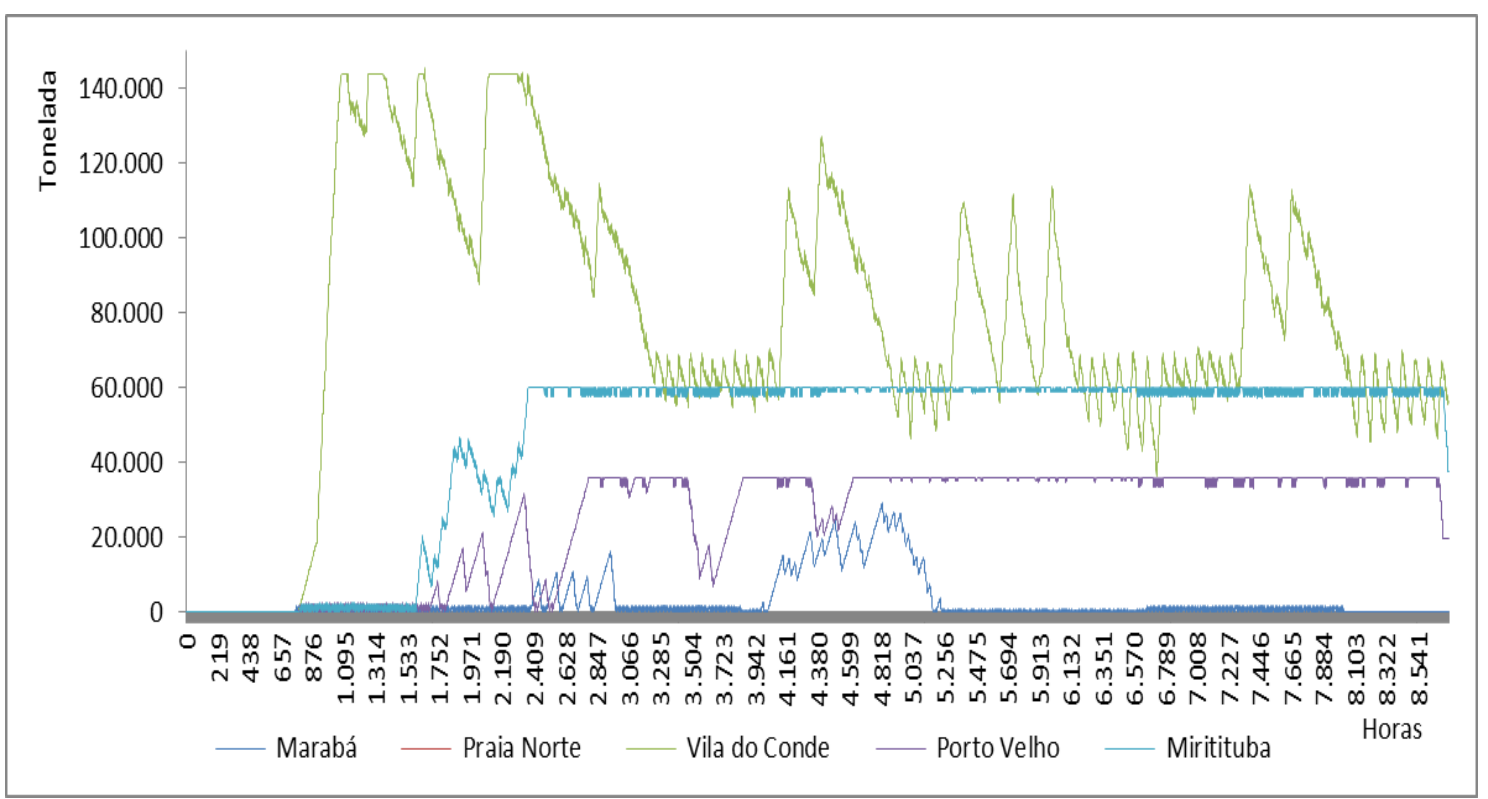

Figura 55: Estoques - cenário $B$ com mix de navios Fonte: o Autor

Cabe salientar que, no caso deste cenário, a frota de navios variando de tamanho acaba mitigando o fator sazonal das hidrovias para o silo em Vila do Conde.

\subsection{CENÁRIO C}

Neste cenário, diferentemente do anterior (B), não há restrição das cotas de nível d'água das hidrovias, porém foi adicionada a sazonalidade na produção de carga nas fazendas, com a demanda sendo de $5 \mathrm{Mtpa}$.

A Tabela 16 apresenta o resumo do cenário $C$. Pode-se observar que os tempos de ciclos das barcaças são maiores que os cenários anteriores, isso se dá devido ao fator sazonal da produção de grãos pelas fazendas. 
Tabela 16: Resumo do cenário C

\begin{tabular}{|c|c|c|c|c|c|c|c|c|c|}
\hline & & & & & & & & Número $\mathrm{m}$ & dio em Fila \\
\hline Origem & $\begin{array}{c}\text { Frota de } \\
\text { Barcaças (\#) }\end{array}$ & $\begin{array}{c}\text { Ciclo das } \\
\text { Barcaças (Dias) }\end{array}$ & Ociosidade (Dias) & Carga Total (t) & $\begin{array}{c}\text { Ocupação das } \\
\text { Barcaças (\%) }\end{array}$ & $\begin{array}{c}\text { Ocupação dos } \\
\text { Navios (\%) }\end{array}$ & $\begin{array}{c}\text { Ocupação das } \\
\text { Barcaças (\%) }\end{array}$ & Navios (\#) & Barcaças (\#) \\
\hline \multicolumn{10}{|c|}{ Cenário 1 - Handymax } \\
\hline Marabá & 5 & 31,6 & 15,5 & 841.500 & 59,2 & - & - & - & - \\
\hline Miritituba & 14 & 23,0 & 4,7 & 2.504 .750 & 64,6 & - & - & - & - \\
\hline Porto Velho & 8 & 39,2 & 6,3 & 833.865 & 50,8 & - & - & - & - \\
\hline Vila do Conde & - & - & - & 833.333 & - & 69,2 & 73,5 & 4,3 & 7,2 \\
\hline \multicolumn{2}{|r|}{ Navio Atendidos: } & 143 & Total: & 5.013 .448 & & & & & \\
\hline \multicolumn{10}{|c|}{ Cenário 2 - Panamax } \\
\hline Marabá & 5 & 32,6 & 16,5 & 841.500 & 59,4 & - & - & - & - \\
\hline Miritituba & 14 & 23,3 & 5,4 & 2.504 .750 & 65,3 & - & - & - & - \\
\hline Porto Velho & 8 & 39,4 & 6,6 & 833.865 & 55,2 & - & - & - & - \\
\hline Vila do Conde & - & - & - & 833.333 & - & 66,8 & 73,3 & 1,9 & 6,7 \\
\hline \multicolumn{2}{|r|}{ Navio Atendidos: } & 77 & Total: & 5.013 .448 & & & & & \\
\hline \multicolumn{10}{|c|}{ Cenário 3 - $80 \%$ Panamax / 20\% Capesize } \\
\hline Marabá & 5 & 32,6 & 16,1 & 841.500 & 61,6 & - & - & - & - \\
\hline Miritituba & 14 & 22,8 & 4,5 & 2.504 .750 & 65,3 & - & - & - & - \\
\hline Porto Velho & 8 & 38,6 & 5,5 & 833.865 & 52,5 & - & - & - & - \\
\hline Vila do Conde & - & - & 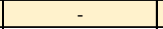 & 833.363 & - & 70,3 & 74,8 & 1,4 & 7,3 \\
\hline \multicolumn{2}{|r|}{ Navio Atendidos: } & 71 & Total: & 5.013 .478 & & & & & \\
\hline
\end{tabular}

Fonte: o Autor

Assim como no cenário anterior (B), o número de comboios foi aumentado devido à restrição da sazonalidade na criação da carga que deverá passar pelo sistema.

Pode-se observar também os tempos de ciclos das barcaças agregados em regime de seca e regime de cheia dos rios nas Tabela 17, Tabela 18 e Tabela 19 , respectivamente.

Tabela 17: Tempos de ciclo cenário $C$ para Handymax

\begin{tabular}{|c|c|c|c|c|c|c|c|c|c|c|}
\hline Origem & $\begin{array}{l}\text { Fila por } \\
\text { berço (h) }\end{array}$ & $\begin{array}{c}\text { Falta de } \\
\text { Material (h) }\end{array}$ & Carregando (h) & $\begin{array}{c}\text { Carregado aguardando } \\
\text { por barcaça }(\mathrm{h})\end{array}$ & $\begin{array}{c}\text { Percurso } \\
\text { Carregado (h) }\end{array}$ & $\begin{array}{c}\text { Tempo de } \\
\text { desmembramento }(h)\end{array}$ & $\begin{array}{c}\text { Tempo de espera } \\
\text { por berço (h) }\end{array}$ & $\begin{array}{c}\text { Tempo de } \\
\text { descarregamento }(\mathrm{h})\end{array}$ & \begin{tabular}{|c|} 
Percurso \\
Descarregado (h)
\end{tabular} & $\begin{array}{l}\text { Tempo totalde } \\
\text { ciclo (dias) }\end{array}$ \\
\hline \multicolumn{11}{|c|}{ Tempo de Ciclo Agregado } \\
\hline Marabá & 371,7 & 76,7 & 18,3 & 0,0 & 30,0 & \begin{tabular}{|r|}
1,7 \\
\end{tabular} & 156,7 & 17,5 & 84,2 & 31,6 \\
\hline Porto Velho & 151,7 & 49,2 & 20,0 & 0,0 & 140,0 & 1,7 & 152,5 & 18,3 & 406,7 & 39,2 \\
\hline Miritituba & 113,3 & 10,0 & 17,5 & 0,0 & 62,5 & \begin{tabular}{|l|}
1,7 \\
\end{tabular} & 154,2 & 16,7 & 175,0 & 23,0 \\
\hline \multicolumn{11}{|c|}{ Tempo de Ciclo durante o Regime de Seca } \\
\hline Marabá & 560,8 & 97,5 & 17,5 & 0,0 & 28,3 & \begin{tabular}{|c|}
1,7 \\
\end{tabular} & 111,7 & 15,8 & 77,5 & 38,0 \\
\hline Porto Velho & 25,0 & 26,7 & 17,5 & 0,0 & 125,0 & 1,7 & 87,5 & 15,0 & 380,0 & 28,3 \\
\hline Miritituba & 15,8 & 0,0 & 15,8 & 0,0 & 60,0 & 1,7 & 91,7 & 14,2 & 162,5 & 15,1 \\
\hline \multicolumn{11}{|c|}{ Tempo de Ciclo durante o Regime de Cheia } \\
\hline Marabá & 298,3 & 48,3 & 20,0 & 0,0 & 28,3 & 1,7 & 195,0 & 19,2 & 87,5 & 29,1 \\
\hline Porto Velho & 151,7 & 49,2 & 20,0 & 0,0 & 141,7 & 1,7 & 171,7 & 18,3 & 416,7 & 40,5 \\
\hline Miritituba & 110,8 & 10,0 & 17,5 & 0,0 & 62,5 & 1,7 & 175,0 & 16,7 & 179,2 & 23,9 \\
\hline
\end{tabular}

Fonte: o Autor

Tabela 18: Tempos de ciclo cenário B para Panamax

\begin{tabular}{|c|c|c|c|c|c|c|c|c|c|c|}
\hline Origem & $\begin{array}{l}\text { Fila por } \\
\text { berço (h) }\end{array}$ & \begin{tabular}{|c|} 
Falta de \\
Material (h)
\end{tabular} & Carregando (h) & $\begin{array}{c}\text { Carregado aguardando } \\
\text { por barcaça }(\mathrm{h})\end{array}$ & $\begin{array}{l}\text { Percurso } \\
\text { Carregado (h) }\end{array}$ & $\begin{array}{c}\text { Tempo de } \\
\text { desmembramento (h) }\end{array}$ & $\begin{array}{c}\text { Tempo de espera } \\
\text { por berço (h) }\end{array}$ & $\begin{array}{c}\text { Tempo de } \\
\text { descarregamento (h) }\end{array}$ & \begin{tabular}{|c|} 
Percurso \\
Descarregado (h)
\end{tabular} & $\begin{array}{l}\text { Tempo totalde } \\
\text { ciclo (dias) }\end{array}$ \\
\hline \multicolumn{11}{|c|}{ Tempo de Ciclo Agregado } \\
\hline Marabá & 396,7 & 83,3 & 18,3 & 0,0 & 30,0 & 1,7 & 148,3 & 18,3 & 84,2 & 32,6 \\
\hline Porto Velho & 157,5 & 55,8 & 20,0 & 0,0 & 137,5 & 1,7 & 145,0 & 17,5 & 409,2 & 39,4 \\
\hline Miritituba & 130,0 & 8,3 & 17,5 & 0,0 & 62,5 & 1,7 & 145,0 & 15,8 & 177,5 & 23,3 \\
\hline \multicolumn{11}{|c|}{ Tempo de Ciclo durante o Regime de Seca } \\
\hline Marabá & 636,7 & 180,8 & 18,3 & 0,0 & 28,3 & 1,7 & 105,0 & 18,3 & 79,2 & 44,5 \\
\hline Porto Velho & 65,0 & 53,3 & 17,5 & 0,0 & 130,0 & 1,7 & 81,7 & 15,8 & 383,3 & 31,2 \\
\hline Miritituba & 10,8 & \#VALOR! & 15,8 & 0,0 & 52,5 & \begin{tabular}{|l|}
1,7 \\
\end{tabular} & 90,0 & 13,3 & 170,0 & 14,8 \\
\hline \multicolumn{11}{|c|}{ Tempo de Ciclo durante o Regime de Cheia } \\
\hline Marabá & 296,7 & 51,7 & 19,2 & 0,0 & 30,8 & \begin{tabular}{|c|}
1,7 \\
\end{tabular} & 182,5 & 19,2 & 84,2 & 28,6 \\
\hline Porto Velho & 160,8 & 60,0 & 19,2 & 0,0 & 135,8 & 1,7 & 165,8 & 17,5 & 413,3 & 40,6 \\
\hline Miritituba & 131,7 & 8,3 & 17,5 & 0,0 & 64,2 & 1,7 & 163,3 & 16,7 & 180,8 & 24,3 \\
\hline
\end{tabular}

Fonte: o Autor 
Tabela 19: Tempos de ciclo cenário C para o mix de navios

\begin{tabular}{|c|c|c|c|c|c|c|c|c|c|c|}
\hline Origem & $\begin{array}{l}\text { Fila por } \\
\text { berço (h) }\end{array}$ & $\begin{array}{c}\text { Falta de } \\
\text { Material (h) }\end{array}$ & Carregando (h) & $\begin{array}{c}\text { Carregado aguardando } \\
\text { por barcaça (h) }\end{array}$ & $\begin{array}{c}\text { Percurso } \\
\text { Carregado (h) }\end{array}$ & $\begin{array}{c}\text { Tempo de } \\
\text { desmembramento (h) }\end{array}$ & $\begin{array}{c}\text { Tempo de espera } \\
\text { por berço (h) }\end{array}$ & $\begin{array}{c}\text { Tempo de } \\
\text { descarregamento }(\mathrm{h})\end{array}$ & \begin{tabular}{|c|} 
Percurso \\
Descarregado $(\mathrm{h})$
\end{tabular} & $\begin{array}{l}\text { Tempo totalde } \\
\text { ciclo (dias) }\end{array}$ \\
\hline \multicolumn{11}{|c|}{ Tempo de Ciclo Agregado } \\
\hline Marabá & 381,7 & 73,3 & 19,2 & 0,8 & 30,8 & \begin{tabular}{|r|}
1,7 \\
\end{tabular} & 187,5 & 19,2 & 83,3 & 33,2 \\
\hline Porto Velho & 142,5 & 43,3 & 20,0 & 0,8 & 140,8 & 1,7 & 180,0 & 19,2 & 405,0 & 39,7 \\
\hline \begin{tabular}{|l|} 
Miritituba \\
\end{tabular} & 100,0 & 5,8 & 17,5 & 0,8 & 62,5 & \begin{tabular}{|l|}
1,7 \\
\end{tabular} & 177,5 & 17,5 & 174,2 & 23,2 \\
\hline \multicolumn{11}{|c|}{ Tempo de Ciclo durante o Regime de Seca } \\
\hline Marabá & 570,0 & 85,8 & 18,3 & 0,8 & 28,3 & 1,7 & 165,8 & 23,3 & 76,7 & 40,5 \\
\hline \begin{tabular}{|l|} 
Porto Velho \\
\end{tabular} & 14,2 & 16,7 & 17,5 & 0,8 & 138,3 & 1,7 & 103,3 & 15,8 & 404,2 & 29,7 \\
\hline \begin{tabular}{|l|} 
Miritituba \\
\end{tabular} & 16,7 & \#VALOR! & 15,8 & 0,8 & 60,0 & \begin{tabular}{|l|}
1,7 \\
\end{tabular} & 107,5 & 14,2 & 161,7 & 15,7 \\
\hline \multicolumn{11}{|c|}{ Tempo de Ciclo durante o Regime de Cheia } \\
\hline Marabá & 317,5 & 48,3 & 19,2 & 0,8 & 31,7 & \begin{tabular}{|l|}
1,7 \\
\end{tabular} & 212,5 & 19,2 & 85,8 & 30,7 \\
\hline Porto Velho & 142,5 & 42,5 & 20,0 & 0,8 & 142,5 & 1,7 & 192,5 & 19,2 & 415,0 & 40,7 \\
\hline$\sqrt{\text { Miritituba }}$ & 99,2 & 5.8 & 175 & 0.8 & 62.5 & 17 & 190,0 & 175 & 1767 & 23,8 \\
\hline
\end{tabular}

Fonte: o Autor

Houve, assim como no cenário $B$, um aumento considerável na frota de caminhões necessária para fazer o carregamento completo da carga proposta.

Tabela 20: Frota de caminhões - Cenário C

\begin{tabular}{|l|c|c|c|c|c|c|c|c|c|c|c|c|c|c|c|}
\hline \multicolumn{1}{|c|}{ Origem } & Janeiro & Fevereiro & Março & Abril & Maio & Junho & Julho & Agosto & Setembro & Outubro & Novembro & Dezembro \\
\hline \multicolumn{8}{|c|}{} \\
\hline $\mathbf{9}$
\end{tabular}

Fonte: o Autor

Os gráficos abaixo apresentam o comportamento dos estoques no sistema para o cenário $\mathrm{C}$.

Observa-se que, diferentemente do cenário anterior, no qual era atingido o máximo de utilização do espaço do silo de Vila do conte em cerca de 4.000 horas, agora como a sazonalidade se dá no começo do ano pelas fazendas, o pico de utilização dos estoque é visto no início do ano, como mostrado na Figura 56. 


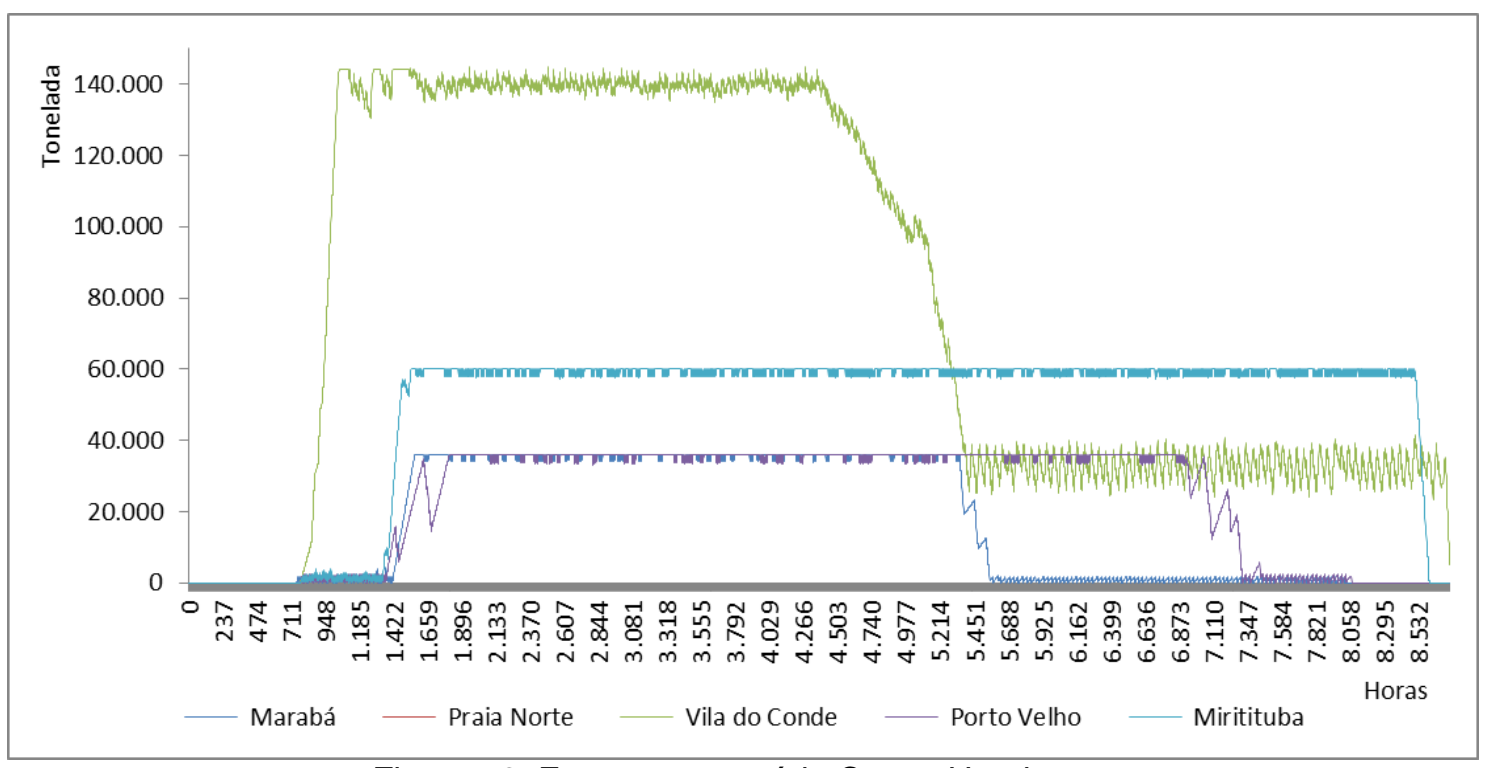

Figura 56: Estoques - cenário $\mathrm{C}$ com Handymax

Fonte: o Autor

A Figura 57 mostra o comportamento do estoque para a frota de navios do tipo Panamax, note que assim só há utilização do silo na capacidade total no período em que há maior produtividade.

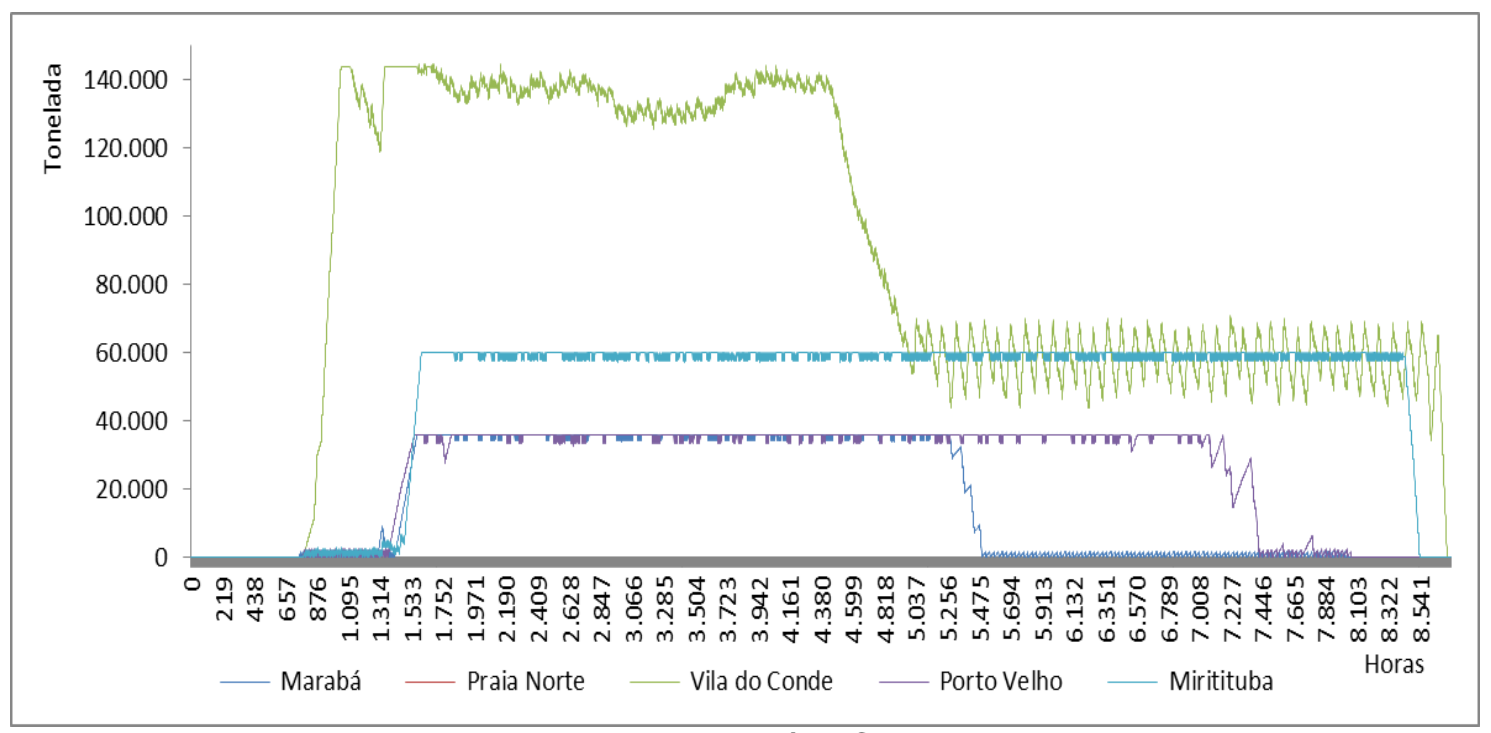

Figura 57: Estoques - cenário C com Panamax Fonte: o Autor

No caso do cenário com o mix de navios, é observado que em determinados momentos o nível de grãos no silo sobe independentemente do período de pico da produção de grãos, isto porque há necessidade de esperar mais tempo para 
acumular carga do navio e, como há menos navios no sistema, demora mais tempo para chegar navios para o embarque da carga, Figura 58.

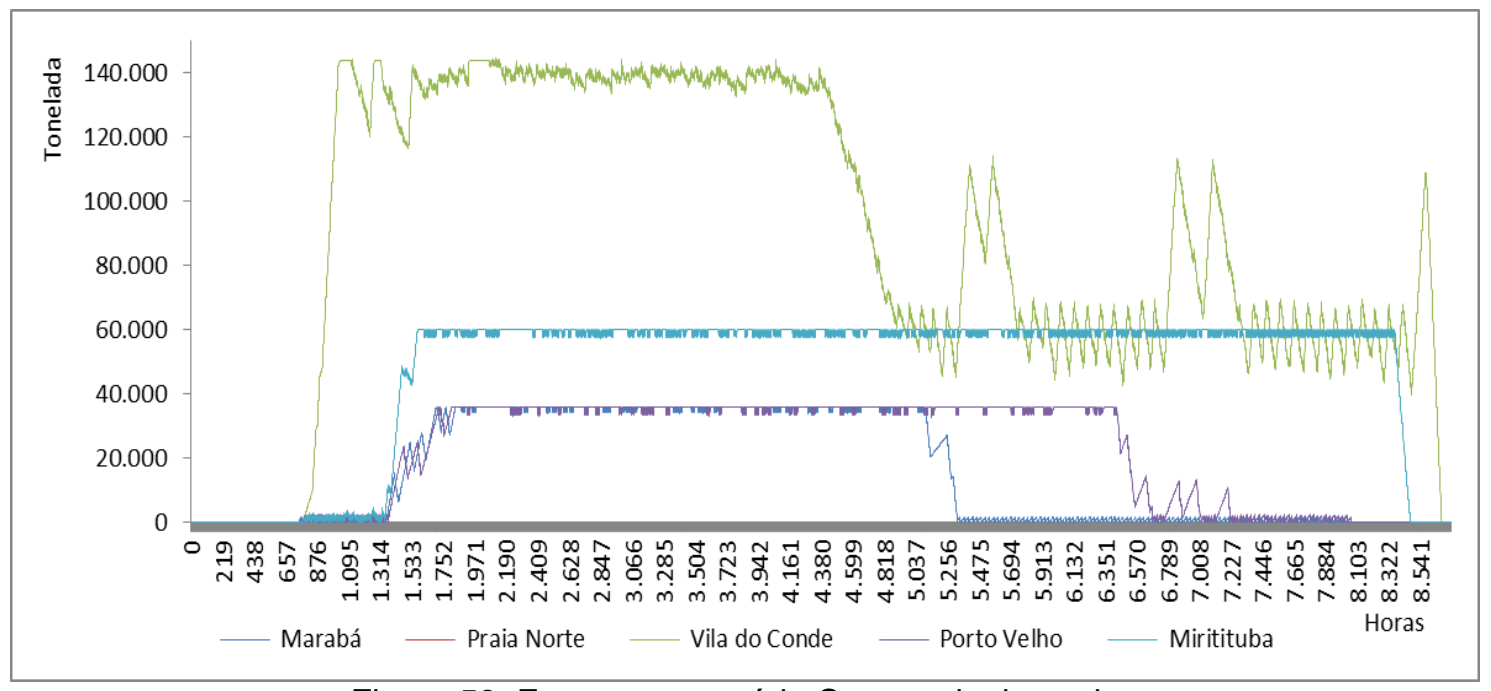

Figura 58: Estoques - cenário $\mathrm{C}$ com mix de navios Fonte: o Autor

\subsection{CENÁRIO D}

Pode-se considerar este cenário como o sistema real de transporte, com as restrições tanto das hidrovias quanto da sazonalidade na oferta de grãos pelas fazendas produtoras.

A Tabela 21, assim como os cenários anteriores, mostra o resumo dos indicadores tirados do modelo de simulação, observa-se que não há diferenças significativas na comparação com os cenários B e C. 
Tabela 21: Resumo do cenário D

\begin{tabular}{|c|c|c|c|c|c|c|c|c|c|}
\hline & & & & & & & & Número $\mathrm{m}$ & dio em Fila \\
\hline Origem & $\begin{array}{c}\text { Frota de } \\
\text { Barcaças (\#) }\end{array}$ & $\begin{array}{c}\text { Ciclo das } \\
\text { Barcaças (Dias) }\end{array}$ & Ociosidade (Dias) & Carga Total $(\mathrm{t})$ & $\begin{array}{l}\text { Ocupação das } \\
\text { Barcaças (\%) }\end{array}$ & $\begin{array}{c}\text { Ocupação dos } \\
\text { Navios (\%) }\end{array}$ & $\begin{array}{l}\text { Ocupação das } \\
\text { Barcaças (\%) }\end{array}$ & Navios (\#) & Barcaças (\#) \\
\hline \multicolumn{10}{|c|}{ Cenário 1 - Handymax } \\
\hline Marabá & 5 & 25,5 & 11,2 & 833.333 & 56,3 & - & - & - & - \\
\hline Miritituba & 14 & 33,0 & 2,7 & 2.500 .000 & 63,4 & - & - & - & - \\
\hline Porto Velho & 8 & 19,7 & 3,2 & 833.333 & 38,4 & - & - & - & - \\
\hline Vila do Conde & - & - & - & 833.333 & - & 0,7 & 0,7 & 5,7 & 5,9 \\
\hline \multicolumn{2}{|r|}{ Navio Atendidos: } & 143 & Total: & 5.000 .000 & & & & & \\
\hline \multicolumn{10}{|c|}{ Cenário 2 - Panamax } \\
\hline Marabá & 5 & 25,2 & 11,3 & 833.333 & 55,3 & - & - & - & - \\
\hline Miritituba & 14 & 32,7 & 2,9 & 2.500 .000 & 61,8 & - & - & - & - \\
\hline Porto Velho & 8 & 19,8 & 3,6 & 833.333 & 37,3 & - & - & - & - \\
\hline \begin{tabular}{|l|} 
Vila do Conde \\
\end{tabular} & - & - & - & 833.333 & - & 73,8 & 73,8 & 2,9 & 5,8 \\
\hline \multicolumn{2}{|r|}{ Navio Atendidos: } & 77 & Total: & 5.000 .000 & & & & & \\
\hline \multicolumn{10}{|c|}{ Cenário 3 - 80\% Panamax / 20\% Capesize } \\
\hline Marabá & 5 & 33,3 & 15,9 & 833.333 & 55,3 & - & - & - & - \\
\hline Miritituba & 14 & 39,8 & 6,0 & 2.500 .000 & 61,8 & - & - & - & - \\
\hline Porto Velho & 8 & 23,3 & 4,2 & 833.333 & 37,3 & - & - & - & - \\
\hline \begin{tabular}{|l|} 
Vila do Conde \\
\end{tabular} & - & - & - & 833.333 & - & 73,8 & 74,1 & 2,4 & 5,8 \\
\hline \multicolumn{2}{|r|}{ Navio Atendidos: } & 71 & Total: & 5.000 .000 & & & & & \\
\hline
\end{tabular}

Fonte: o Autor

Os tempos de ciclo das barcaças são dados pela Tabela 22, Tabela 23 e Tabela 24 , respectivamente.

Tabela 22: Tempos de ciclo cenário D para Handymax

\begin{tabular}{|c|c|c|c|c|c|c|c|c|c|c|}
\hline Origem & $\begin{array}{l}\text { Fila por } \\
\text { berço }(\mathrm{h})\end{array}$ & $\begin{array}{c}\text { Falta de } \\
\text { Material (h) }\end{array}$ & Carregando $(\mathrm{h})$ & $\begin{array}{c}\text { Carregado aguardando } \\
\text { por barcaça (h) }\end{array}$ & $\begin{array}{l}\text { Percurso } \\
\text { Carregado (h) }\end{array}$ & $\begin{array}{c}\text { Tempo de } \\
\text { desmembramento (h) }\end{array}$ & $\begin{array}{c}\text { Tempo de espera } \\
\text { por berço (h) }\end{array}$ & $\begin{array}{c}\text { Tempo de } \\
\text { descarregamento }(\mathrm{h})\end{array}$ & \begin{tabular}{|c|} 
Percurso \\
Descarregado (h)
\end{tabular} & $\begin{array}{l}\text { Tempo totalde } \\
\text { ciclo (dias) }\end{array}$ \\
\hline \multicolumn{11}{|c|}{ Tempo de Ciclo Agregado } \\
\hline Marabá & 271,7 & 59,2 & 15,0 & 0,0 & 30,8 & 1,7 & 125,8 & 14,2 & 80,8 & 25,0 \\
\hline \begin{tabular}{|l|} 
Porto Velho \\
\end{tabular} & 68,3 & 25,0 & 16,7 & 0,0 & 140,8 & 1,7 & 117,5 & 15,8 & 387,5 & 32,3 \\
\hline Miritituba & 83,3 & 5,8 & 15,8 & 0,0 & 63,3 & 1,7 & 119,2 & 14,2 & 169,2 & 19,7 \\
\hline \multicolumn{11}{|c|}{ Tempo de Ciclo durante o Regime de Seca } \\
\hline Marabá & 245,8 & 92,5 & 11,7 & 0,0 & 29,2 & 1,7 & 64,2 & 11,7 & 70,8 & 22,0 \\
\hline Porto Velho & 1,7 & 0,0 & 7,5 & 0,0 & 152,5 & 1,7 & 13,3 & 6,7 & 333,3 & 21,6 \\
\hline Miritituba & 2,5 & \#VALOR! & 7,5 & 0,0 & 65,0 & 1,7 & 12,5 & 6,7 & 166,7 & 11,0 \\
\hline \multicolumn{11}{|c|}{ Tempo de Ciclo durante o Regime de Cheia } \\
\hline Marabá & 233,3 & 44,2 & 19,2 & 0,0 & 30,8 & 1,7 & 194,2 & 18,3 & 84,2 & 26,1 \\
\hline Porto Velho & 70,0 & 35,0 & 19,2 & 0,0 & 140,0 & 1,7 & 148,3 & 18,3 & 427,5 & 35,8 \\
\hline Miritituba & 84,2 & 5,8 & 17,5 & 0,0 & 61,7 & 1,7 & 155,0 & 15,8 & 176,7 & 21,6 \\
\hline
\end{tabular}

Fonte: o Autor

Tabela 23: Tempos de ciclo cenário D para Panamax

\begin{tabular}{|c|c|c|c|c|c|c|c|c|c|c|}
\hline Origem & $\begin{array}{l}\text { Fila por } \\
\text { berço (h) }\end{array}$ & $\mid \begin{array}{c}\text { Falta de } \\
\text { Material (h) }\end{array}$ & Carregando (h) & $\begin{array}{c}\text { Carregado aguardando } \\
\text { por barcaça }(\mathrm{h})\end{array}$ & $\begin{array}{l}\text { Percurso } \\
\text { Carregado (h) }\end{array}$ & $\begin{array}{c}\text { Tempo de } \\
\text { desmembramento (h) }\end{array}$ & $\begin{array}{c}\text { Tempo de espera } \\
\text { por berço (h) }\end{array}$ & $\begin{array}{c}\text { Tempo de } \\
\text { descarregamento }(\mathrm{h})\end{array}$ & $\begin{array}{c}\text { Percurso } \\
\text { Descarregado (h) }\end{array}$ & $\begin{array}{l}\text { Tempo totalde } \\
\text { ciclo (dias) }\end{array}$ \\
\hline \multicolumn{11}{|c|}{ Tempo de Ciclo Agregado } \\
\hline Marabá & 277,5 & 68,3 & 15,8 & 0,0 & 31,7 & 1,7 & 120,8 & 15,0 & 81,7 & 25,5 \\
\hline Porto Velho & 73,3 & 23,3 & 16,7 & 0,0 & 143,3 & 1,7 & 114,2 & 15,8 & 392,5 & 32,5 \\
\hline Miritituba & 86,7 & 5,0 & 15,8 & 0,0 & 63,3 & 1,7 & 113,3 & 15,0 & 170,8 & 19,7 \\
\hline \multicolumn{11}{|c|}{ Tempo de Ciclo durante o Regime de Seca } \\
\hline Marabá & 325,0 & 82,5 & 10,8 & 0,0 & 30,8 & \begin{tabular}{|l|}
1,7 \\
\end{tabular} & 64,2 & 10,8 & 70,8 & 24,9 \\
\hline Porto Velho & 2,5 & 0,0 & 7,5 & 0,0 & 159,2 & 1,7 & 13,3 & 6,7 & 333,3 & 21,8 \\
\hline \begin{tabular}{|l|} 
Miritituba \\
\end{tabular} & 5,8 & \#VALOR! & 8,3 & 0,0 & 62,5 & \begin{tabular}{|l|}
1,7 \\
\end{tabular} & 13,3 & 7,5 & 150,0 & 10,4 \\
\hline \multicolumn{11}{|c|}{ Tempo de Ciclo durante o Regime de Cheia } \\
\hline Marabá & 231,7 & 60,0 & 20,0 & 0,0 & 30,8 & \begin{tabular}{|l|}
1,7 \\
\end{tabular} & 186,7 & 18,3 & 88,3 & 26,6 \\
\hline Porto Velho & 75,8 & 33,3 & 19,2 & 0,0 & 140,0 & 1,7 & 139,2 & 17,5 & 420,8 & 35,3 \\
\hline Miritituba & 90,0 & 5,0 & 16,7 & 0,0 & 62,5 & 1,7 & 141,7 & 15,8 & 181,7 & 21,5 \\
\hline
\end{tabular}

Fonte: o Autor 
Tabela 24: Tempos de ciclo cenário D para o mix de navios

\begin{tabular}{|c|c|c|c|c|c|c|c|c|c|c|}
\hline Origem & $\begin{array}{l}\text { Fila por } \\
\text { berço }(\mathrm{h})\end{array}$ & $\mid \begin{array}{c}\text { Falta de } \\
\text { Material (h) }\end{array}$ & Carregando (h) & $\begin{array}{c}\text { Carregado aguardando } \\
\text { por barcaça }(\mathrm{h})\end{array}$ & $\begin{array}{l}\text { Percurso } \\
\text { Carregado (h) }\end{array}$ & $\begin{array}{c}\text { Tempo de } \\
\text { desmembramento (h) }\end{array}$ & $\begin{array}{c}\text { Tempo de espera } \\
\text { por berço (h) }\end{array}$ & $\begin{array}{c}\text { Tempo de } \\
\text { descarregamento }(\mathrm{h})\end{array}$ & \begin{tabular}{|c|} 
Percurso \\
Descarregado $(\mathrm{h})$
\end{tabular} & $\begin{array}{l}\text { Tempo totalde } \\
\text { ciclo (dias) }\end{array}$ \\
\hline \multicolumn{11}{|c|}{ Tempo de Ciclo Agregado } \\
\hline Marabá & 285,8 & 66,7 & 15,0 & 0,0 & 30,8 & \begin{tabular}{|r|}
1,7 \\
\end{tabular} & 121,7 & 15,0 & 81,7 & 25,8 \\
\hline \begin{tabular}{|l|l} 
Porto Velho \\
\end{tabular} & 78,3 & 25,8 & 16,7 & 0,0 & 140,8 & 1,7 & 115,8 & 16,7 & 385,0 & 32,6 \\
\hline Miritituba & 87,5 & 5,0 & 15,0 & 0,0 & 63,3 & \begin{tabular}{|l|}
1,7 \\
\end{tabular} & 116,7 & 14,2 & 171,7 & 19,9 \\
\hline \multicolumn{11}{|c|}{ Tempo de Ciclo durante o Regime de Seca } \\
\hline Marabá & 357,5 & 97,5 & 13,3 & 0,0 & 30,0 & \begin{tabular}{|l|}
1,7 \\
\end{tabular} & 55,8 & 12,5 & 70,8 & 26,6 \\
\hline Porto Velho & 0,8 & 0,0 & 7,5 & 0,0 & 142,5 & 1,7 & 15,8 & 6,7 & 337,5 & 21,4 \\
\hline Miritituba & 4,2 & \#VALOR! & 7,5 & 0,0 & 64,2 & \begin{tabular}{|l|}
1,7 \\
\end{tabular} & 9,2 & 7,5 & 168,3 & 10,9 \\
\hline \multicolumn{11}{|c|}{ Tempo de Ciclo durante o Regime de Cheia } \\
\hline Marabá & 249,2 & 55,0 & 19,2 & 0,0 & 30,8 & \begin{tabular}{|l|}
1,7 \\
\end{tabular} & 189,2 & 18,3 & 86,7 & 27,1 \\
\hline Porto Velho & 84,2 & 40,8 & 19,2 & 0,0 & 136,7 & 1,7 & 143,3 & 18,3 & 416,7 & 35,9 \\
\hline Miritituba & 88,3 & 5,0 & 16,7 & 0,0 & 63,3 & 1,7 & 147,5 & 15,0 & 180,0 & 21,6 \\
\hline
\end{tabular}

Fonte: o Autor

Assim como nos cenários anteriores, tem-se, também neste cenário, a frota de veículos terrestres, mostrada na Tabela 25.

Tabela 25: Frota de caminhões - Cenário D

\begin{tabular}{|l|c|c|c|c|c|c|c|c|c|c|c|c|c|c|c|}
\hline \multicolumn{1}{|c|}{ Origem } & Janeiro & Fevereiro & Março & Abril & Maio & Junho & Julho & Agosto & Setembro & Outubro & Novembro & Dezembro \\
\hline \multicolumn{8}{|c|}{} \\
\hline $\mathbf{9}$
\end{tabular}

Fonte: o Autor

Analogamente aos cenários anteriores, tem-se o nível dos estoques para cada frota de navios.

A Figura 59 mostra o comportamento dos estoques em condições reais de sazonalidade, tanto por parte das hidrovias quanto por parte da produção de grãos. Pode-se notar que devido à sobreposição do efeito sazonal na produção dos grãos sobre a sazonalidade nas hidrovias, há duas situações distintas. No primeiro caso a utilização dos silos é alta, no segundo momento, mesmo com o regime de baixa dos rios, sua utilização é menor, como ilustrado. 


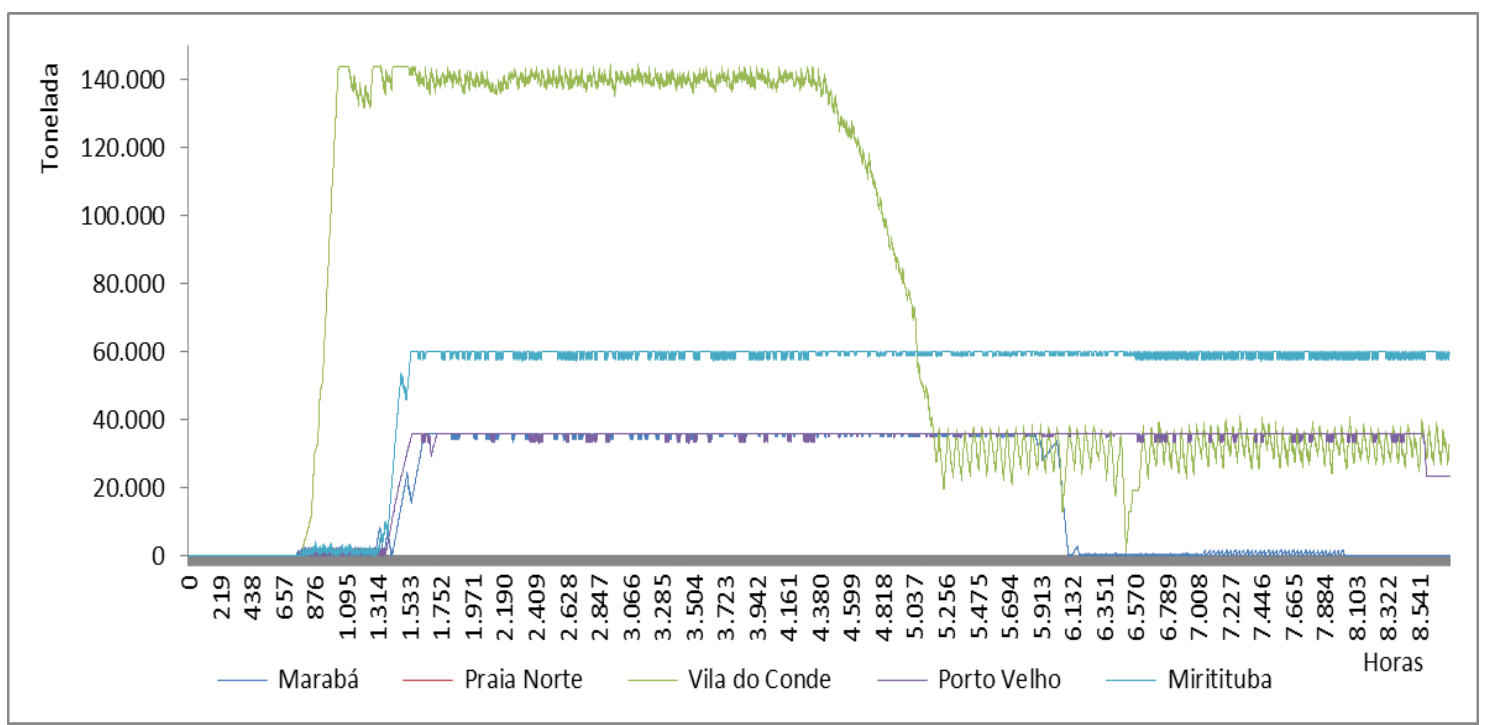

Figura 59: Estoques - cenário D com Handymax

Fonte: o Autor

No caso da Figura 60, a utilização do silo no segundo semestre aumentou devido à espera por navios já que, com uma embarcação de maior porte, não há necessidade do mesmo número de navios com relação ao cenário com Handymax.

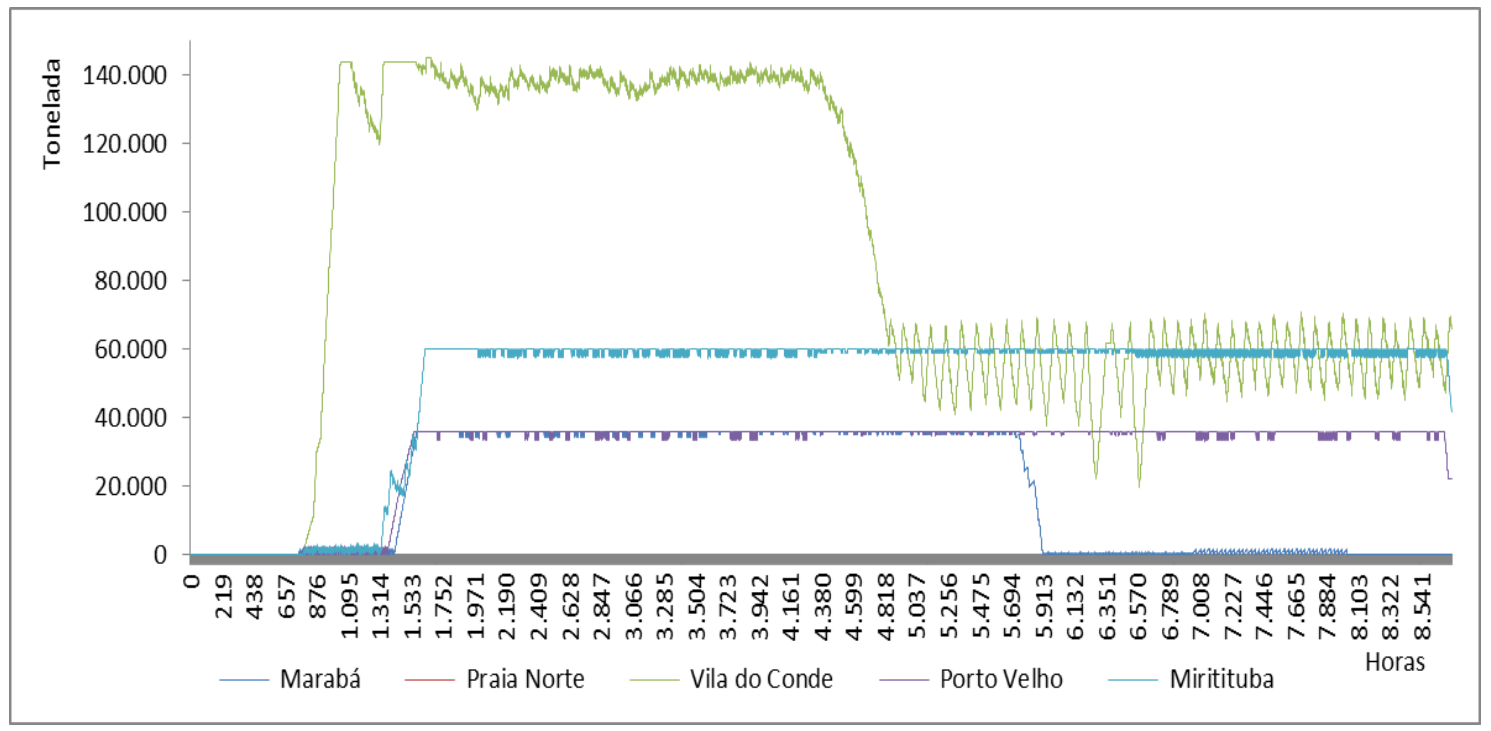

Figura 60: Estoques - cenário D com Panamax

Fonte: o Autor

Assim como para o cenário com Panamax, o cenário com o mix de navios tem sua utilização de silagem maior devido ao maior tempo de espera entre embarcações, Figura 61. 


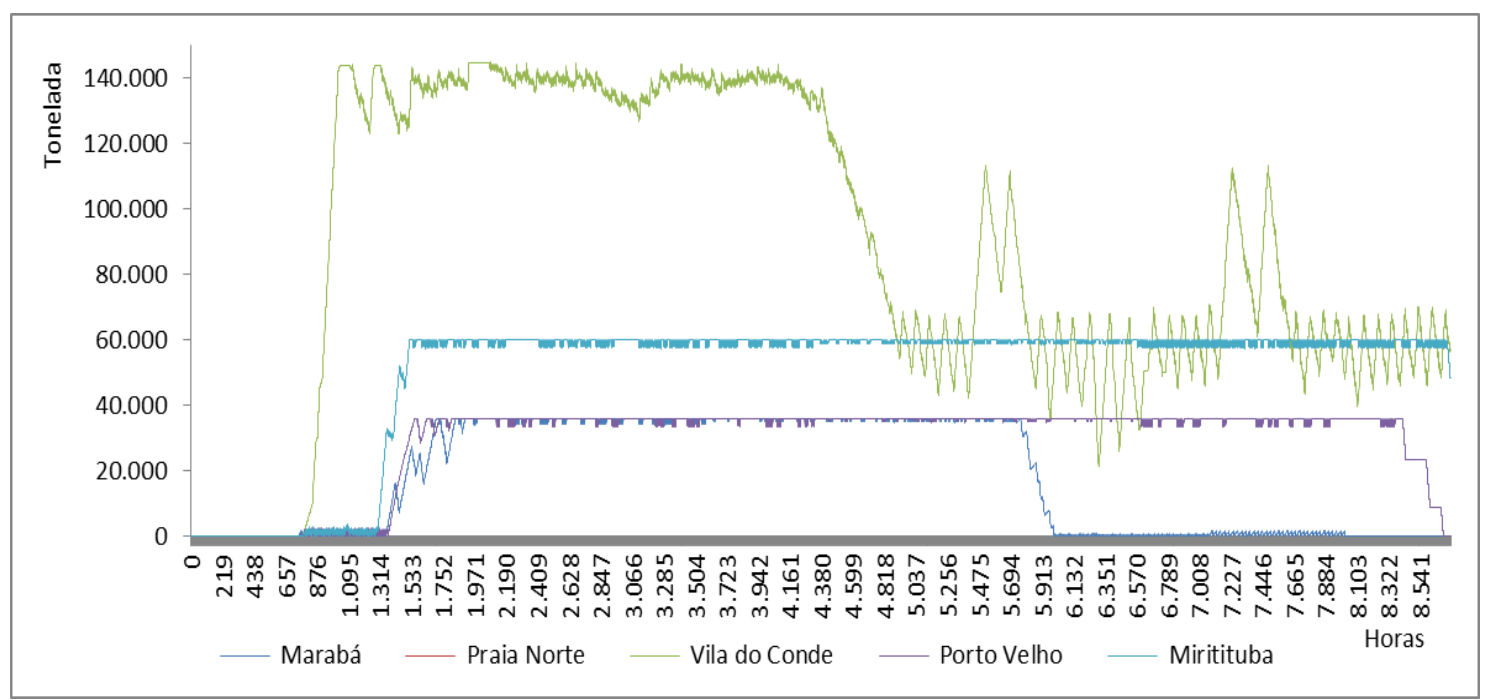

Figura 61: Estoques - cenário D com mix de navios Fonte: o Autor

Observa-se, na Tabela 26, um quadro comparando os quatro principais cenários testados para avaliar as influências de cada restrição sazonal separadamente. Ambas as restrições oferecem impedâncias ao sistema proposto, no entanto, a restrição do cenário $\mathrm{C}$, de sazonalidade nas hidrovias, apresenta diferenças significativas nos principais indicadores propostos.

Apesar das ocupações se manterem parecidas, o tempo médio em fila dos navios tem mudança expressiva entre cenários. Semelhante comportamento pode ser observado com relação aos comboios em fila, que se mantiveram maior para os três tipos de frota no cenário $\mathrm{C}$.

As ociosidades que existem no sistema são inerentes da sazonalidade na oferta de produtos. Cabe salientar que, em função das restrições da hidrovia, bem como da sazonalidade na demanda, os efeitos restritivos se somam, embora não linearmente. Além disso, pode-se notar que a capacidade de estocagem nos terminais, considerando uma taxa de carregamento das barcaças de $600 \mathrm{t} / \mathrm{h}$, é crítica, pois boa parte do tempo os silos nos terminais de transbordo estão no limite da sua capacidade, como observado nos gráficos de estoques. A consequência é maior fila de caminhões esperando para descarregar os produtos nos silos, obrigando a aumentar a frota de caminhões para realizar o transporte, formando, assim, um estoque sobre rodas. 
As taxas de ocupações dos recursos são compatíveis com esse tipo de operação e mostram que as filas geradas nos cenários puderam ser dissipadas durante a simulação, permitindo que o porto atendesse toda a demanda de transporte, considerando o cenário D. 
Tabela 26: Comparação entre os cenários A, B, C e D

\begin{tabular}{|c|c|c|c|c|c|c|c|c|c|c|c|c|}
\hline \multirow[b]{2}{*}{ Principais Indicadores } & \multicolumn{3}{|c|}{ Cenário A } & \multicolumn{3}{|c|}{ Cenário B } & \multicolumn{3}{|c|}{ Cenário C } & \multicolumn{3}{|c|}{ Cenário D } \\
\hline & Handymax & Panamax & Mix & Handymax & Panamax & Mix & Handymax & Panamax & Mix & Handymax & Panamax & Mix \\
\hline Ocupação berço navios + espera por produto (\%) & 70,7 & 70,2 & 71,9 & 73,3 & 71,5 & 71,7 & 69,2 & 66,8 & 66,8 & 74,8 & 73,8 & 73,8 \\
\hline Ocupação do berço navios (\%) & 63,4 & 60,6 & 60,3 & 63,5 & 60,6 & 60,1 & 63,7 & 60,5 & 60,3 & 63,6 & 60,6 & 60,3 \\
\hline Número médio de Navios em Fila (\#) & 1,8 & 1,2 & 1,3 & 2,8 & 1,7 & 1,7 & 4,3 & 1,9 & 1,9 & 5,7 & 2,9 & 2,4 \\
\hline Tempo médio de navios em fila (h) & 94,7 & 109,1 & 130,4 & 142,6 & 156,8 & 169,3 & 222,0 & 179,1 & 199,1 & 288,6 & 274,3 & 224,9 \\
\hline Demanda Exportada ( $t$ ) & 5.000 .000 & 5.000 .000 & 5.000 .000 & 5.000 .000 & 5.000 .000 & 5.000 .000 & 5.000 .000 & 5.000 .000 & 5.000 .000 & 5.000 .000 & 5.000 .000 & 5.000 .000 \\
\hline Número médio de Navios Atendidos (\#) & 142,5 & 76,7 & 70,8 & 142,5 & 76,7 & 70,8 & 142,5 & 76,7 & 70,8 & 142,5 & 76,7 & 70,8 \\
\hline Número médio de Comboios em Fila (\#) & 1,7 & 1,7 & 2,3 & 5,7 & 6,1 & 5,8 & 7,2 & 6,7 & 8,3 & 5,9 & 5,8 & 5,8 \\
\hline Ocupação do berço de descarga comboio (\%) & 73,3 & 73,7 & 75,8 & 76,2 & 77,1 & 77,5 & 73,5 & 73,3 & 76,7 & 74,6 & 73,8 & 74,1 \\
\hline Ocupação de Tombador em Marabá (\%) & 21,2 & 21,2 & 21,2 & 21,2 & 21,2 & 21,2 & 21,2 & 21,2 & 21,2 & 21,2 & 21,2 & 21,2 \\
\hline Ocupação de Tombador em Porto Velho (\%) & 21,2 & 21,2 & 21,2 & 21,2 & 21,2 & 21,2 & 21,2 & 21,2 & 21,2 & 21,2 & 21,2 & 21,2 \\
\hline Ocupação de Tombador em Miritituba (\%) & 63,4 & 63,4 & 63,4 & 63,4 & 63,4 & 63,4 & 63,4 & 63,4 & 63,4 & 63,4 & 63,4 & 63,4 \\
\hline Ocupação de Tombador em Vila do Conde (\%) & 21,2 & 21,2 & 21,2 & 21,2 & 21,2 & 21,2 & 21,2 & 21,2 & 21,2 & 21,2 & 21,2 & 21,2 \\
\hline Ocupação do Berço em Marabá (\%) & 69,8 & 71,1 & 62,6 & 72,5 & 71,5 & 68,2 & 59,2 & 59,4 & 55,9 & 56,3 & 55,7 & 55,3 \\
\hline Ocupação do Berço em Porto Velho (\%) & 45,0 & 48,0 & 39,6 & 43,8 & 42,3 & 44,0 & 50,8 & 55,2 & 45,2 & 38,4 & 36,2 & 37,3 \\
\hline Ocupação do Berço em Miritituba (\%) & 58,0 & 57,4 & 54,4 & 63,8 & 61,4 & 63,8 & 64,6 & 65,3 & 60,5 & 62,3 & 61,8 & 61,8 \\
\hline Frota Fluvial para Marabá (\#) & 3 & 3 & 3 & 5 & 5 & 5 & 5 & 5 & 5 & 5 & 5 & 5 \\
\hline Frota Fluvial para Porto Velho (\#) & 6 & 6 & 6 & 8 & 8 & 8 & 8 & 8 & 8 & 8 & 8 & 8 \\
\hline Frota Fluvial para Miritituba (\#) & 9 & 9 & 9 & 14 & 14 & 14 & 14 & 14 & 14 & 14 & 14 & 14 \\
\hline
\end{tabular}

Fonte: o Autor 


\subsection{CENÁRIO E}

Foi considerada uma eficiência de $50 \%$ sobre todas as taxas nominais dos equipamentos. Em função disso, análises de sensibilidades foram conduzidas sobre essas taxas, nas quais é feita a variação das taxas de descarregamento das barcaças e carregamento dos navios. No primeiro cenário (E1) se testou a variação da taxa de carregamento das embarcações fluviais (de 750 tph para 1.000 tph); no E2 foi alterada a taxa de carregamento dos navios (de 1.000 tph para 1.250 tph) e manteve-se a produtividade normal das barcaças; e no terceiro cenário (E3), quando foram alteradas ambas as taxas, também 250 tph, maiores que as taxas originais, o sistema apresenta um trade-off entre a capacidade de silagem existente nos terminais de fluviais de transbordo e o número de veículos necessários para atender à demanda de transporte rodoviário.

Os resultados para o cenário E3 mostram melhoras em todos os indicadores que compõem do sistema. O aumento das taxas derivou em um menor nível dos estoques ao longo do ano nos terminais fluviais de transbordo, bem como no porto em Vila do Conde, em comparação com os cenários onde as taxas são menores (cenário D) - Figura 62.
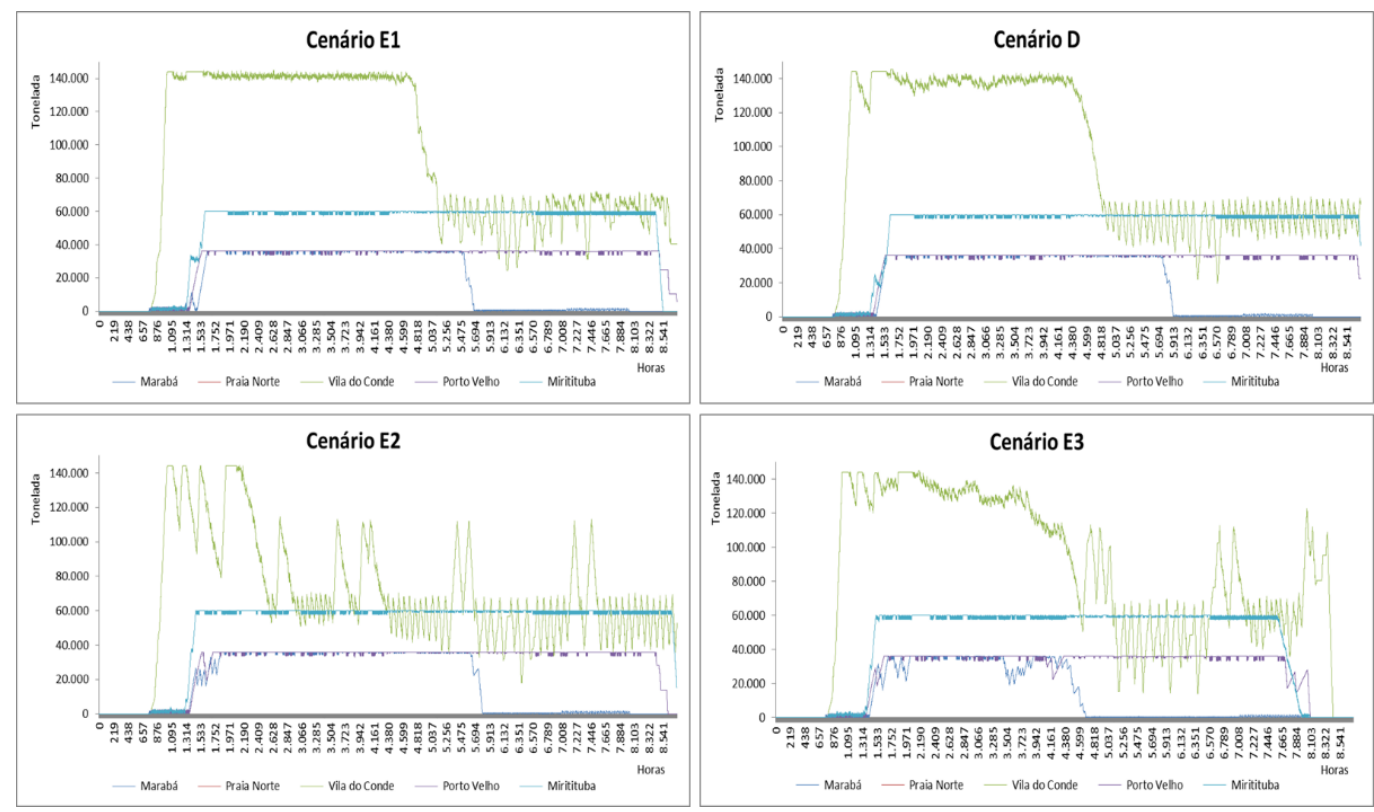

Figura 62: Comparação dos cenários de sensibilidade Fonte: o Autor 
Além disso, os outros indicadores apresentaram melhoras, como a taxa de ocupação dos berços de carregamento de navios e descarga de barcaças apresentaram redução em relação aos outros cenários, Tabela 27.

Outro ponto importante é que o número de caminhões necessários para realizar o transporte também apresentou uma redução significativa (entre as fazendas e os terminais intermediários), pois as esperas dos caminhões são minimizadas pela rapidez no esvaziamento dos silos. 
Tabela 27: Comparação entre os cenários de análise de sensibilidade

\begin{tabular}{|c|c|c|c|c|c|c|c|c|c|c|c|c|}
\hline \multirow[b]{2}{*}{ Principais Indicadores } & \multicolumn{3}{|c|}{ CenárioD } & \multicolumn{3}{|c|}{ CenárioE1 } & \multicolumn{3}{|c|}{ CenárioE2 } & \multicolumn{3}{|c|}{ CenárioE3 } \\
\hline & Handymax & Panamax & Mix & Handymax & Panamax & Mix & Handymax & Panamax & Mix & Handymax & Panamax & Mix \\
\hline Ocupação berço navios + espera por produto (\%) & 74,8 & 73,8 & 73,8 & 71,3 & 70,1 & 69,5 & 69,7 & 70,7 & 70,8 & 62,4 & 61,3 & 60,3 \\
\hline Ocupação do berço navios (\%) & 63,6 & 60,6 & 60,3 & 63,5 & 59,8 & 60,3 & 52,3 & 49,3 & 48,8 & 52,3 & 49,1 & 48,9 \\
\hline Número médio de Navios em Fila (\#) & 5,7 & 2,9 & 2,4 & 4,9 & 2,2 & 2,1 & 2,3 & 2,8 & 2,3 & 1,3 & 0,9 & 1,0 \\
\hline Tempo médio de navios em fila (h) & 288,6 & 274,3 & 224,9 & 253,3 & 208,8 & 216,4 & 115,4 & 259,2 & 234,5 & 67,0 & 87,3 & 105,0 \\
\hline Demanda Exportada (t) & 5.000 .000 & 5.000 .000 & 5.000 .000 & 5.000 .000 & 5.000 .000 & 5.000 .000 & 5.000 .000 & 5.000 .000 & 5.000 .000 & 5.000 .000 & 5.000 .000 & 5.000 .000 \\
\hline Número médio de Navios Atendidos (\#) & 142,5 & 76,7 & 70,8 & 142,5 & 76,7 & 70,8 & 142,5 & 76,7 & 70,7 & 142,5 & 76,7 & 70,8 \\
\hline Número médio de Comboios em Fila (\#) & 5,9 & 5,8 & 5,8 & 5,0 & 4,8 & 5,2 & 5,3 & 5,9 & 6,2 & 3,8 & 4,0 & 4,3 \\
\hline Ocupação do berço de descarga comboio (\%) & 74,6 & 73,8 & 74,1 & 66,2 & 65,6 & 67,4 & 71,9 & 74,2 & 75,6 & 64,2 & 64,6 & 65,8 \\
\hline Ocupação de Tombador em Marabá (\%) & 21,2 & 21,2 & 21,2 & 21,2 & 21,2 & 21,2 & 21,2 & 21,2 & 21,2 & 21,2 & 21,2 & 21,2 \\
\hline Ocupação de Tombador em Porto Velho (\%) & 21,2 & 21,2 & 21,2 & 21,2 & 21,2 & 21,2 & 21,2 & 21,2 & 21,2 & 21,2 & 21,2 & 21,2 \\
\hline Ocupação de Tombador em Miritituba (\%) & 63,4 & 63,4 & 63,4 & 63,4 & 63,4 & 63,4 & 63,4 & 63,4 & 63,4 & 63,4 & 63,4 & 63,4 \\
\hline Ocupação de Tombador em Vila do Conde (\%) & 21,2 & 21,2 & 21,2 & 21,2 & 21,2 & 21,2 & 21,2 & 21,2 & 21,2 & 21,2 & 21,2 & 21,2 \\
\hline Ocupação do Berço em Marabá (\%) & 56,3 & 55,7 & 55,3 & 56,6 & 56,7 & 56,2 & 59,3 & 54,4 & 53,1 & 67,4 & 66,3 & 63,2 \\
\hline Ocupação do Berço em Porto Velho (\%) & 38,4 & 36,2 & 37,3 & 38,2 & 40,8 & 38,5 & 45,3 & 35,9 & 34,6 & 52,3 & 49,2 & 45,7 \\
\hline Ocupação do Berço em Miritituba (\%) & 62,3 & 61,8 & 61,8 & 64,0 & 64,3 & 63,6 & 64,8 & 61,5 & 60,2 & 71,3 & 70,3 & 68,0 \\
\hline Frota Fluvial para Marabá (\#) & 5 & 5 & 5 & 5 & 5 & 5 & 5 & 5 & 5 & 5 & 5 & 5 \\
\hline Frota Fluvial para Porto Velho (\#) & 8 & 8 & 8 & 8 & 8 & 8 & 8 & 8 & 8 & 8 & 8 & 8 \\
\hline Frota Fluvial para Miritituba (\#) & 14 & 14 & 14 & 14 & 14 & 14 & 14 & 14 & 14 & 14 & 14 & 14 \\
\hline
\end{tabular}

Fonte: o Autor 


\section{CONCLUSÃO}

Conclui-se que a simulação de eventos discretos é uma ferramenta que possibilita trabalhar com sistemas complexos, dimensionando diferentes frotas em um sistema intermodal de transporte de cargas com todas as restrições reais impostas pelo próprio sistema e/ou naturais.

Esta metodologia, como ferramenta de apoio à tomada de decisão para o planejamento estratégico, é de grande serventia aos gestores empresariais.

Sendo assim, a dissertação atingiu o objetivo de desenvolver uma ferramenta computacional, baseada em simulação estocástica, que fosse capaz de representar um sistema intermodal de transportes de grãos, com todas as restrições intrínsecas ao sistema, e pôde avaliar a impedância que cada restrição tem sobre o sistema como um todo.

O modelo permitiu, ainda, avaliar a capacidade de escoamento do porto de Vila do Conde, assim como a utilização dos silos de armazenamento tanto do porto quanto dos terminais de transbordo intermediários.

Verificou-se que, embora cada restrição, isoladamente, tivesse grande impedância oferecida ao sistema, quando foi simulado o cenário real, com as duas restrições agindo juntas, o impacto percebido não foi a simples soma linear dessas restrições. Isso se deve ao fato de que, quando a seca dos rios está no seu pico, a produção de grãos está no vale, ou seja, quando o sistema hidrológico não pode transportar sua capacidade total de carga, o sistema de produção das fazendas não têm como ofertar uma quantidade de grãos como no auge da safra.

Cabe ressaltar que quanto melhor for o desempenho dos equipamentos de carregamento e descarregamento, mais será mitigado o efeito das sazonalidades no sistema como um todo. No entanto, os silos intermediários já estão com a sua utilização no máximo, ou seja, se o carregamento desses silos for mais rápido, serão formadas maiores filas nesses terminais. Porém, se esta taxa diminuir, faltará produto do outro lado do sistema. 
Sendo assim, é visível o trade-off entre capacidade de silagem e a performance dos equipamentos neste sistema.

Cabe salientar também que a frota proposta de caminhões para atender à demanda de 5 milhões de toneladas/ano é muito grande, e talvez torne o sistema inviável caso não tenha o transporte hidroviário, em que determinados anos teve um regime de seca intenso quando não possibilitou o transporte de comboios em diversos trechos das hidrovias.

Outra motivação para este estudo é com relação ao gerenciamento dos riscos inerentes ao dimensionamento de frotas de veículos, neste caso, tanto rodoviário quanto hidroviário, nos quais, caso o tomador de decisão não tenha em mente que seu dimensionamento é dinâmico ao longo do ano, ele pode superdimensionar ou sub-dimensionar as frotas, proporcionando maiores custos ao processo ou não conseguindo transportar toda demanda prevista, respectivamente.

O modelo contribuiu para ser mais uma forma de abordagem para o problema de dimensionamento não só de frota, mas também de silos intermediários de um sistema de transporte a granel, utilizando mais de um modal de transporte.

Sendo assim, pode-se dizer que a ferramenta desenvolvida neste trabalho é um avaliador de riscos, levando-se em consideração fatores sazonais, os quais nem sempre estão perceptíveis ou há uma sobreposição de restrições que dificultam essa percepção.

Devido à complexidade do sistema modelado, não foram abordados alguns pontos que podem contribuir ainda mais com essa pesquisa. Como recomendação, apontam-se os seguintes itens:

- Para o sistema rodoviário, foi modelada uma solução que garante a frota necessária para o transporte de toda a demanda, no entanto, essa solução não garante o número ótimo da frota e nem garante que este número esteja perto do ótimo. Então, propõe-se a implementação de um algoritmo de otimização para este modal.

- Propor um estudo com o transporte para o porto de Vila do Conde por trem e não hidrovia, minimizando, assim, os problemas gerados durante os períodos de seca dos rios. 
- Tentar minimizar as distâncias percorridas pelo sistema rodoviário, já que, devido às leis trabalhistas, esse sistema tem seu ciclo aumentado.

- Fazer uma análise econômica desse sistema em estudo, principalmente com relação ao sistema rodoviário, onde acaba inviabilizando a utilização do mesmo, devido à quantidade de veículos necessárias para transportar 5 milhões de toneladas por ano. 


\section{REFERÊNCIAL BIBILOGRÁFICO}

ALDIGUERI, D. R., OLIVEIRA, A. R. G. Análise de trade-offs entre o escoamento imediato da produção de soja e a armazenagem com escoamento controlado. Programa de Pós-Graduação em Transporte da Universidade de Brasília - PPGT/UnB. 2009.

ALMEIDA, C. SELEME, R. ALVES, V. Modelagem matemática e simulação para otimizar o escoamento da soja. RACE, Unoesc, v. 12, n. 1, p. 199-225, jan./jun. 2013.

ANA - Agência Nacional de Águas. Monitoramento Hidrológico. Brasília, 2014. Disponível

em:<http://arquivos.ana.gov.br/infohidrologicas/monitoramento/AmazoniaOcide ntal/BoletimMonitoramentoAO_n_032-2014.pdf>Acesso em: 11 Mar 2015.

Agência Nacional de Transportes Aquaviários- ANTAQ. Transporte de Cargas nas Hidrovias Brasileiras em 2011. Brasília, Ago 2012.

. Portos. Principais Portos. Brasília, 2013.

BALLOU, R. H. Gerenciamento da Cadeia de Suprimentos/ Logística Empresarial. Porto Alegre: Bookman, 2006.

Logística empresarial: transporte, administração de materiais e distribuição física. São Paulo: Atlas, 1993.

BNDES - Banco Nacional do Desenvolvimento Econômico e Social. Análise e Avaliação da Organização Institucional e da Eficiência de Gestão do Setor Portuário Brasileiro. São Paulo: Booz\&Company, vol. 1, 2012.

Análise e Avaliação da Organização Institucional e da Eficiência de Gestão do Setor Portuário Brasileiro. São Paulo: Booz \& Company, vol. 2, 2012.

BOTTER, R. C. Analysis of time-windows on ship arrival and its influence on port operations performance. The International Workshop on Harbour, Maritime \& Multimodal Logistics Modelling and Simulation, Rio de Janeiro, 2004.

BUCHBERGER, S., WELLS, G. Intensity, Duration, and Frequency of Residential Water Demands. Journal of Water Resources Planning and Management.vol. 122. p. 11-19. 1996.

CAIXETA-FILHO, J. V. GAMEIRO, A. H. Sistemas de gerenciamento de transportes: modelagem matemática. São Paulo: Atlas, 2001. 
CARNEIRO, de M. R. Commodities, choques externos e crescimento: reflexões sobre a América Latina. Nações Unidas, Santiago Chile, ISSN 16808843, 2012.

Centro de Estudos Avançados em Economia Aplicada (CEPEA). PIB do Agronegócio. Departamento de Economia, Administração e Sociologia - DEAS, Escola Superior de Agricultura "Lui de Queiro " - ESALQ, Universidade de São Paulo - USP. São Paulo, 2015. Disponível em: <http://cepea.esalq.usp.br/pib/>. Acesso em: 03Fev 2015.

CHWIF, L.; MEDINA, A. Modelagem e Simulação de Eventos Discretos: Teoria e Aplicações. 4 ed. Rio de Janeiro: Elsevier, 2015.

CNT - Confederação Nacional do Transporte. Pesquisa CNT de Ferrovias 2011. Brasília, 2011.

COMPANHIA NACIONAL DE ABASTECIMENTO (CONAB). Produtividade e Produção, Relativas às Safras 1976/77 a 2014/15 de Grãos: Janeiro, 2015. Disponível em:

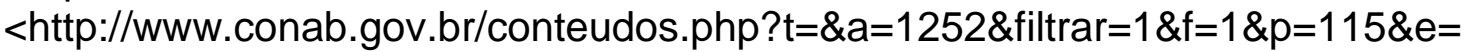
$0 \& d=0 \& m=0 \& s=0 \& a c=0 \& t p s=0 \& \mid v s=0 \& l=0 \& e d=0 \& i=>$ Acesso em: 05 Jan. 2015.

Centro de Estudos em Logística (COPPEAD - UFRJ). Transporte de Carga no Brasil: ameaças e oportunidades para o desenvolvimento do país. 2002. Disponível em: <http://www.cel.coppead.ufrj.br/fs-pesquisa.htm>. Acesso em: 12 Nov. 2015.

DAMBROSIO, M. A., REDIVO, A., Redivo, A. R., REDIVO, G. A. Custos da Padronização e Armazenagem da Soja em Armazém Próprio no Município de Sorriso/MT. Revista Contabilidade \& Amazônia, Sinop, v. 2, n. 1, art. 10, pp. 118-133, Jan./Dez. 2009.

DEVORE, J. Probability and Statistics for Engineering and the Sciences. 5nd Ed., Pacific Grove: Duxbury Press, 2000.

FLEURY, P. F. Gestão Estratégica do transporte. COPPEAD. Centro de Estudos em Logística. UFRJ. 2005. Disponível em: $<$ http://www.cel.coppead.ufr..br/fsbusca.htm?fr-estrat-trans.htm>. Acesso em: 01 Out. 2015.

HARRINGTON, T.C.; LAMBERT, D.M.; Sterling, J.U. Simulating the financial impact of marketing and logistics decisions. International Journal of Physical Distribution \& Logistics Management, Vol. 22 No. 7, 3-12.1992.

HARROD, S. Numerical Methods for Realizing Nonstationary Poisson Processes with Piecewise-Constant Instantaneous-Rate Functions. Simulation, Vol. 82, Issue 3, p. 147-157. 2006.

HOFF, A.; ANDERSSON, H.; CHRISTIANSEN, M.; HASLEC, G.; LOKKETANGEN, A. Industrial Aspects and Literature Survey: Fleet 
Composition and Routing. Computers \& Operations Research, v. 37, n. 12, p. 2041-2061, 2010.

JASPER, S. P., BIAGGIONI, M. A. M., RIBEIRO, J. P. Viabilidade econômica de aquisição de um silo-secador para pequenas áreas de produção. Eng. Agríc., Jaboticabal, v.26, n.3, p.795-803, set./dez. 2006.

JUNIOR, S. N.; TSUNECHIRO, A. Pontos Críticos da Armazenagem de Grãos no Brasil. Análise e Indicadores do Agronegócio, v. 6, p. 1-5, 2011.

KELTON, D., SADOWSKI, R., SADOWSKI, D. Simulation with Arena. Boston: McGraw Hill, 1998.

LAW, A. M.; KELTON, W. D. Simulation Modeling and Analysis. 3th. Ed. McGraw-Hill, 2000.

MARTINS, R. S., REBECHI, D., PRATI, C. A., CONTE, H. Decisões Estratégicas na Logística do Agronegócio: Compensação de Custos Transporte-Armazenagem para a Soja no Estado do Paraná. RAC, v. 9, n. 1, Jan./Mar.: p. 53-78, 2005.

MINISTÉRIO DO DESENVOLVIMENTO, INDÚSTRIA E COMÉRCIO EXTERIOR (MDIC). Exportação: Mercado de Commodities. Disponível em: $<$ http://www.mdic.gov.br/sistemas_web/aprendex/cooperativismo/index/conteud o/id/304> Acesso em: 15 Fev. 2015.

MUNDIM, J. U. C. Uso de simulação de eventos discretos para o dimensionamento de frota para a colheita e transporte de cana-de-açúcar. Dissertação (Mestrado) - Departamento de Engenharia de Transportes, Escola Politécnica da Universidade de São Paulo, São Paulo, 2009.

NETTO, J. F. Modelo de simulação para dimensionamento da frota de contêineres movimentada por navios em rota dedicada. Dissertação (Mestrado) - Engenharia de Sistemas Logísticos, Escola Politécnica da Universidade de São Paulo, São Paulo, 2012.

PEGDEN, C. D.; SADOWSKI, R. P.; SHANNON, R. E. Introduction to simulation using SIMAN. New York: Ed. McGraw-Hill, 1995.

PEREIRA, N. N. Alternativas de tratamento da água de lastro em portos exportadores de minério de ferro. Tese (Doutorado) - Escola Politécnica da Universidade de São Paulo. Departamento de Engenharia Naval e Oceânica. 2012.

PIRES, F. Os avanços do transporte ferroviário de carga no brasil após as privatizações: uma análise segundo a perspectiva de usuários, prestadores de serviço e governo. 2005. Disponível em: $<$ www.cel.coppead.ufrj.br/fsbusca.htm?fr-avanco.htm>. Acesso em: 01 Out. 2015. 
PRADO, D.S. Usando o arena em simulação. Editora de Desenvolvimento Gerencial. Belo Horizonte. Minas Gerais. 1999.

SAMPAIO, L.; SAMPAIO, Y.; COSTA, E. Mudanças políticas recentes e competitividade no mercado internacional de soja. Revista de Economia e Sociologia Rural. V. 44, p. 383-411, 2006.

SANTOS, A. S. Modelagem do escoamento de granéis agrícolas aplicada à estratégia operacional nos terminais portuários da região Sudeste do Brasil. Dissertação (Mestrado) - Escola Politécnica da Universidadede São Paulo. Departamento de Engenharia Naval e Oceânica. São Paulo, 2014.

SANTANA, A.C. de. Métodos quantitativos em economia: elementos e aplicações. Belém: UFRA, 2003.

SCALABRIN, L. A. Dimensionamento de silos metálicos para armazenagem de grãos. Dissertação (Mestrado) - Universidade Federal do Rio Grande do Sul, Porto Alegre, 2008.

SECRETARIA DO COMÉRCIO EXTERIOR (SECEX), 2010 Disponível em: <http://portal.siscomex.gov.br/legislacao/orgaos/secretaria-de-comercioexterior-secex> Acesso em: 28/12/2014.

SECRETARIA DO COMÉRCIO EXTERIOR (SECEX), 2012 Disponível em: <http://aliceweb.mdic.gov.br//menu/index/item/outrasEstatisticas> Acesso em: 29/04/2015.

SIDRA - Sistema IBGE de Recuperação Automática. Produção Agrícola Municipal (anos 1990 a 2013): tabela 1612, área plantada, área colhida, quantidade produzida e valor da produção da lavoura temporária. Brasília, 2013.

Disponível em: $<$ http://www.sidra.ibge.gov.br/bda/tabela/listabl.asp?c=1612\&z=t\&o=11>. Acesso em: 09 Mar 2015.

SILVEIRA, V. VARGAS, I. A competitividade da soja do centro-oeste através da logística de redes de transporte de grãos de soja para exportação do estado do Mato-Grosso. XLV Congresso da Sober. p. 1-20, 2007.

SINOTT, E.; Nash, J.; De la Torre, A. Natural resources in Latin America and the Caribean: Beyond booms and Busts. Washington: The World Bank, 2010.

SOARES, M. G.; GALVANI, P. R. C.; CAIXETA-FILHO, J. V. Transporte de soja em grãos e farelo de soja no Brasil. Piracicaba, Preços Agrícolas. v. 11, no 126, abr. 1997.

STRINGHER, F. G. Designação de Rotas para Frota Dedicada em uma Rede de Distribuição de Linha Branca. Dissertação (Mestrado) - Departamento de Engenharia de Transportes, Escola Politécnica da Universidade de São Paulo, São Paulo, 2004. 
TOSTA, M. A. R. Transportes e logística de grãos no brasil situação atual, problemas e soluções. Revista de política agrícola, v. 14, n. 2, 2005.

UNITED STATES DEPARTMENT OF AGRICULTURE (USDA). Commodity Inteligence Report. Foreign Agricultural Service/USDA, USA, 2007

USDA - United States Department of Agriculture. Economic Research Service. Agriculture Baseline Database. Washington, DC, 2013. Disponível em: $<$ http://www.ers.usda.gov/data-products/agricultural-baseline-database/customqueries.aspx>. Acesso em: 09 Mar 2015.

WEBER, R. A. Excelência em beneficiamento e armazenagem de grãos. Canoas: Salles Editora, 2005. 


\section{ANEXO 1 - ANÁLISE DAS COTAS DE NÍVEL D’ÁGUA}

Esse anexo tem como objetivo mostrar as análises de nível d'água feita para os diversos pontos das três hidrovias que fazem parte deste estudo, como mencionados no capítulo 1.

Para a hidrovia do Rio Madeira (Figura 63), tem-se os pontos de: Abunã; Balsa do Rio Abunã; Palmeiral; Salto Teotônio; Porto Velho; Porto Velho Jusante; Prosperidade; Calama; Manicoré; Novo Arupuranã; Fazenda Vista Alegre; Borba; Nova Olinda do Norte.

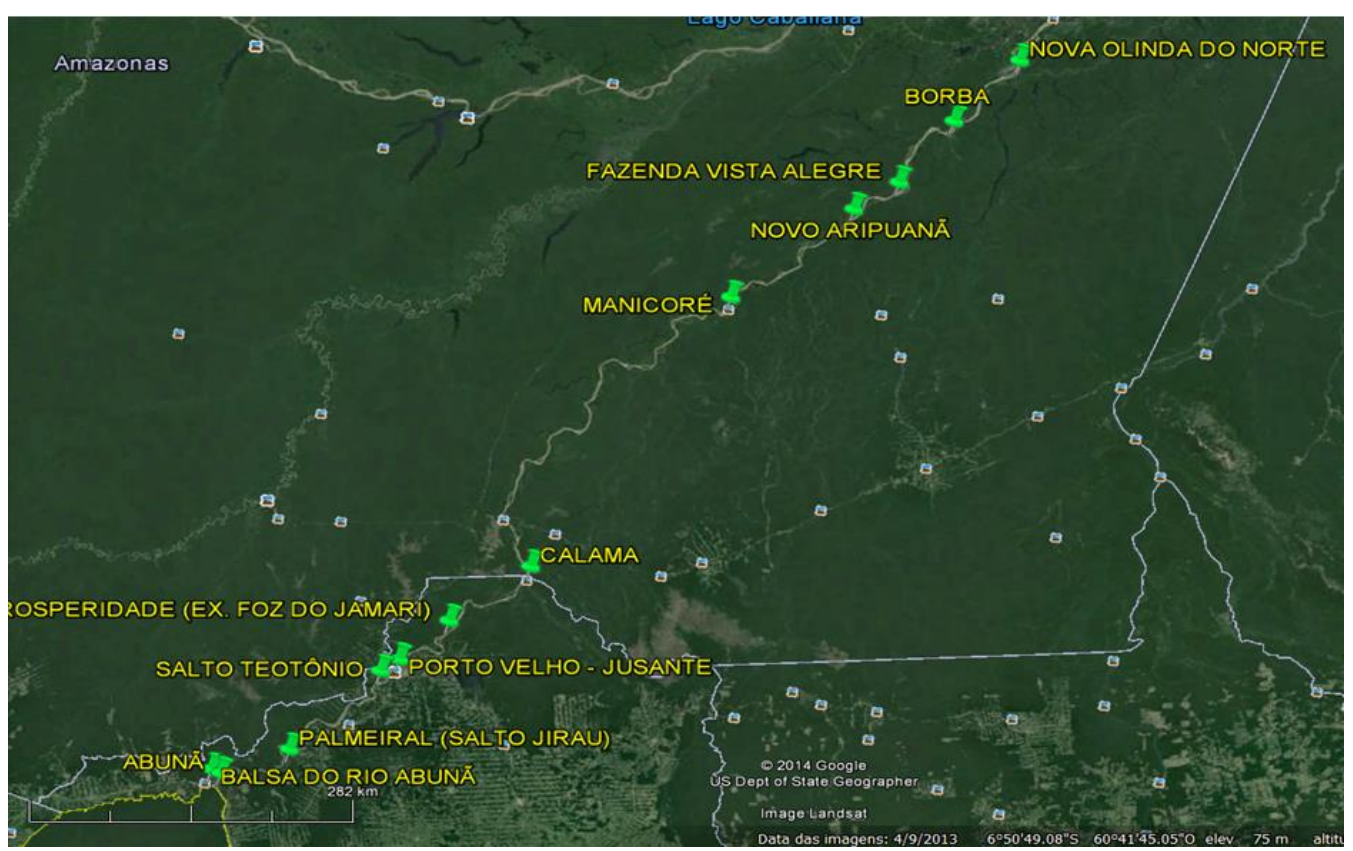

Figura 63: Hidrovia do Rio Madeira

Fonte: o Autor

Foram feitas as análises para cada um dos pontos dessa hidrovia, apresentados nas figuras abaixo. 

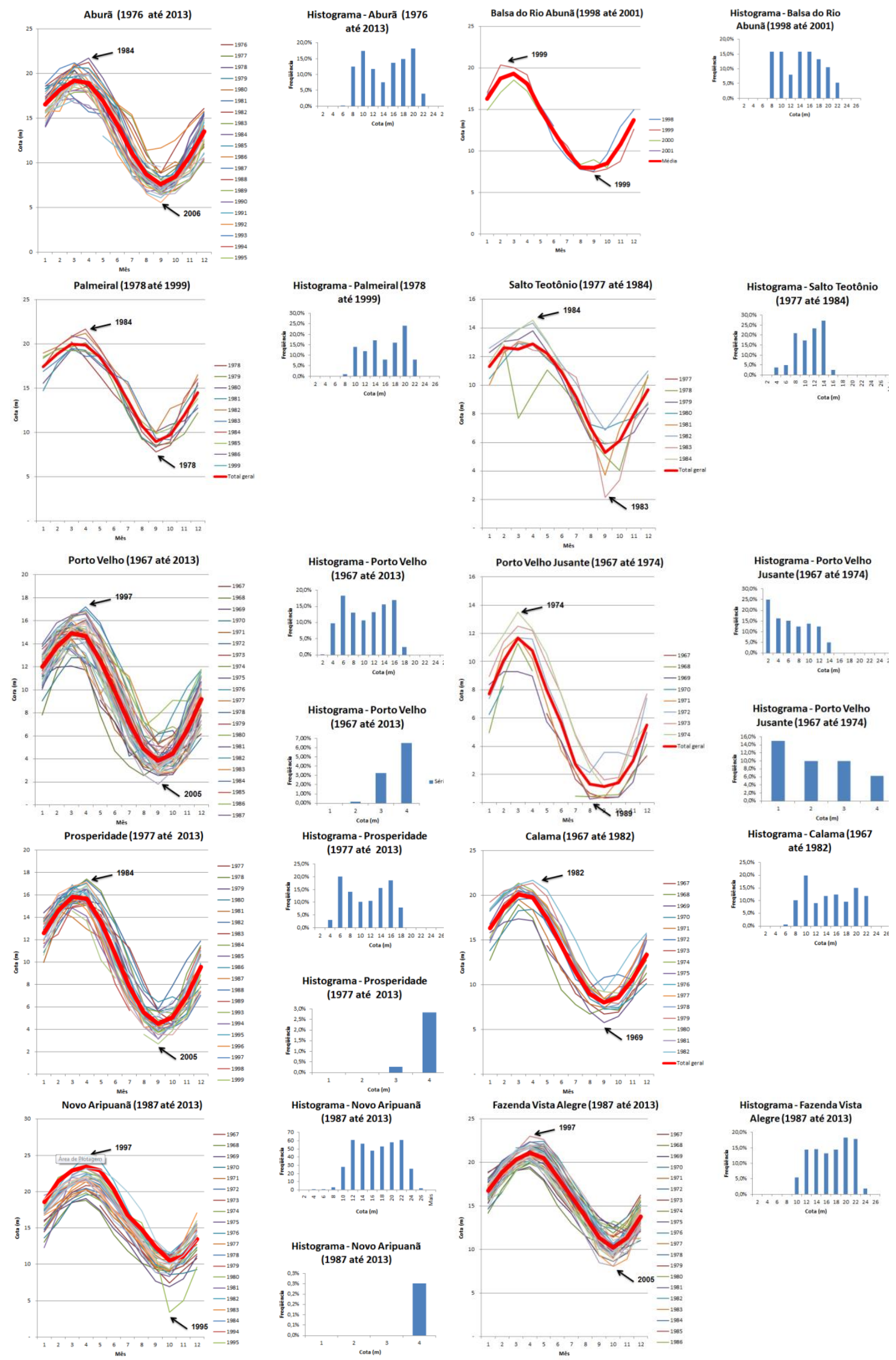

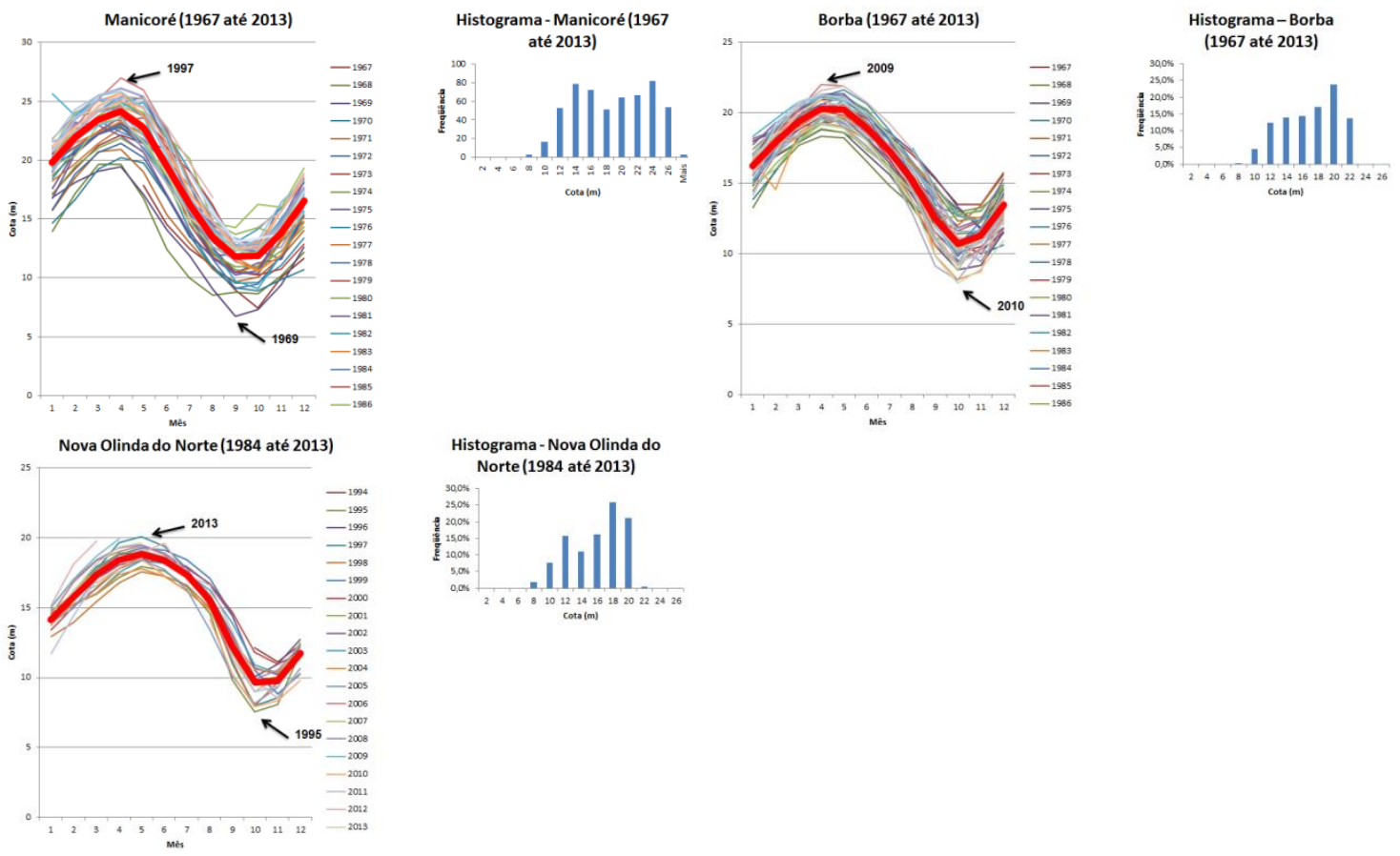

$$
\begin{aligned}
& \text { Histograma - Nova Olinda do } \\
& \text { Norte (1984 até 2013) }
\end{aligned}
$$

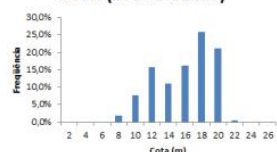

Para a hidrovia do Rio Tapajós (Figura 64), os pontos são: Barra do são Manuel; Fortaleza; Jatobá; Acará do Tapajós; Barreiras; Itaituba; Fordlândia; Santarém.

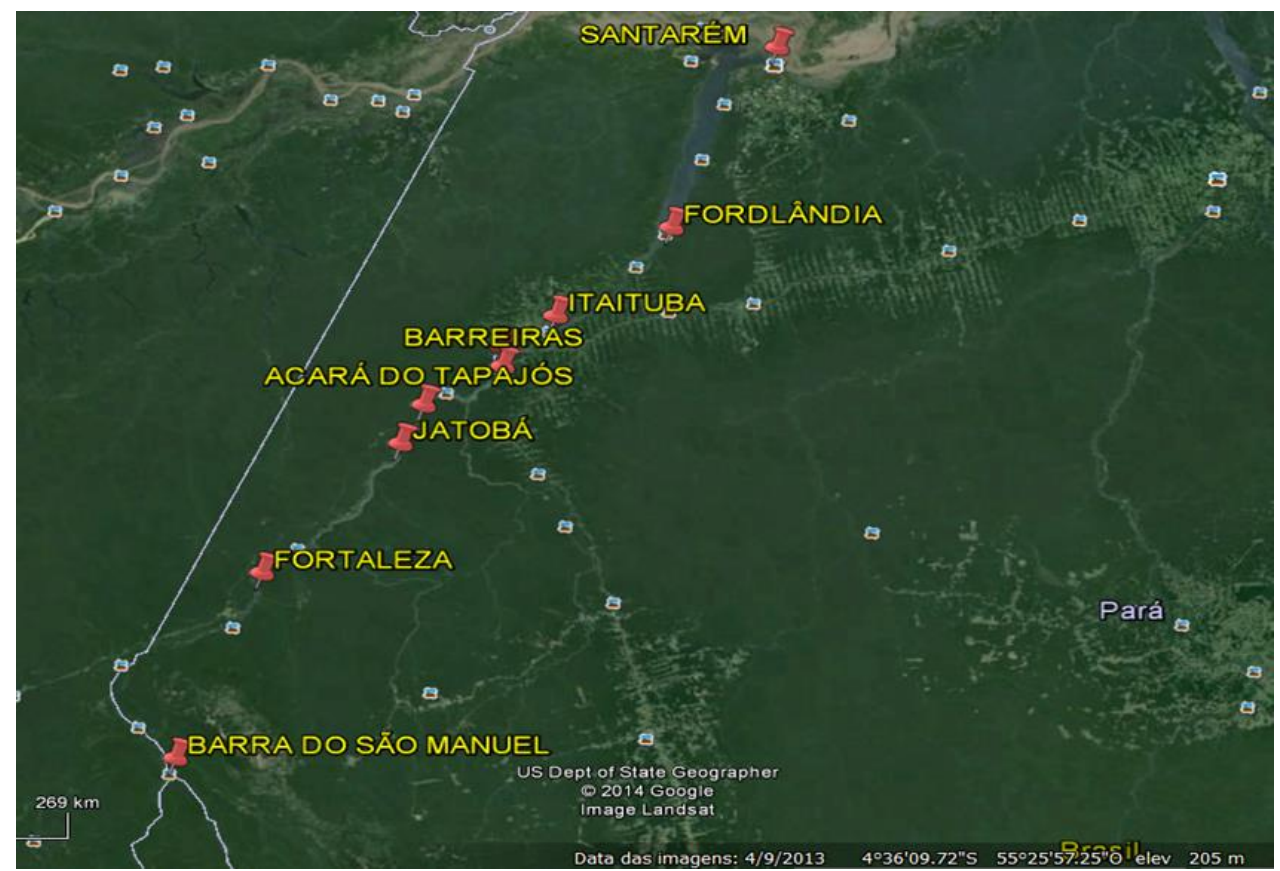

Figura 64: Hidrovia do Rio Tapajós Fonte: o Autor 

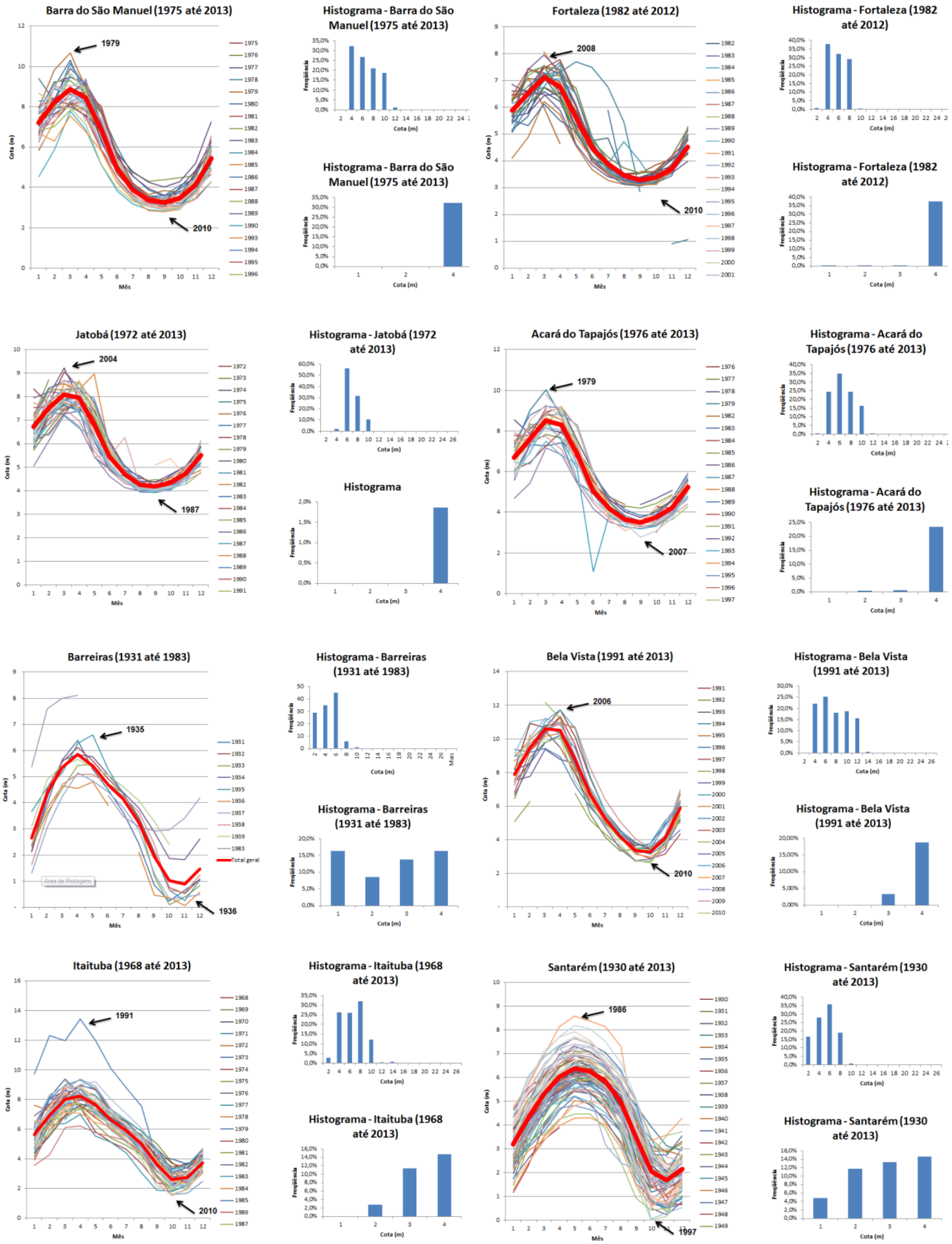

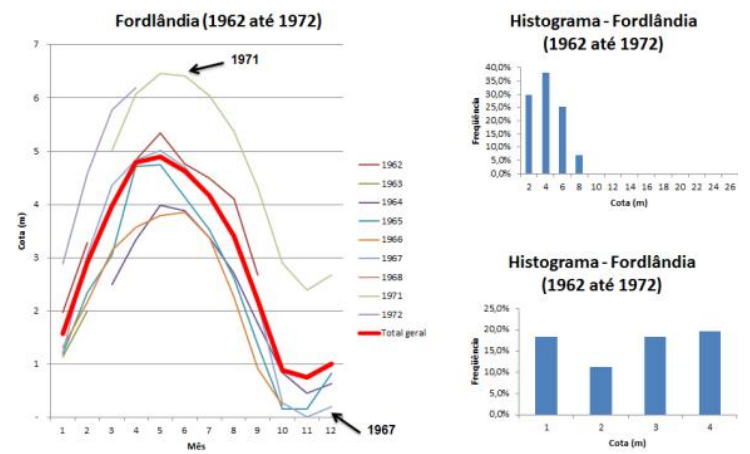

Analogamente às outras hidrovias, temos o Rio Tocantins (Figura 65) e seus pontos de análise de cotas d'água: Baião; Cidade de Cameta; Fazenda Ipitinga; Fazenda São Tomé; Ipixuna; Itupiranga; Jatobal; Marabá; Nazaré dos Patos; Tucuruí.

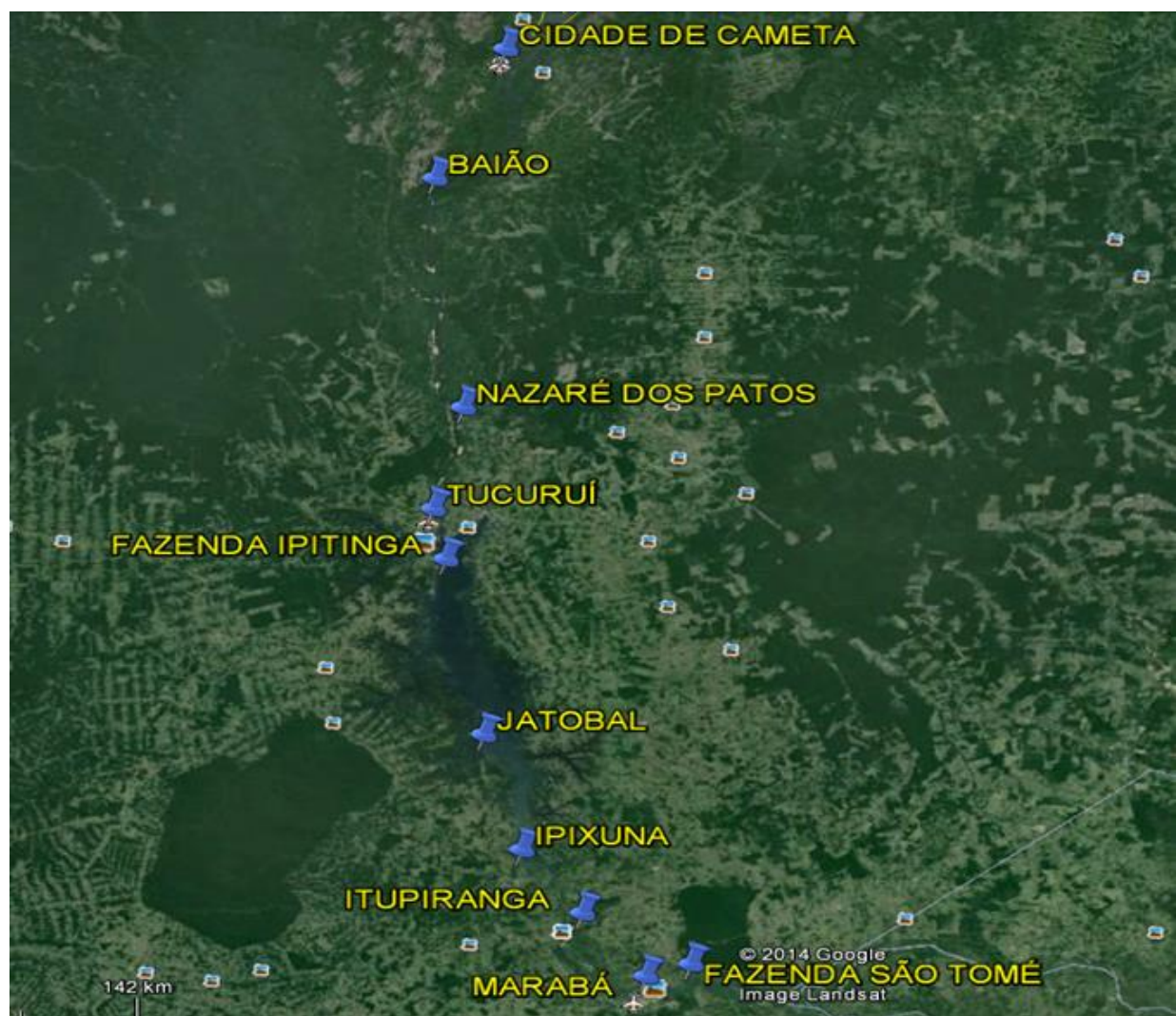

Figura 65: Hidrovia do Rio Tocantins Fonte: o Autor 

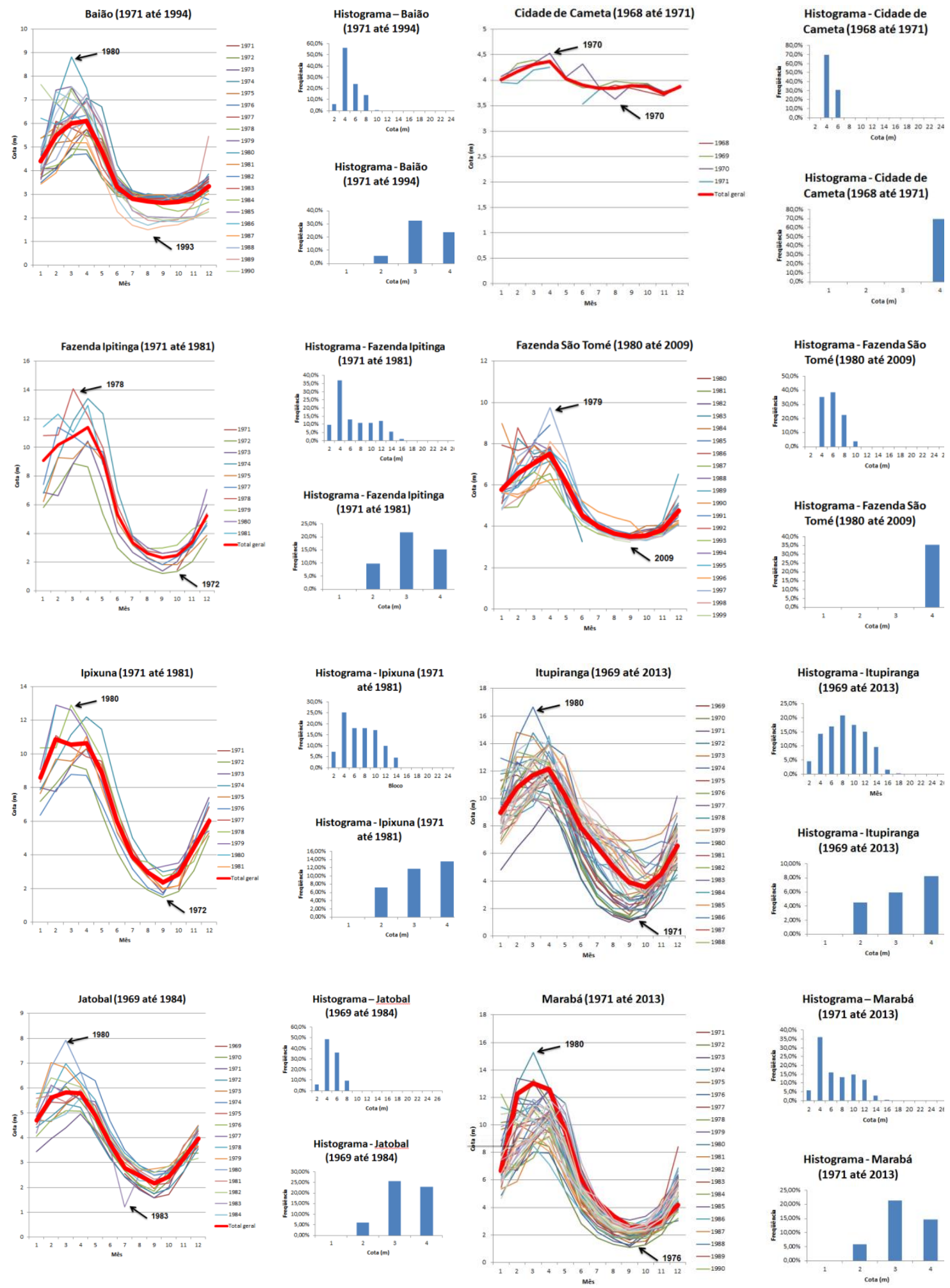
105
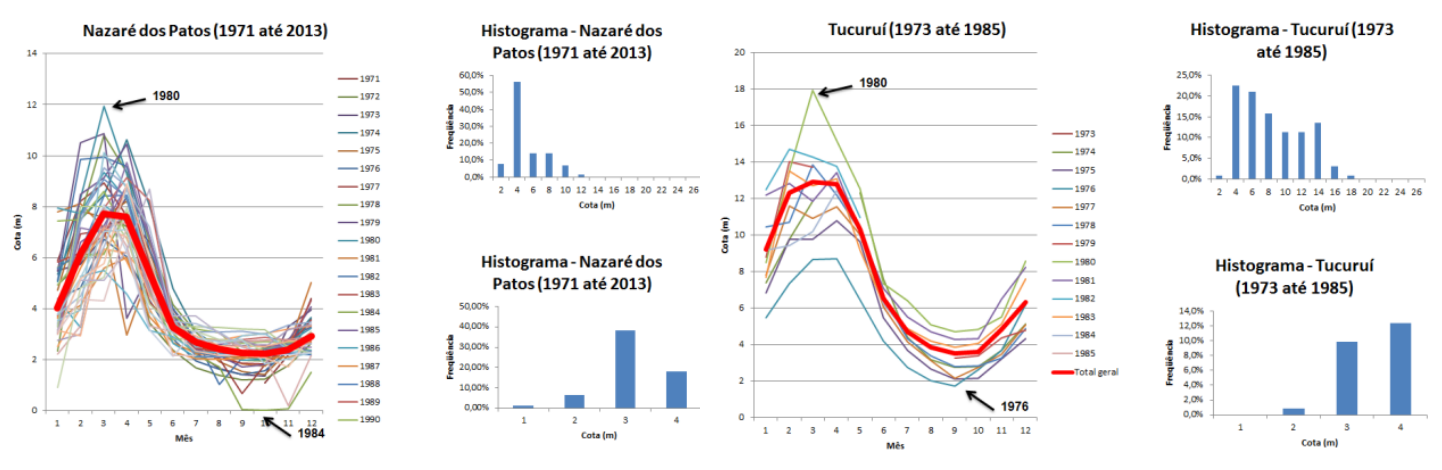